University of Rhode Island

DigitalCommons@URI

Open Access Dissertations

2020

\title{
NEW INSIGHTS INTO MODELING CHOICE BEHAVIOR UNDER UNCERTAINTY
}

Priya Sara Behanan

University of Rhode Island, behananpriya@gmail.com

Follow this and additional works at: https://digitalcommons.uri.edu/oa_diss

\section{Recommended Citation}

Behanan, Priya Sara, "NEW INSIGHTS INTO MODELING CHOICE BEHAVIOR UNDER UNCERTAINTY" (2020). Open Access Dissertations. Paper 1188.

https://digitalcommons.uri.edu/oa_diss/1188

This Dissertation is brought to you for free and open access by DigitalCommons@URI. It has been accepted for inclusion in Open Access Dissertations by an authorized administrator of DigitalCommons@URI. For more information, please contact digitalcommons-group@uri.edu. 
NEW INSIGHTS INTO MODELING CHOICE BEHAVIOR UNDER UNCERTAINTY

$\mathrm{BY}$

PRIYA SARA BEHANAN

A DISSERTATION SUBMITTED IN PARTIAL FULFILLMENT OF THE REQUIREMENTS FOR THE DEGREE OF DOCTOR OF PHILOSOPHY

IN

ENVIRONMENTAL AND NATURAL RESOURCE ECONOMICS

UNIVERSITY OF RHODE ISLAND

2020 


\section{DOCTOR OF PHILOSOPHY DISSERTATION}

OF

PRIYA SARA BEHANAN

APPROVED:

Dissertation Committee:

$\begin{array}{ll}\text { Major Professor } & \text { Todd Guilfoos } \\ & \text { Hirotsugu Uchida } \\ & \text { David Bidwell } \\ & \text { Carlos Garcia-Quijano }\end{array}$

Nasser H. Zawia

DEAN OF THE GRADUATE SCHOOL

\section{UNIVERSITY OF RHODE ISLAND}




\begin{abstract}
This dissertation explores alternative ways to understand choice preferences and explain data better. Understanding choice behavior has important policy implications. Choices are dependent on numerous factors, some of which are uncertain and unobservable to the researcher. To model choice behavior under uncertainty, researchers make several assumptions regarding individuals' cognitive thought processes, the functional form of utility, and which behavioral anomalies to incorporate.

In this research, the choice behavior of three distinct sets of stakeholders is investigated. The first chapter examines location choices made by recreational fishermen using an alternative model called the Case-Based Decision Theory (CBDT). This model captures the thinking process of a decision-maker based on the similarity of circumstances. CBDT hypothesizes that decision-makers rely on stored memory, past experience, and analogical reasoning to make choices. Fishermen tend to be biased towards qualitatively assessing their alternative locations based on their intuition and experience rather than numerically estimating the expected value. As a result, we find that CBDT outperforms the conventional Linear Additive Model when comparing both in and out of sample fits.

The second chapter investigates variety-seeking and habit forming behavior exhibited by birdwatchers when it comes to choosing bird watching sites. Birdwatchers unlike fishermen are variety-seekers in site choice preferences. Variety-seeking behavior makes it difficult to predict choice preferences and therefore difficult to identify any change in site preference when there is a policy change. This chapter introduces a two-stage model based on the framework adapted from CBDT to capture this effect. With this model, we find a statistically significant combined effect for variety-seeking
\end{abstract}


and habit forming among birdwatchers. This approach to predict choice behavior by agents using case-based reasoning in my first two chapters has been observed in several empirical settings, however, it has never been applied in a natural resource or an environmental context or used in non-market valuation studies.

The final chapter investigates how introducing a visual representation of policy alternatives regarding a local dam affects the choice preferences of residents in the city where the dam is located. This study uses a split sample labeled choice experiment to describe five possible future alternatives for the dam via text, images with text, and video with text. Previous studies support the theory that visualizing the available choices help better comprehend information. Drawing from this conjecture, we find that certain dam alternatives have a relatively higher preference when images are introduced while alternatives such as dam removal have a lower preference when the video is introduced. 


\section{ACKNOWLEDGMENTS}

I am grateful to my advisor, Dr. Todd Guilfoos, for providing me with the guidance required to complete my dissertation. Under his mentorship, I was encouraged to pursue a creative research path with broader implications and was able to improve on skills needed for my professional future, such as multitasking, time management, research methods, data analysis and academic writing.

Special thanks to my dissertation committee for guiding me through this process with valuable feedback and advice. Gratitude to the support provided by the faculty members at the ENRE department. I wish to especially thank Dr. Simona Trandafir for giving me constant encouragement and numerous opportunities to learn. Thank you Dr. Emi Uchida for the much-needed push for improvement and critical thinking.

My education and research would not have been possible without the financial support from institutions such as the US Department of Agriculture Hatch program, that 'dam' project funded by the National Science Foundation and the University of Rhode Island College of Environmental and Life Sciences, University of Rhode Island.

I would also like to thank all the graduate students at the ENRE department especially Vasu Gaur, Ben Blachly and Andrew Carr-Harris (Lou) for always being ready to help me move forward with my research. I would not have been successful without our brainstorming sessions and shared experiential learning. Finally, I wish to thank my family for always supporting me, especially my father, Behanan John and my husband, Ron Thomas. 


\section{PREFACE}

This dissertation follows the manuscript format with three independent chapters intended for publication. The main objective of all three studies is to provide new insights into choice behavior. The first chapter examines the location choice behavior of recreational fishermen using case-based reasoning. This paper is co-authored with Todd Guilfoos and is to be submitted to the Journal of Environmental Economics and Management. The second chapter proposes a new method adapted from the case-based reasoning framework to account for habit forming and variety-seeking effect on birding site choice among birdwatchers. This paper is to be submitted to the Journal of the Association of Environmental and Resource Economists and is co-authored with Todd Guilfoos and Sonja Kolstoe. The third chapter explores the effect of introducing visual representation of policy alternatives on choice. This paper is co-authored with Simona Trandafir, Todd Guilfoos, Emi Uchida and Emily Vogler and is prepared to be submitted to the journal, Ecological Economics. 


\section{TABLE OF CONTENTS}

ABSTRACT ............................. ii

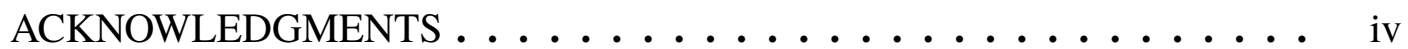

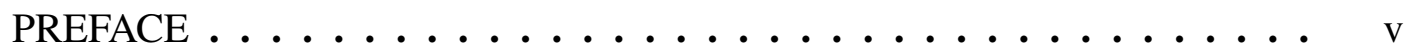

TABLE OF CONTENTS ........................... vi

LIST OF TABLES $\ldots \ldots \ldots \ldots \ldots \ldots$ ix

LIST OF FIGURES ...................... xi

CASE-BASED REASONING AND LOCATION CHOICE MODELING • 1

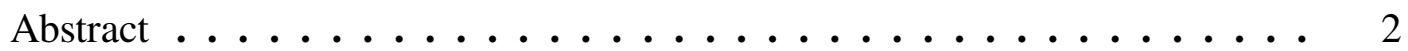

1.1 Introduction . . . . . . . . . . . . . . 2

1.2 Rule-based and Case-based Reasoning . . . . . . . . . . . . . 7

1.3 Methods . . . . . . . . . . . . . . . . . . 8

1.3.1 Random Utility Theory . . . . . . . . . . . . . . . . . 9

1.3.2 Case-based Decision Theory . . . . . . . . . . . . 10

1.3.3 Inertia Model . . . . . . . . . . . . . . . . . . . . . 12

1.3.4 Stochastic Choice Rule . . . . . . . . . . . . . . . . . 13

1.4 Welfare Analysis with CBDT . . . . . . . . . . . . 13

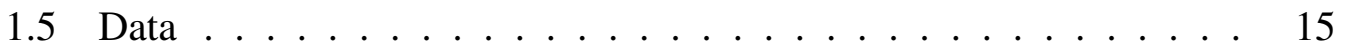

1.5.1 Site Congestion . . . . . . . . . . . . . . 17

1.5 .2 Site History . . . . . . . . . . . . . . . . . 18 
1.5.3 Expected Catch Rate . . . . . . . . . . . . . . . . 18

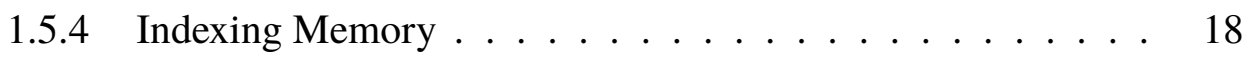

1.6 Model Fit Comparison . . . . . . . . . . . . . . . . . . . . . . . . 19

1.7 Results . . . . . . . . . . . . . . . . . . . . . . . . 19

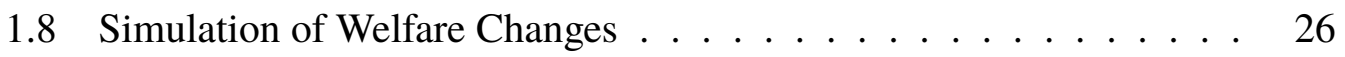

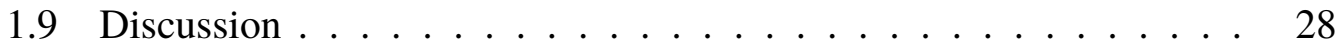

1.10 Conclusion $\ldots \ldots \ldots \ldots \ldots \ldots \ldots \ldots \ldots \ldots \ldots \ldots$

ESTIMATING HABIT-FORMING AND VARIETY-SEEKING BEHAVIOR: NON-MARKET VALUATION OF BIRDING SITE CHOICE PREFER-

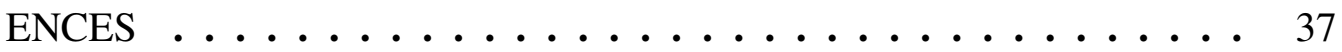

Abstract ......................... 38

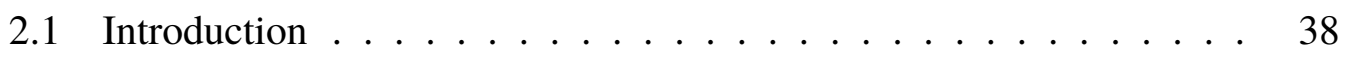

2.2 Methodology: Two-Stage Model . . . . . . . . . . . . . . . 42

2.2.1 First Stage: Linear Probability Model with Case-based Scores 42

2.2.2 Second Stage: Mixed Logit Model . . . . . . . . . . . . 45

2.3 Memory and Welfare $\ldots \ldots \ldots \ldots \ldots \ldots$

2.4 Model Fit Comparison . . . . . . . . . . . . . . . . . 48

2.5 Data . . . . . . . . . . . . . . . . 50

2.6 Results . . . . . . . . . . . . . . . . . . . 54

2.6.1 Two-Stage Model Results . . . . . . . . . . . . . . . . . 54

2.6 .2 WTP Results . . . . . . . . . . . . . . . . . . . . . 59

2.6.3 Model Comparison . . . . . . . . . . . . . . . . . . 61

2.7 Discussion and Conclusion $\ldots \ldots \ldots \ldots \ldots$

IMPACT OF VISUAL REPRESENTATION OF LABELS IN A CHOICE EXPERIMENT: VALUING PREFERENCES FOR A LOCAL DAM . . . 82

Abstract ....................... 83

3.1 Introduction $\ldots \ldots \ldots \ldots \ldots \ldots \ldots \ldots \ldots$ 
3.1 .1 Dams in New England . . . . . . . . . . . . 86

3.2 Methodology .......................... 89

3.2.1 Visualization Treatments . . . . . . . . . . . . . 89

3.2.2 Attributes ....................... 92

3.2.3 Survey Design and Recruitment . . . . . . . . . 95

3.2 .4 Econometric Model . . . . . . . . . . . . . . . . . . 100

3.3 Empirical Results . . . . . . . . . . . . . . . . . 103

3.3.1 Effect of Visualization . . . . . . . . . . . . 103

3.3.2 Dam Alternative Preference Order . . . . . . . . . . . 105

3.3.3 Effect of External Funding . . . . . . . . . . . . 106

3.3.4 WTP for Attributes . . . . . . . . . . . . . . 107

3.4 Discussion and Conclusion . . . . . . . . . . . . . . . 108

BIBLIOGRAPHY . . . . . . . . . . . . . . . 122 


\section{LIST OF TABLES}

1.1 Description of Variables . . . . . . . . . . . . . 17

1.2 Summary Statistics of Key Variables . . . . . . . . . . . . . . . . . 19

1.3 LA Model Results . . . . . . . . . . . . . . . . . . . . . . . 20

1.4 Estimated Parameters using CBDT . . . . . . . . . . . . . . 22

1.5 Comparison of Model Selection Criteria . . . . . . . . . . . . . 24

1.6 Out of Sample Fit: Log-likelihood Comparison _ . . . . . . . . . . 24

1.7 Model Selection Estimated Weights for Different Target Species . . 25

1.8 Description of Simulated Data f . . . . . . . . . . . . 27

1.9 Poisson Model to Estimate Expected Catch . . . . . . . . . . . . . . 35

2.1 Description of Variables. . . . . . . . . . . . 53

2.2 First Stage Results: Linear Probability Model . . . . . . . . . . . . 55

2.3 Mixed Logit Results: Second Stage Model . . . . . . . . . . . . 57

2.4 Comparison of WTP: Select Estimates . . . . . . . . . . . . . 60

2.5 Likelihood Ratio Test . . . . . . . . . . . . . . . . . . 62

2.6 Comparison of Model Selection Criteria . . . . . . . . . . 62

2.7 Types of Eco-region . . . . . . . . . . . . . . . 70

2.8 Types of Land Cover $\ldots \ldots 71$

2.9 LPM Marginal Similarity Scores . . . . . . . . . . . . . 75

2.10 Mixed Logit Results: Second Stage Full Model _ . . . . . . . . . . 76

2.11 Comparison of WTP: All Estimates _ . . . . . . . . . . 78

2.12 Mixed Logit Results: Second Stage and Static Models . . . . . . . . 79

2.13 Mixed Logit Results: Benchmark Models . . . . . . . . . . . . . . 80

3.1 Socioeconomic Characteristics of Survey Participants . . . . . . . 98 
3.2 Mixed Logit Results with Treatment Effects . . . . . . . . . . . . . 104

3.3 Annual marginal WTP per household . . . . . . . . . . . . . 107

3.4 Socioeconomic Characteristics across Treatments . . . . . . . . . 117

3.5 Mixed Logit Results: Interactions with number of years as a resident 118

3.6 Mixed Logit Results: Connection to the Dam . . . . . . . . . . . . 121 


\section{LIST OF FIGURES}

1.1 Range of Estimates of the Travel Cost Coefficient. (Each dot represents the range of the estimates from 1,500 simulations.) $\ldots 28$

3.1 Visual representation of alternatives displayed in the image treatment (a) Repair Dam, (b)Technical Denil Fish Ladder and (c) Nature-like

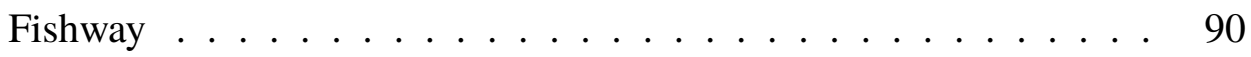

3.2 Visual representation of alternatives displayed in the image treatment (d) Pool and Weir Bypass Channel and (e) Remove Dam . . . . . . 91

3.3 Attributes and attribute levels used in the choice experiment . . . . 93

3.4 Sample choice experiment . . . . . . . . . . . . . . 95

3.5 Levels of connection with the dam . . . . . . . . . . . . 99

3.6 Willingness to pay per year $(\$) \ldots \ldots$. . . . . . . . 106

3.7 Survey Question: Number of years in Keene . . . . . . . . . . . . 117

3.8 Survey Question: Levels of connection to the Dam . . . . . . . . 118 
CASE-BASED REASONING AND LOCATION CHOICE MODELING

(To be submitted to Journal of Environmental Economics and Management.)

By

Priya Behanan ${ }^{1}$ and Todd Guilfoos ${ }^{1}$

${ }^{1}$ Department of Environmental and Natural Resource Economics,

University of Rhode Island 


\title{
CHAPTER 1
}

\begin{abstract}
We adapt case-based decision theory to location choice behavior. The classical approach used to understand discrete choices under uncertainty is typically expressed through the linear additive Random Utility Model, which uses rule-based reasoning. Case-based reasoning, based on cognitive processes, forms expectations by comparing the similarity between past problems and the current problem faced by a decision-maker. This study compares the empirical fit and predictive capacity of both models using location choice behavior of recreational fishers in Connecticut. We conclude, through out-of-sample model fit, that the case-based decision model performs better than the traditional rule-based model. Using simulated data we also demonstrate the potential accuracy issues of welfare estimates from the use of a linear model if the data generating process is case-based.
\end{abstract}

\subsection{Introduction}

The random utility model (RUM) is the workhorse of discrete choice analysis in economics, which includes but is not limited to, location choice modeling, travel cost analysis, choice experiments, and contingent valuation. RUM spans both revealed choice and stated choice research across most disciplines of economics to explain choice behavior. The explosion in modeling discrete choice behavior and estimating demand from these choices can be traced to the early 1970s, when luminaries such as Daniel McFadden pioneered work in discrete choice modeling and economic choice (McFadden, 1974; Manski, 1977; McFadden, 2001). The stochastic utility 
models underlying this literature, in practice, usually makes strong assumptions about rationality. The general practice when applying these approaches to empirical data is to choose models that exhibit high levels of rationality and are linear combinations of explanatory factors, or a reduced form specification. ${ }^{1}$ These assumptions are justified in the sense that estimation is easy to carry out, the model is consistent with neo-classical theory, and the model is easy to interpret. McFadden notes that the structure of the indirect utility function implies an important structure on preferences (McFadden, 2001), and also calls for a more significant role in how the formation of perceptions and preferences occur in the standard models (McFadden, 2001). In this work, we introduce a method of estimation based on case-based decision theory that does not rely on high levels of rationality and uses structural equation estimation.

The classical approach used to model discrete choice behavior under uncertainty is the linear additive (LA) random utility model. In this framework, the agents have complete knowledge regarding all possible outcomes in all states of the world. This method assumes that the agent not only compares and measures all possible outcomes but also considers every possible state of the world each time she makes a decision. A choice situation that does not conform to these conditions is one with 'structural ignorance' (Gilboa and Schmeidler, 2001). If all possible outcomes in all states of the world are naturally defined and are constructed by the agent, then the Expected Utility Theory (EUT) may be a suitable decision theory to model choices under uncertainty. However, a more realistic assumption would be that when facing choices under uncertainty, individuals have incomplete knowledge regarding outcomes and of states. In such a scenario, a decision-maker will not follow the assumptions of complete rationality but instead makes a choice based on her cognitive process and available information(Kahneman, 2003). Expected Utility Theory describes how an individual should make a choice rather than how they make a choice (Gilboa and Schmeidler, 1995).

\footnotetext{
${ }^{1}$ There is a robust literature on learning models and Markov decision models that do not use these same assumptions, but these are typically not used in non-market valuation or location choice modeling.
} 
Two critical assumptions are usually made when modeling discrete choice with a linear additive random utility model. First, all observations are used to inform the choice of an agent; in other words, an agent's memory is complete with all observable instances of the data. Second, agents use rule-based reasoning to make decisions. Rule-based decisions come from the functional form of utility, namely that is linear and additive in components. The agents use rules that average the effect of dependent variables on the choice variable across observations. Case-based reasoning, on the other hand, posits that agents take cases from memory and compare the similarity of past problems to the current decision problem they are faced with, to form an expected utility of choices. In other words, agents reason through analogies to make choices rather than reason through rules. Based on this notion, individuals would expect similar problems to have similar outcomes (Gilboa and Schmeidler, 1995). There is support in psychology and economics for case-based reasoning in which agents weigh their own experiences more than other available information (Shepard, 1987; Pape and Kurtz, 2013; Bleichrodt et al., 2017) which suggests that there are apparent bounds of what is contained in an agent's memory when making decisions. Agents may use rule-based reasoning or case-based reasoning or a combination of the two in practice. Only careful inspection of observed choice can illuminate the decision process.

This paper introduces case-based decision theory (CBDT) modeling to location choice behavior estimation. Our work makes multiple contributions to the literature on discrete choice modeling. We demonstrate how to apply CBDT to an empirical application in which the definition of the problem and memory are tractable for the researcher and can be used in other non-market valuation studies. With an application to recreational fisheries, we show that this model suggests itself for more questions in applied work. Specifically, we find that CBDT fits the data better than LA models with out-of-sample measures. Further, we explore the implications of non-market valuation and welfare analysis to including this mode of behavioral models of decision making. Using simulations, we show that there are serious concerns when using the 
LA model to estimate welfare when the data generating process comes from a casebased decision-maker in discrete choice settings.

The implications for employing the case-based reasoning framework on questions of location choice or other discrete choice questions are twofold. First, if the data generating process that creates choice data is different from the model used, then we are more likely to suffer in out-of-sample prediction. A model consistent with what we know about choice behavior should be better in situations where out-of-sample predictions are of particular importance (i.e., climate change scenarios, hypothetical scenarios $)^{2}$. Second, using the wrong model for inference on choices will impair our estimates for welfare. Therefore a model that incorporates what we know about the psychology of choice and that explains the data well is likely a better measure to construct demand. Others also make this argument that welfare analysis should be based on our understanding of the behavioral processes that generate the data (Cerigioni and Fabra, 2019; Rubinstein and Salant, 2011; Manzini and Mariotti, 2014).

Several studies in the economics literature show that CBDT performs well in explaining empirical data. Ossadnik et al. (2013) conduct a repeated choice experiment where individuals' choice behavior was assessed based on an urn ball experiment. Decision models such as the Maximin Decision Criteria, Reinforcement Learning Model, and CBDT were applied to the obtained data set. The results revealed that CBDT explained the experimental data better than a maximin decision criteria model or a reinforcement learning model. Another study conducted a comparative analysis between the linear additive reduced form model and the CBDT model on an experimental repeated Prisoner's Dilemma data set, revealing that CBDT predicts aggregate human behavior better (Guilfoos and Pape, 2016). Pape and Kurtz (2013) shows CBDT explains human classification learning data well. Kinjo and Sugawara (2016) shows CBDT explains the viewing decisions of Japanese TV dramas well. Case-based Decision Theory predicts decisions well in a number of empirical set-

\footnotetext{
${ }^{2}$ Behavioral anomalies can be important to model selection. For instance, if loss framing is important, then a model based on prospect theory may be appropriate.
} 
tings. However, this theory has never been applied in non-market valuation studies, location choice modeling, and welfare implications have not been explored. Further, CBDT has not been adapted to empirical applications in dynamic choice environments, with the exception of Guilfoos and Pape (2019); Pape and Kurtz (2013). Our paper builds on the estimation methods presented in (Guilfoos and Pape, 2019) and apply CBDT to a dynamic empirical application outside of the lab.

Location choice behavior is important for environmental policy and management. It reveals preferences for attributes of the choice made and can illuminate important policy choices for non-market goods. We apply CBDT to reacreationl fishers. Unlike commercial fishers, recreational fishers are not motivated by generating revenue. Their motivations range from spending time with friends and family, catching a trophy fish, deriving aesthetic pleasure, to catching a target species (Rubio et al., 2014). Research on choice behavior of recreational fishermen is important as this activity contributes a value addition of 38.7 billion dollars to the nation, generating more than 472 thousand employment opportunities and provides 24.3 billion dollars as annual income in the United States as of the year $2016^{3}$. As a result, the conservation of fishing locations and maintaining an adequate level of fish populations to sustain recreational fishing is an essential economic incentive to the nation. Fisheries management strive to conserve fishing areas, protect marine life, avoid fish stock depletion, and administers policy changes that may cause unintended consequences, especially in the behavior and distribution of recreational anglers (Pauly et al., 2005). Therefore, a clear understanding of site selection behavior enables us to design effective regulatory measures and understand how fishermen respond to management policies (Cinti et al., 2010). For example, regulators often reserve or close fishing grounds in order to protect marine life and avoid stock depletion. However, such choices are dependent on numerous factors, some of which are uncertain and unobservable to the researcher (Holland, 2008).

\footnotetext{
${ }^{3}$ https://www.fisheries.noaa.gov/content/fisheries-economics-united-states-2016
} 


\subsection{Rule-based and Case-based Reasoning}

To provide clarity about rule-based reasoning and case-based reasoning (reasoning by analogy), we provide an example of both. Suppose an agent is interested in purchasing a boat and is deciding which boat satisfies her demand for certain attributes (size, color, style) while constrained by a budget. A rule-based decision would reason "I want to buy a boat and boats cost $\$ 1,000$ per additional foot of length" while reasoning by analogy would reason "my friend's boat cost $\$ 20,000$ and I want to buy a boat of the same size and characteristics, so it should cost a similar amount". The predictions of a rule-based reasoning and case-based reasoning could be very similar but the processes differ in the decision making mechanisms. In location choice modeling, reasoning by analogy is very intuitive, as agents choose to visit locations that are similar to past locations that generated high levels of utility. This might present itself negatively as well; "we had a horrible time at Beach $\mathrm{A}$ and Beach $\mathrm{Z}$ is very similar to Beach A so we will not visit Beach Z". Case-based reasoning can also fit into the Random Utility Model as utility can be viewed as random, but CBDT suggests a specific functional form and draws its inference through the concept of memory. This is very similar to the idea of learning algorithms and case-based reasoning is a close relative of reinforcement learning which draws on similar psychological support. (Gilboa et al., 2007; Shepard, 1987; Guilfoos and Pape, 2016, 2019).

CBDT was introduced in Gilboa and Schmeidler (1995). This decision theory captures the thinking process of a decision-maker based on the similarity of circumstances. A fully rational EUT decision-maker never encounters a situation they have not considered, while a CBDT posits how expectations are formed for new problems explicitly. The CBDT framework could be useful to explore issues in environmental and natural resource economics because it provides a framework to estimate welfare for new hypothetical location choices. For example, a new public park, the restoration of fishing ground, or other conservation initiatives. All of these examples naturally fit into a CBDT framework. CBDT hypothesizes that decision-makers rely on stored 
memory, experience, and reasoning by analogy to make choices of whether to visit locations and how they derive value from that choice.

How a resource user chooses a location to visit is difficult to know and construct (Hess et al., 2018). For example, fishers seem to qualitatively assess alternative locations to visit based on intuition and experience. Ethnographic interviews conducted by Holland (2008) show that choice behavior of fishers often does not conform to the assumptions of expected utility. However, as with other location choice modeling, fishing location research has relied on LA models. Bockstael and Opaluch (1983) was one of the first to incorporate uncertainty in fishermen's choice model via the RUM. Mistiaen and Strand (2000) use a mixed multinomial logit to understand the short-run heterogeneous risk preferences in fishing choice behavior. Ran et al. (2011) use a LA model to examine the behavior of the Gulf of Mexico shrimpers.

Gravity models, which capture the negative effect of distance to a site, are commonly used in the recreational demand literature to capture aspects of cost of visiting a site. Random utility models that captures this negative distance effect is popular while studying recreational fishing site choice preferences (Train, 1998; Rubio et al., 2014; Morey et al., 1991). The recreational fishing literature focuses on collecting all attributes that could potentially influence behavior such as cost to travel to the fishing site, fishing quality, water quality, congestion in the site, expected catch, and site history. We propose to characterize the same attributes through similarity from past experiences to generate expectations and form utility, much like reinforcement learning, and agents choose locations based on expectations formed through case-based reasoning.

\subsection{Methods}

In this section we describe the methods to estimate both the LA and CBDT models, both using a random utility model framework. We first discuss the model components, the stochastic choice rule, and how to applied the models to data. 


\subsubsection{Random Utility Theory}

In random utility theory, an individual decision maker faced with a finite choice set $K$, assigns a utility value to each choice $\left(U_{1}, U_{2}, \ldots, U_{K}\right)$ depending on a vector of individual specific, time specific and alternative specific characteristics denoted as $X$. The decision rule behind this framework hypothesizes that the decision maker would choose an alternative $j \in K$ where the utility derived from $j$ is the maximum possible utility that could be derived from the given choice set (Hess et al., 2018). The probability of choosing the the alternative $j$ is given in equation 1.1:

$$
\operatorname{Pr}(j \mid K, X): \operatorname{Pr}\left(U_{j}>U_{i}\right) \text { for all } i \neq j \in K
$$

The random utility function $U_{j}$ is the maximum utility attained by the decision maker given the vector of attributes influencing his decision. This utility is a combination of both deterministic as well as stochastic components $\left(U_{j}\left((X ; \theta), \epsilon_{j}\right)\right)$. The deterministic component contains the observed vector of attributes, $X$, whereas the stochastic component, $\epsilon_{j}$, is assumed to contain unobserved attributes that can cause any deviation from mean utility, $\bar{U}_{j}$ and $\theta$ is the parameter vector. This unobserved portion is assumed to be independently and identically distributed (iid).The functional form of this utility is expressed in equation 1.2:

$$
U_{n j}=f(X ; \beta)+\epsilon_{n j},
$$

where $U_{n j}$ is the utility function for the $n^{\text {th }}$ individual choosing the alternative $j$.

The functional form of utility could take many forms. The linear additive version takes information about the decision maker and site characteristics and uses equation 1.3 to model location choice. We refer to this model as the LA RUM.

$$
f(X ; \beta)=\sum_{i=1}^{I} \beta_{i} X_{i}
$$




\subsubsection{Case-based Decision Theory}

In this section we demonstrate how the deterministic part of the RUM is characterized for CBDT. This can be seen as a behavioral model of decision making that can be incorporated into the random utility modeling approach. The Case-based Decision Theory measures utility by incorporating the similarity between current scenario and scenarios in memory, which are called cases. According to this model, every agent has a memory $(M)$, which stores a set of cases $(C)$. Each case is a combination of a set of problems $(P)$, a set of actions $(A)$ taken to resolve this problem and the subsequent set of outcomes or results $(R)$ obtained from applying the action to the problem. CBDT assumes that agents refer to their memory of cases and forms expectations based on the weighted similarity of results between past cases and the current problem. Doing so agents put more weight on past cases that are more similar to the current problem faced. The similarity between the current problem $(p)$ and past problems $(q)$ are weighed by a similarity function. Past problems, need not be drawn from the decision makers own experience. These memories could be a case of another person, which the agent observes, or they could be hypothetical constructs. The expected utility is a combination of the cases in memory and the results of those cases, weighed by the similarity function. Another component considered in casebased decision theory is the aspiration level $(H)$. Aspiration denotes the satisficing amount of utility the agent pursues and incorporates exploration of new choices when utility falls below this satisficing level. A combination of the above components, that is the similarity function, utility function and aspiration level, in a specific functional form provides us with the case-based utility of the agent (Gilboa and Schmeidler, 1995).

In the recreational fishers location choice model, $M$ is defined as the set of fishing trips stored in the fisher's memory. The problem, $P$, is the environment faced by the fisher during each fishing trip, such as weather conditions, travel cost, or day of the week the trip is taken. The action, $A$, is chosen location of the fisher. The 
result, $R$, is a binary indicator variable which equates one when the fisher catches his target species ${ }^{4}$. The aspiration level, $H$, for the fisher is the satisficing level of utility derived from his fishing trip. In this study we have constrained the aspiration level to be zero because identification is confounded when estimating the initial attractions to locations and the aspiration level ${ }^{5}$. According to this model, the weighted similarity index between past $(q)$ and current problems $(p)$ of the fisherman, will form their expectations of utility for each available location in their choice set.

We use the weighted summation of the inverse exponential function as the similarity function to measure the distance between the two problems since it has been previously successful in other empirical applications (Pape and Kurtz, 2013; Guilfoos and Pape, 2019). This function is used to establish a resemblance between past problems and the current problem faced by the decision maker. As per CBDT, each fisherman will have a set of cases stored in her memory, which she will refer to, when making current decisions. The similarity function is given in equation 1.4.

$$
s(w, p, q)=\frac{1}{\exp (d(w, p, q))},
$$

where $w$ is the estimated weight between a vector of information from the current case $(p)$ and past case $(q)$. The greater the resemblance between information in the two cases the greater the estimated weight.

The consequent Case-based Utility(CBU) function is given in equation 1.5.

$$
C B U_{i j q}=\sum_{i j q \in M} s(w, p, q)[u(r)-H]
$$

In the above equation, the Case-based Utility for individual $i$ for location choice $j$, includes the similarity function $s(w, p, q)$, the utility function, $u(r)$, which denotes the utility derived from the $r$ and $H$, denotes the aspiration level which is that level where the agent is satisfied. $M$ denotes the level of memory the agent has that

\footnotetext{
${ }^{4}$ There are many possible choices for the result which we explored. These could be the number of fish caught or the weight of accumulated catch. We find that the target species is a good proxy for the result in this setting.

5This point is made in (Guilfoos and Pape, 2019)
} 
includes all the cases involved with the chosen alternative $j$. The Case-based Utility is then measured by taking the summation of the similarity function, weighted by the difference between $u(r)$ and $H$ (Guilfoos and Pape, 2016). The maximum likelihood estimation procedure is then used to estimate the parameters that are most probable to obtain the observed data.

\section{Distance Measure}

The similarity measure between cases can take many function forms. A commonly used metric in cognitive psychology is the Euclidean distance measure (Nosofsky, 1992). The distance function that follows the euclidean distance metric $(d(w, p, q))$ is given equation 1.6.

$$
d(w, p, q)=\sqrt{\sum_{v=1}^{n}\left[w_{v}\left(p_{v}-q_{v}\right)^{2}\right]}
$$

In the above equation, $v$ denotes the explanatory variables used in the model. This similarity functional form was used in Pape and Kurtz (2013) to describe data from a human classification learning problem experiment. Guilfoos and Pape (2019) also used the same functional form in mixed strategy equilibria games and found that it performed well in describing the data from those experiments.

\subsubsection{Inertia Model}

In order to evaluate the general performance of CBDT, we estimate a baseline model, called the inertia model. The inertia model takes the past choice behavior and uses that as the prediction for the next period, therefore it does not use any information in prediction except the immediate preceding choice. For the first period the inertia model randomizes equally across all choices. The inertia model acts as a minimum performance measure when we consider the other models. 


\subsubsection{Stochastic Choice Rule}

A common stochastic choice rule applied in discrete choice modeling literature is the logit response model. The multinomial logit model is used when the choice set faced by an individual has multiple discrete alternatives. For instance, recreational fishers have multiple fishing sites in their choice set. The choice probability that a decision maker chooses one of the alternative, $j \in K$ is given in equation 1.7.

$$
P(j \mid K, X)=\frac{\exp \left(\lambda, U_{n j}\left(\beta, \mathrm{x}_{\mathrm{nj}}\right)\right)}{\sum_{i=1}^{K} \exp \left(\lambda, U_{n i}\left(\beta, \mathrm{x}_{\mathrm{ni}}\right)\right)},
$$

where $U_{n j}\left(\beta, \mathrm{x}_{\mathrm{nj}}\right)$ is the utility of alternative, $j$ for individual $n$ which is a linear additive function of attributes (x) in the LA form and a summation of utility weighted similarity functions for CBDT. The sensitivity parameter, $\lambda$, which is assumed to be one in LA models, are estimated in CBDT. $\lambda$ has been shown to be important to estimation of learning models on laboratory data of discrete choice and is considered in Guilfoos and Pape (2019). The above choice rule implies that the probability of a fisherman choosing site $j$ from choice set $K$, is the exponential of the utility from site $j$ divided by the sum of all of the exponentiated utilities (Hess et al., 2018).

\subsection{Welfare Analysis with CBDT}

In this section, we discuss welfare within the CBDT framework. Welfare estimation is essential for policy implications; we, therefore, need to understand how CBDT choice affects our estimates of willingness to pay for goods. An important assumption when measuring welfare in discrete choice models is the interpretation of the cost coefficient as the marginal utility from income. This monetary value is then used to compute the fishers' willingness to pay estimates for a change in site attribute, holding all else constant (McConnell, 1995; Hanemann, 1983).

The theory of welfare valuation is unaffected by CBDT's assumption of a functional form of utility, but there are practical considerations to confront when imple- 
menting CBDT. For instance, based on the assumptions we make regarding memory, we need to construct a history of experiences that resemble a representative agent from the data to understand how the payoffs from choices are incorporated into the choice set.

The conditional indirect case-based utility function as defined in equation 1.8.

$$
C B U_{i j}=C B V_{i}\left(y_{i}-Q_{j}, x_{i j}\right)+\epsilon
$$

where $y$ denotes the income for individual $i$; $Q_{j}$ being the attribute for choice $j$ and $x$ denotes other explanatory variables affecting utility. Equation 1.9, demonstrates how a change in policy that alters the site attribute from $Q^{0}$ to $Q^{1}$ can be measured:

$$
C S_{i j}=\frac{\ln \left[\sum_{j=1}^{J} e^{C B V\left(Q_{j}^{1}\right)}\right]-\ln \left[\sum_{j=1}^{J} e^{C B V\left(Q_{j}^{0}\right)}\right]}{\frac{\partial C B V_{i j}}{\partial y}}
$$

To compute the value of a change in site attributes we need to make assumptions about all site attributes. Similar to the linear additive form of utility models when variables are held at their means in the numerator of equation 1.9, in CBDT, we need to make assumptions on the values of variables in the similarity function. When valuing a change in result, like catching a target species of fish, the similarity function is held at some assumed value. On the other hand, when valuing a change in the attribute, $Q$, in the similarity function, we must consider if the attribute affects the result, $(r)$, as well as the similarity function. The indirect $\mathrm{CBU}$ as a function of a particular $Q$ is given in equation 1.10 .

$$
C B V\left(Q_{j}^{1}\right)=\frac{1}{e^{\sqrt{{ }^{w} Q_{j}^{1}\left(p_{Q^{1} j_{j}}-q_{Q^{A}}\right)^{2}}}} u\left(r \mid Q_{j}^{1}\right)
$$

In $\mathrm{CBV}$, we make assumptions about the past problems in memory, $q_{Q}$, either by taking the average distribution of past attributes $\left(Q^{A}\right)$, or by another measure of a representative past. Assumptions are also required regarding how $Q_{j}^{1}$ affects the 
result, $r$. To measure how attributes affect results we need to establish a functional form, as provided in equation 1.11, that measures the effect of the attributes on the results.

$$
r(X)=f\left(\beta_{v}, X_{v}\right)+\epsilon
$$

We then use the predictions from equation 1.11 to construct the average result, $r\left(Q_{j}^{1}\right)$, conditional on attribute $Q_{j}^{1}$ for a particular site $j$ and estimate location choice model using CBDT as outlined in section 1.3.2. Lastly, we need a measure of the marginal utility of income, $y$ to interpret the effect of a change of in attribute on utility in dollar terms. We hypothesize that the marginal utility of income could be rule-based or case-based. If rule-based, we would typically recover a constant marginal utility of income. However if case-based, the derivative of CBU with respect to cost (or measure of income) would potentially affect both the result, $r$, and the comparison to past cases through the estimated weights in the similarity function. The estimates from the location choice model and the predictions from equation 1.11 are used as inputs into the equation 1.10 .

\subsection{Data}

We use data from Connecticut recreational fishers to test the empirical fit of casebased reasoning versus rule-based reasoning. Recreational fishing in Connecticut is encouraged with several opportunities in terms of information access and enhanced opportunity fishing programs. The data used in this study was obtained from the Volunteer Angler Survey Program (VAS) provided by the Connecticut Department of Energy and Environmental Protection (DEEP) ${ }^{6}$. In this program the fish trip and catch information are recorded in survey logbooks by anglers voluntarily. The survey logbooks are provided to each angler participant and they are encouraged send in the completed logbooks via mail. Weather data is obtained from the NOAA's (National Oceanic and Atmospheric Administration) National Centers for Environmental In-

\footnotetext{
${ }^{6}$ The website http: //www.ct.gov/deep/cwp/view. asp? $a=2696 \& q=322750$ provides details about VAS program in Connecticut.
} 
formation (NCEI) ${ }^{7}$ and joined to the trip data by day of trip. The VAS data received, after accounting for missing values, has a total of 16,599 observations which includes trips taken by 51 survey participants from the year 2013 to 2016 .

The area assigned to recreational anglers in Connecticut is appropriated into area codes. Each code (a three digit code) denotes a smaller part of a chart area provided in the Fishing Vessel Trip Report Reporting Instructions for the Great Atlantic Region provided by NOAA ${ }^{8}$. All area codes provided in this data set are found within the Long Island Sound. The anglers have visited seven different areas within this region. Among them only six areas are recorded in the Fishing Vessel Trip Report. Those observations belonging to areas which have not been recorded have been grouped into a sixth area denoted as 'other' in this study. This category contains site choices that are not recorded in the Fishing Vessel Trip Report Reporting Instructions provided by NOAA but was visited by recreational fishermen who participated in the VAS program in Connecticut. Furthermore, as per the VAS data entry mechanism, the species caught, number of fish caught, weight and size of each catch are recorded as separate records. Therefore, by considering only one trip per day for each participant and after eliminating missing values, our final data set has been reduced to 3182 trips made by 51 participants with 6 possible location choices for recreational fishing.

Table 1.1 provides a description of the variables provided in this data set. The key variables of interest are site congestion, expected catch rate, site history and period and the summary statistics for the same are included in Table 1.2. The variables described in Table 1.1 are used to derive the key variables commonly used in fisheries literature (McConnell et al., 1995; Hunt, 2005; Timmins and Murdock, 2007). These variables are site congestion, site history, and expected catch rate.

\footnotetext{
${ }^{7}$ The website https: //www.ncdc.noaa.gov/ provides details about the NCEI and details about how to obtain weather data and information.

${ }^{8}$ The document https://www.greateratlantic.fisheries.noaa.gov/public/nema/ apsd/vtr_inst.pdf is the Fishing Vessel Trip Report Reporting Instructions for the Great Atlantic Region provided by NOAA. It provides details about the areas appropriated into grid codes in the New England region.
} 
Table 1.1: Description of Variables

\begin{tabular}{|c|c|}
\hline Variable & Description \\
\hline Work Day & $=1$ if the trip is taken on a weekday \\
\hline Month and Year & $\begin{array}{l}\text { Yearly data from } 2013 \text { to } 2016 \text { and monthly data from April to } \\
\text { December is available. }\end{array}$ \\
\hline Wind Speed & Measures the daily average wind speed in meters per second. \\
\hline Temperature & The daily average temperature measured in Fahrenheit. \\
\hline Precipitation & $\begin{array}{l}=1 \text { if the daily average precipitation measure is greater than } 0.005 \\
\text { inches. }\end{array}$ \\
\hline Trace Precipitation & $\begin{array}{l}=1 \text { if the daily average precipitation measure is less than or equal to } \\
0.005 \text { inches. }\end{array}$ \\
\hline Angler Number & The number of anglers recruited under a single participant identity. \\
\hline Fishing Hours & $\begin{array}{l}\text { The number of hours spent fishing recoded under each participant } \\
\text { identity }\end{array}$ \\
\hline Trip Mode & $\begin{array}{l}\text { This variable describes whether the angler was surveyed on a private } \\
\text { boat, charter boat, party boat, the shore or at the enhanced shore } \\
\text { fishing site. }\end{array}$ \\
\hline Payout & $\begin{array}{l}=1 \text { if the target species is caught by the fisher. This variable is used } \\
\text { to define the result or outcome of the case in case-based decision } \\
\text { model. }\end{array}$ \\
\hline
\end{tabular}

\subsubsection{Site Congestion}

The variable site congestion is proxy measure for the number of other fishermen encountered during the fishing trip. The effect of congestion as a site attribute is important when modelling location choice preferences. Previous studies in recreational demand literature that have measured this effect and have concluded that omitting this attribute leads to biased results. The common hypothesis is that congestion beyond a certain degree is less desirable and acts as a disutility in the site choice model (Timmins and Murdock, 2007; Bujosa et al., 2015; Schuhmann and Schwabe, 2004; Kolstoe et al., 2018). In this study, congestion is measured as the share of total fishing trips taken in the same month of the previous year for each location within the sample (Kolstoe and Cameron, 2017; Murdock, 2006) ${ }^{9}$.

\footnotetext{
${ }^{9}$ Site Congestion for site $\mathrm{j}=$ Share of trips made per month to site $\mathrm{j}$ in year $\mathrm{t}-1$
} 


\subsubsection{Site History}

Another attribute that affects the utility of a fishing site is previous site visited. Site History is a binary indicator for whether the chosen site was visited in the previous period. This is an easy way to capture how habit formation and repeat visitation is important in site selection.

\subsubsection{Expected Catch Rate}

The expected catch represents the expected payout received in terms of fish caught per unit effort from a particular site by each participant. This variable was estimated using attributes such as number of anglers, fishing hours, area, trip mode, weather variables, work day, year and month. This predicted measure for catch rate is estimated using a Poisson process model, an approach popularized by McConnell et al. (1995). (Refer to Appendix A1)

\subsubsection{Indexing Memory}

In case based decision theory, each case in the decision maker's memory, which in this study are previous fishing trips, are chronologically ordered and indexed using a variable we call period. This variable is a constructed variable which equals the accumulated number of trips an angler takes. This is used to gain a measure of recency in CBDT. Realistically, a relatively recent case may have a larger influence in the decision making process than an older case. In order to account for this, we capture the measure of recency by including period in the model as an attribute to measure similarity. A case in the far past is given less weight that a similar case in the recent past when considering recency. In a LA model this variable acts as a proxy for individual fishing experience within our sample size, given that it is equal to the number of trips that an angler has taken at that point in time. 
Table 1.2: Summary Statistics of Key Variables

\begin{tabular}{lcccc}
\hline \hline Variable & Mean & Std Dev & Min & Max \\
\hline Expected Catch Rate & 12.23 & 11.35 & 0.43 & 112.9 \\
Site Congestion & 0.12 & 0.15 & 0 & 1 \\
Site History (Yes = 1) & 0.87 & 0.33 & 0 & 1 \\
Period & 100 & 120 & 1 & 502 \\
Payout & 0.69 & 0.46 & 0 & 1 \\
\hline
\end{tabular}

\subsection{Model Fit Comparison}

The in-sample quantitative fit of LA, CBDT and Inertia models are compared using the Akaike Information Criterion as well as the Bayesian Information Criterion. When comparing the information criteria for the estimated results, a relatively smaller AIC or BIC value means that the model explains the data better (Atkinson, 1981).

Out-of-sample predictions for all models are also conducted. For model selection, the out-of-sample procedure is preferred since in-sample fit can be more easily manipulated by the addition of controls which may mask how well the underlying model is actually performing. We use a method of roll forward samples to estimate out-of-sample fit as measured by log-likelihood. In this approach, a percentage of decision maker's choice data, which comprises of cases ordered chronologically, is used to predict the remaining hold-out sample. We conducted a rolling window selection for out-of-sample fit comparison using 15, 25, 50, 75 and 90 percent of choice data for all models.

\subsection{Results}

The estimated regression coefficients for the LA model are reported in Table 1.3. The five recorded location choices available to the recreational fishermen are listed in this table with 'other' acting as the base category. 
Table 1.3: LA Model Results

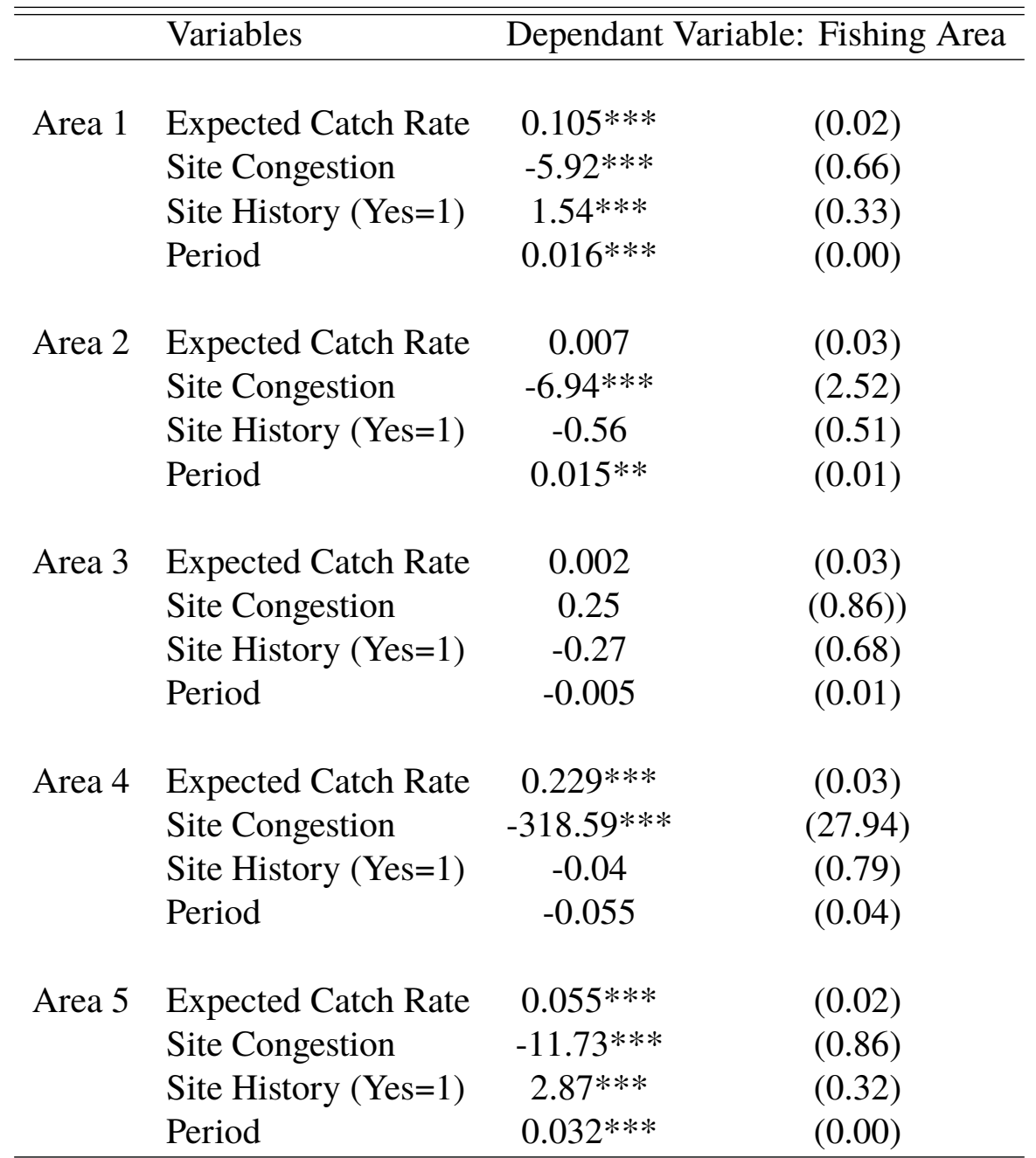

Notes: $N=3,182$. The choice area 'other' acts as a reference area in this model. Standard errors are given in parentheses. $* * * * *$ and $*$ denotes significance at 1 percent, 5 percent and 10 percent.

The coefficients in the LA model are interpreted as log odds ratios. For instance, the positive significance of the coefficient for variable, expected catch implies that a unit more level of expected catch would lead to an expected increase in the multinomial log odds by 0.105 relative to the referent site for the first site and 0.229 for the fourth site, holding all other variables constant. Similarly the estimates for site congestion is significant and negative for four out of five areas. This result is consistent with the recreational fishing literature regarding the negative effect fishers have when encountered with high concentration of anglers at a fishing site (Martinson and Shelby, 1992). The coefficients for site history when positive implies that fishers 
are loyal to the previous site visited whereas a negative sign implies a preference for variety. However, significance is obtained only for the positive coefficients. The variable period, acts as a proxy for individual fishing experience within our sample size. Three out of five areas exhibit a significant and positive log odds for this variable, implying that a more experienced fisher would visit these areas relative to the referent area.

The parameters estimated in Case-based Decision Theory (CBDT) are the weights, $w_{v}$, given to that parameter in the similarity function as specified in equation 1.6. The significance marks their importance in weighing attributes in the similarity function between problems, $p$. The coefficients in CBDT, similar to the LA model, are estimated using the maximum likelihood estimation procedure. The parameter estimates, represents the coefficients for each area code as well as the estimated weights for the vector of information (independent variables) used in predicting choice. The coefficients for "Area $\mathrm{i}$ " are relative initial attractions to the stated areas. This is similar to attractions to strategies that learning rules accumulate in behavioral game theory Guilfoos and Pape (2019). This initial attraction serves a role similar to fixed effects. Initial attractions to locations and aspiration levels are not separable in estimate and therefore we leave out $H$. The initial attraction coefficients along with the similarity weighted functions represent the case-based utility function.

Table 1.4 provides the estimates obtained for CBDT. Four models, each with a different selection of variables, are estimated in the above table. The model in column (4) with all variables used in the LA model, with the lower AIC and BIC, is the preferred model. The coefficients of the area codes measures a given predetermined preference for each choice, whereas the weights, if positive, indicate a degree of similarity between current and past cases. Similarly, a negative significant weight represents a degree of dissimilarity between the past and current cases of that variable. 
Fishing Area as Dependant Variable

Variables

(1)

(2)

(3)

(4)

$\begin{array}{ccccc}\text { Area } 1 \text { (Initial Attraction) } & 2.99 * * * & 0.56 * * * & 0.35 * * * & 0.29 * * * \\ & (0.38) & (0.09) & (0.06) & (0.05) \\ \text { Area } 2 \text { (Initial Attraction) } & -1.23 * * * & -0.24 * * & -0.21 * * & -0.18 * * * \\ & (0.52) & (0.11) & (0.08) & (0.07) \\ \text { Area } 3 \text { (Initial Attraction) } & -2.54 * * * & -0.49 * * * & -0.41 * * * & -0.33 * * * \\ & (0.66) & (0.14) & (0.11) & (0.09)\end{array}$

$\begin{array}{lllll}\text { Area } 4 \text { (Initial Attraction) } & -3.45 * * * & -0.67 * * * & -0.58 * * * & -0.48 * * *\end{array}$
$(0.78)$
$(0.16)$
$(0.13)$
$(0.10)$

Area 5 (Initial Attraction)

$$
\begin{array}{cccc}
5.02 * * * & 0.99 * * * & 0.64 * * * & 0.49 * * * \\
(0.48) & (0.12) & (0.08) & (0.06)
\end{array}
$$

Sensitivity Parameter $(\lambda) \quad 41.7 * * * \quad 207.9 * * * \quad 267.2 * * * \quad 333.2 * * *$

$$
\text { (2.99) (21.82) (25.52) (31.25) }
$$

$\begin{array}{lllll}\text { Expected Catch Rate } & 0.009 * * * & 0.02 * * * & 0.002 * & 0.001\end{array}$

$\begin{array}{llll}(0.00) & (0.00) \quad(0.00) \quad(0.00)\end{array}$

Period

$$
\begin{array}{ccc}
0.068 * * * & 0.065 * * * & 0.043 * * * \\
(0.01) & (0.01) & (0.01)
\end{array}
$$

Site Congestion

$$
\begin{array}{ll}
542.8 * * & 412.2 * * \\
(105.8) & (84.8)
\end{array}
$$

Site History (Yes=1)

$8.57 * * *$

\begin{tabular}{lllll} 
AIC & 2611.849 & 2413.509 & 2041.109 & 1876.629 \\
BIC & 2654.306 & 2462.031 & 2095.697 & 1937.281 \\
\hline
\end{tabular}

Notes: $N=3,182$. The first column lists the site choices and variables used in the model.The respective parameter estimates for the areas, the sensitivity parameter as well as the CBDT weights estimated for each variable for four CBDT models is mentioned in the subsequent columns. 
For instance, the estimated weight for site congestion is substantial, positive and significant which indicates a high degree of similarity between the congestion level for the current and past chosen location and hence more weight is given to this variable by the fisher. The variable, expected catch rate, although positive, has a smaller weight and becomes insignificant when other key variables are included in the model. The small weight indicates that when fishermen extrapolate from past experiences, they do not think 'expected catch rate' to be very useful in that extrapolation. This insignificance of the estimated weight for expected catch rate conforms to the literature that non-catch related site attributes such as fish size, water quality, aesthetics play an important role in recreational fishers' location choice decisions (Hunt, 2005; Rubio et al., 2014). The estimated weight for the variable period accounts for recency. The statistical significance of this estimate implies that among the similar cases in the fisher's memory, those that are in the recent past have more weight and are likely to be accounted towards the current decision making process compared to the cases that have occurred earlier. In other words, the similarity weight period accounts for the temporal distance between a relatively recent fishing trip and an older trip.

A direct comparison between the inertia model, CBDT model, and Linear additive model is made using AIC and BIC in Table 1.5, concludes that the CBDT model has closer fit to the data relative to the LA model, and with less estimated parameters in the model. However, in terms of interpretation one cannot be substituted for the other. Coefficients from LA model provide a rule-based reasoning interpretation of how the log odds ratios changes as conditions change. Coefficients from the similarity function in CBDT tell us how different information is weighed using case-based reasoning and memory of the subject. 
Table 1.5: Comparison of Model Selection Criteria

\begin{tabular}{llll}
\hline \hline & Log-Likelihood & AIC & BIC \\
Linear Additive Model & -1194.664 & 2439.328 & 2590.959 \\
CBDT & -928.314 & 1876.629 & 1937.281 \\
Inertia Model & -2336.29 & 4690.58 & 4745.167 \\
\hline
\end{tabular}

Notes: AIC and BIC denote Akaike Information Criteria and Bayesian Information Criteria respectively. In the above model selection criteria, the smallest represents the preferred model. The inertia model has no parameters so we do not report a BIC for that model.

To guard against over fitting the models based solely on in-sample fits, we compared the out-of-sample fit for all models. We compare the rolling out of sample fit based on fishers' memory. Table 1.6 reports the log-likelihood value for all three models. CBDT performs consistently better than the LA and Inertia model irrespective of the percentage of memory used for prediction. We also notice that with more memory the gap between the predictive fit for LA model and CBDT reduces due to smaller samples being predicted. This finding suggests CBDT as a model to predict location choice for anglers.

Table 1.6: Out of Sample Fit: Log-likelihood Comparison

\begin{tabular}{lccccc}
\hline \hline & \multicolumn{5}{c}{ Percentage of Memory } \\
Model & $15 \%$ & $25 \%$ & $50 \%$ & $75 \%$ & $90 \%$ \\
\hline Linear Additive & -44247 & -6543 & -1643 & -363 & -163 \\
CBDT & -961 & -805 & -447 & -207 & -85 \\
Inertia & -1997 & -1735 & -1171 & -640 & -316 \\
\hline
\end{tabular}

Notes: In the above model selection criteria, the largest log-likelihood represents the preferred model. Column (2) to (6) represents different percentage (increasing order) of decision-makers memory used to predict the remaining choice outcomes in the data set.

The results estimated till now include all fish species and use the success of 
catching the target species (a binary indicator) specified by the individual fishermen as payout. We check the robustness of our results by conducting analysis for each target species separately. Table 1.7 reports the estimated weights for the top four target species considered by recreational fishermen in our data set. The AIC model selection criteria shows CBDT has a better fit than LA for striped bass, blue fish, fluke and black sea bass.

Table 1.7: Model Selection Estimated Weights for Different Target Species

\begin{tabular}{lcccc}
\hline \hline & Striped Bass & Blue Fish & Fluke & Sea Bass \\
\hline (i) $\underline{\text { Similarity Weights }}$ & & & & \\
Exp Catch & $0.002^{*}$ & 0.024 & $0.013^{* *}$ & 0.001 \\
Period & 0.027 & $0.046^{* *}$ & 0.007 & $0.15^{* * *}$ \\
Congestion & $0.12^{* *}$ & $9.78^{*}$ & $33.9 * *$ & $1088^{* * *}$ \\
Site History & $26.15^{* *}$ & 232.8 & $11.1^{* *}$ & 0.49 \\
(ii) Model Selection Criteria & & & & \\
LA & 1281 & 643 & 705 & 460 \\
CBDT & 987 & 601 & 689 & 348 \\
$\mathrm{~N}$ & 1849 & 1026 & 966 & 413 \\
\hline
\end{tabular}

Notes: The four columns represents the top four target species preferred by recreational fishermen in this data set. The CBDT estimated weights for expected catch rate, site congestion, site history and period for each target species are provided under part (i) and the model selection criteria (AIC) for LA and CBDT models along with the number of observations are provided in part (ii).

In terms of interpretation, the coefficient for expected catch shows significance for striped bass and fluke. The estimated weight for site congestion on the other hand is significant, positive and substantial for all target species, especially for black sea bass. This implies that choice location weighs cases in the past with similar congestion very high when constructing which location is preferred for a fisher. This conforms to the existing literature regarding importance of including congestion effects when modelling recreational choice behavior (Schuhmann and Schwabe, 2004; Bujosa 
et al., 2015; Timmins and Murdock, 2007).

\subsection{Simulation of Welfare Changes}

We use simulated data to demonstrate the errors in estimating welfare when using a linear additive model when the data generating process is from a case-based decisionmaker. We use simulation for two critical reasons. First, it allows us to add in a measure of marginal utility of money, which is lacking from our recreational fishing data. Second, we can run controlled experiments with simulated data varying the relationships between random variables.

The generated discrete choice data follows equation 1.12 where we index the current period $(t)$ to reference past periods $(q)$, in memory. Decision maker $i$, considers attributes, $k$, for two locations $j=[1,2]$ with a random variable for travel cost, $C$. The site attributes $(k)$ are expected catch rate (ECR) and site congestion (SC), and the index for time (period). Additionally, we assume the error term, $\epsilon$, to be independent and identically distributed and comes from the logistic function. Following the premise behind CBDT, memory is constructed on the three previous periods, after which the fourth and subsequent periods are forgotten. The result (or reinforcement mechanism) is a binary indicator that equates to one if the fisher caught their preferred species at location $\mathrm{j}$, referenced as catch.

$$
C B V_{i j q}=\beta_{0 j}+\beta_{1} * C_{i j t}+\sum \frac{\operatorname{catch}_{i j q}}{e^{\sqrt{\sum w_{k} *\left(p_{k i j t}-q_{k i j q}\right)^{2}}}}+\epsilon_{i j t}
$$

Descriptive statistics for the parameters and the distributions of random variables are provided in Table 1.8.

Each simulation contains 400 observations, 200 time periods, and is repeated 1,500 times. In Table 1.8, the correlation parameter describes the level of correlation between ECR and C. After each simulation, we use the standard logit model to estimate the coefficients from equation 1.13. We then use a Wald test to assess if the recovered coefficients are equal to the 'real' coefficients that generated the data. The 
Table 1.8: Description of Simulated Data

\begin{tabular}{ll}
\hline \hline Variable & Description \\
\hline Period & takes values from 1 to 200. \\
Travel Cost $(C)$ & $=\mathrm{N}(2,0.5)$ \\
Expected Catch Rate (ECR) & $=\mathrm{N}(2,0.2)$ \\
Site Congestion (SG) & $=0.5+\mathrm{U}[0,1]$ \\
Catch & $=1$ if $\mathrm{N}(2,0.2)>$ ECR for sites visited. \\
Correlation Parameter & within number range from 0 to 0.95 \\
Intercept $\left(\beta_{0}\right)$ & $=1$ for site $\mathrm{j}=1$ and $=2$ for site $\mathrm{j}=2$ \\
Travel Cost Coefficient $\left(\beta_{1}\right)$ & $=-0.15$ \\
Recency Similarity Coefficient $\left(\mathrm{w}_{1}\right)$ & $=0.60$ \\
ECR Similarity Coefficient $\left(\mathrm{w}_{2}\right)$ & $=0.20$ \\
SG Similarity Coefficient $\left(\mathrm{w}_{3}\right)$ & $=0.85$ \\
\hline
\end{tabular}

travel cost coefficient, $\beta_{1}$, and the coefficient on a prior catch in at location $j, \beta_{4}$, is used to assess how the marginal willingness to pay for a target species is estimated. Since we assumed a linear additive cost structure, the 'real' coefficient is equal to -0.15 , which is the marginal utility of money. While the marginal increase in the previous period catch is one over the average similarity function from the previous period, 0.418 , we can further accumulate the value of all past catches as far back as an agent's memory goes to assess cumulative effects of catches at a particular location. Willingness to Pay for a site is acquired in the same manner, provided we assume a value for past catches or the expected value of catching the preferred species.

$$
C B V_{i j q}=\beta_{0 j}+\beta_{1} * C_{i j t}+\beta_{2} * E C R_{i j t}+\beta_{3} * S G_{i j t}+\beta_{4} * C a t c h_{i j, t-1}+\epsilon_{i j t}
$$

The error rate in identifying $\beta_{1}$ is rather low $(5 \%)$ with a $\mathrm{p}$-value $<0.05$. The error rate in identifying the marginal value of a previous catch is high $(24 \%)$ with a p-value $<0.05$. The linear additive model lacks precision, though, as the standard errors of estimates are rather large, so that the mode and mean of point estimates for $\beta_{1}$ are systematically lower than the 'true' parameter, which may inflate the willingness to pay of any attribute. As the correlation between a random variable within the similarity function and the linear additive part of the data generating process increases, so do the issues with precision around the marginal utility of money. As shown in 
figure 1.1, the spread in recovered parameters for the $\beta_{1}$ increases with the increase in correlation between travel cost, $\mathrm{C}$, and expected catch rate, ECR. The range starts larger than the real coefficient $(-0.15)$ and increases to almost quadruple the size of the actual coefficient.

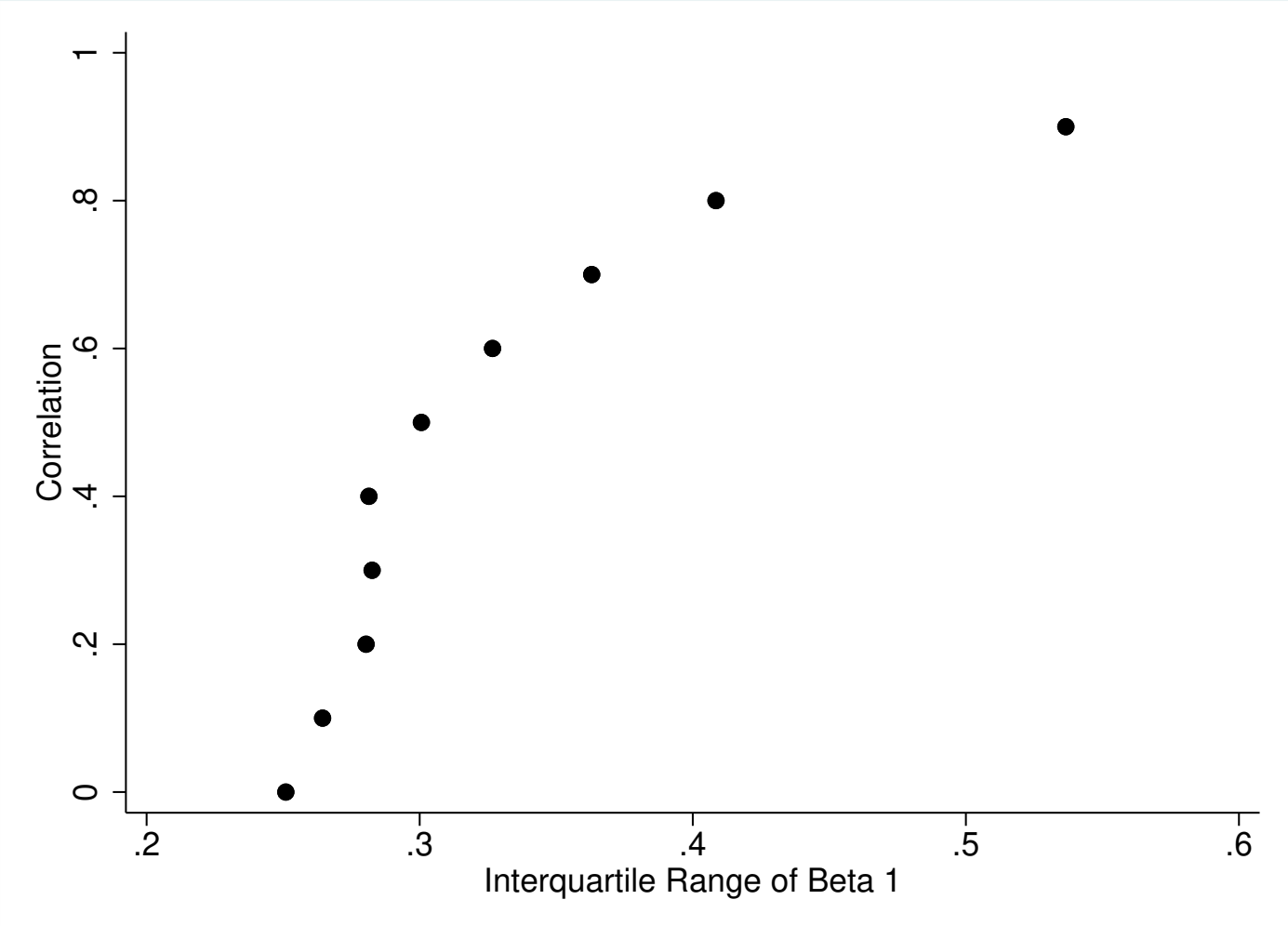

Figure 1.1: Range of Estimates of the Travel Cost Coefficient.

(Each dot represents the range of the estimates from 1,500 simulations.)

The marginal willingness to pay for a preferred species by construction is $\$ 2.79$. The LA model retrieves between $\$ 0.49$ and an infinitely high number due to the small point estimate of the marginal utility of money. This, of course, is troubling because we may recover a wide range of welfare measures due to the fragility of the estimates.

\subsection{Discussion}

We find support to recommend case-based reasoning to empirical location choice data, but there are limitations with such an approach. When applying models to empirical data, there is often much the researcher does not know about the choice data, such as preferences and the experiences that shaped those preferences. Therefore, in 
constituting the memory of an agent using CBDT, we may leave out or misconstrue what is in memory or how a particular memory enters into Utility. One difficulty in measuring how a location choice enters into Utility is the 'result' of a particular choice. In our case, we use the catch that a recreational fisher gets as their reward for fishing in a particular location. An ideal data set would be a panel of choice observations where the information set and result is known to the researcher. The lack of a 'result' is a limitation in most travel cost studies. CBDT suggests that this is a vital piece of information that would reinforce choices in a repeated choice setting. In our setting, recreational fishers may be motivated by the number of fish caught, type of fish, size of the fish caught or spending quality time with family. Information about the level of success attained as a consequence of a past choice made is an essential determining factor behind how individuals make future decisions. We feel that whether the target species was caught is a good measure of the result, $R$, though in other settings, a measure of success of a choice may be difficult or impossible to know and is often omitted from survey data.

A particular limitation in this study is omitted variables. We lack information about individual characteristics of fishers, such as income, education, and travel cost to the site. While we contend that the omitted variables do not favor one model over the other, a complete set of variables is desirable.

An important critique against the multinomial logit model, which we use to estimate parameters for both LA RUM and CBDT, is the assumption of Independence of Irrelevant Alternatives (IIA) (Train, 1998). This assumption implies that the Utility from one alternative is solely influenced by individual-specific characteristics which are constant across alternatives. Fisheries economists have applied Mixed Logit or Random Parameters Logit, which incorporates alternative specific characteristics into the model (Mistiaen and Strand, 2000). A prospective future application in CBDT is to account for unobserved heterogeneity by allowing parameters to vary across observations. Such a model would be comparable to the mixed multinomial logit or random parameters logit model. 


\subsection{Conclusion}

In this study, we find that case-based decision theory explains location choice behavior better than the typical linear additive model used pervasively in the literature of location choice. While we frame the differences as a test of models, that does not need to be the case. Using both models, or mixes of behavioral models in investigating empirical choice can only give us more insight into the mechanisms for choice and the importance of information to the decision-makers.

Both in-sample and out-of-sample measures favor CBDT, which is promising for behavioral modeling of discrete choice data. Further research is needed to understand how to best match and collect data for behavioral decision-making models such as CBDT. However, we can imagine future efforts in surveys may capture explicit measures of success of trips and aspiration values. Further work may also find when or if this type of behavioral modeling is needed to understand the observed choice.

This work and past empirical work on CBDT (Guilfoos and Pape, 2019; Kahneman, 2003; Gilboa et al., 2007; Bleichrodt et al., 2017; Ossadnik et al., 2013) suggest themselves to other applications outside of location choice modeling. Behavioral modeling is not limited to the functional form of choice but can involve cognition, rationalization, or other psychological aspects of choice. The extension of behavioral modeling, and specifically case-based reason modeling, to other choice settings, may improve the prediction of choice in modeling and provide more accurate welfare estimates when based on models that better match our understanding of how people make decisions.

Lastly, care needs to be taken when considering discrete choice modeling and valuation work. We demonstrate the potential for substantial differences in welfare from using the wrong model. Using simulation data, we demonstrate the potential fragility of the reduced form model, assuming that the data generating process is case-based. 


\section{References}

Atkinson, A. C. (1981). Likelihood ratios, posterior odds and information criteria. Journal of Econometrics, 16(1):15-20.

Bleichrodt, H., Filko, M., Kothiyal, A., and Wakker, P. P. (2017). Making Case-Based Decision Theory Directly Observable. American Economic Journal: Microeconomics, 9(1):123-151.

Bockstael, N. E. and Opaluch, J. J. (1983). Discrete modelling of supply response under uncertainty: The case of the fishery. Journal of Environmental Economics and Management, 10(2):125-137.

Bujosa, A., Riera, A., Hicks, R. L., and McConnell, K. E. (2015). Densities Rather than Shares: Improving the Measurement of Congestion in Recreation Demand Models. Environmental and Resource Economics, 61(2):127-140.

Cerigioni, F. and Fabra, U. P. (2019). Retrieving Preferences when some Choices are Automatic. Universitat Pompeu Fabra, (1673):47.

Cinti, A., Shaw, W., Cudney-Bueno, R., and Rojo, M. (2010). The unintended consequences of formal fisheries policies: Social disparities and resource overuse in a major fishing community in the Gulf of California, Mexico. Marine Policy, 34(2):328-339.

Gilboa, I., Gayer, G., and Lieberman, O. (2007). Rule-Based and Case-Based Reasoning in Housing Prices. B.E. Journal of Theoretical Economics, Vol.7, $\mathrm{n}^{\circ} 1:$ pp.1-37. 
Gilboa, I. and Schmeidler, D. (1995). Case-Based Decision Theory. The Quarterly Journal of Economics, 110(3):605-639.

Gilboa, I. and Schmeidler, D. (2001). A Theory of Case-Based Decisions. Cambridge University Press.

Guilfoos, T. and Pape, A. (2019). Case-based learning and estimation. Working Paper.

Guilfoos, T. and Pape, A. D. (2016). Predicting human cooperation in the Prisoner's Dilemma using case-based decision theory. Theory and Decision, 80(1):1-32.

Hanemann, W. M. (1983). Marginal welfare measures for discrete choice models. Economics Letters, 13(2):129-136.

Hess, S., Daly, A., and Batley, R. (2018). Revisiting consistency with random utility maximisation: theory and implications for practical work. Theory and Decision, 84(2):181-204.

Holland, D. S. (2008). Are Fishermen Rational? A Fishing Expedition. Marine Resource Economics, 23(3):325-344.

Hunt, L. M. (2005). Recreational fishing site choice models: insights and future opportunities. Human Dimensions of Wildlife, 10(3):153-172.

Kahneman, D. (2003). Maps of Bounded Rationality: Psychology for Behavioral Economics. American Economic Review, 93(5):1449-1475.

Kinjo, K. and Sugawara, S. (2016). Predicting Empirical Patterns in Viewing Japanese TV Dramas Using Case-Based Decision Theory. The B.E. Journal of Theoretical Economics, 16(2):679-709.

Kolstoe, S., Cameron, T. A., and Wilsey, C. (2018). Climate, Land Cover, and Bird Populations: Differential Impacts on the Future Welfare of Birders across the Pacific Northwest. Agricultural and Resource Economics Review, 47(2):272-310. 
Manski, C. F. (1977). The structure of random utility models. Theory and Decision, $8(3): 229-254$.

Manzini, P. and Mariotti, M. (2014). Welfare economics and bounded rationality: the case for model-based approaches. Journal of Economic Methodology, 21(4):343360.

Martinson, K. S. and Shelby, B. (1992). Encounter and Proximity Norms for Salmon Anglers in California and New Zealand. North American Journal of Fisheries Management, 12(3):559-567.

McConnell, K. E. (1995). Consumer Surplus from Discrete Choice Models. Journal of Environmental Economics and Management, 29(3):263-270.

McConnell, K. E., Strand, I. E., and Blake-Hedges, L. (1995). Random utility models of recreational fishing: catching fish using a poisson process. Marine Resource Economics, 10(3):247-261.

McFadden, D. (1974). The measurement of urban travel demand. Journal of Public Economics, 3(4):303-328.

McFadden, D. (2001). Economic Choices. American Economic Review, 91(3):351378.

Mistiaen, J. A. and Strand, I. E. (2000). Location Choice of Commercial Fishermen with Heterogeneous Risk Preferences. American Journal of Agricultural Economics, 82(5):1184-1190.

Morey, E. R., Shaw, W. D., and Rowe, R. D. (1991). A discrete-choice model of recreational participation, site choice, and activity valuation when complete trip data are not available. Journal of Environmental Economics and Management, 20(2):181-201.

Nosofsky, R. M. (1992). Similarity Scaling and Cognitive Process Models. Annual Review of Psychology, 43(1):25-53. 
Ossadnik, W., Wilmsmann, D., and Niemann, B. (2013). Experimental evidence on case-based decision theory. Theory and Decision, 75(2):211-232.

Pape, A. D. and Kurtz, K. J. (2013). Evaluating case-based decision theory: Predicting empirical patterns of human classification learning. Games and Economic Behavior, 82:52-65.

Pauly, D., Watson, R., and Alder, J. (2005). Global trends in world fisheries: impacts on marine ecosystems and food security. Philosophical Transactions of the Royal Society B: Biological Sciences, 360(1453):5-12.

Ran, T., R, and Kazmierczak, R. (2011). Location Choice Behavior of Gulf of Mexico Shrimpers under Dynamic Economic Conditions. Journal of Agricultural and Applied Economics, Volume 43(Number 1).

Rubinstein, A. and Salant, Y. (2011). Eliciting welfare preferences from behavioural data sets. The Review of Economic Studies, 79(1):375-387.

Rubio, G., Brinson, A., and Wallmo, K. (2014). Attitudes and Preferences of Saltwater Recreational Anglers: Report from the 2013 National Saltwater Angler Survey, Volume II Regional Analysis.

Schuhmann, P. W. and Schwabe, K. A. (2004). An Analysis of Congestion Measures and Heterogeneous Angler Preferences in a Random Utility Model of Recreational Fishing. Environmental and Resource Economics, 27(4):429-450.

Shepard, R. N. (1987). Toward a universal law of generalization for psychological science. Science, 237(4820):1317-1323.

Timmins, C. and Murdock, J. (2007). A revealed preference approach to the measurement of congestion in travel cost models. Journal of Environmental Economics and Management, 53(2):230-249.

Train, K. E. (1998). Recreation Demand Models with Taste Differences over People. Land Economics, 74(2):230-239. 


\section{Appendix A1: Poisson Model to Estimate Expected Catch}

The variable expected catch rate is the predicted measure for fish caught per trip per site and is estimated using a Poisson process model (Table 1.9). This approach, popularized by McConnell et al. (1995), assumes the number of fish caught to have a Poisson distribution. The explanatory variables that influence fisher behavior are used to predict this estimate. expected catch. This accounts for any variation in catch across fishers. The variables used in this model include area, workday, a binary indicator for a week day; weather controls such as wind speed, temperature and precipitation (inches); fishing hours, used as a proxy for fishing effort; number of anglers per fisher Id; fishing trip mode, that is., charted boat (reference category), part boat, private boat, shore and enhanced shore fishing site; year and month fixed effects.

Table 1.9: Poisson Model to Estimate Expected Catch

\begin{tabular}{lcccc}
\hline \hline \multirow{2}{*}{ Variables } & \multicolumn{4}{c}{ Number of Fish Caught as Dependent Variable } \\
& $(1)$ & $(2)$ & $(3)$ & $(4)$ \\
\hline Number of Anglers & 0.092 & 0.079 & 0.069 & 0.102 \\
& $(0.02)^{* * *}$ & $(0.02)^{* * *}$ & $(0.02)^{* * *}$ & $(0.02)^{* * *}$ \\
Fishing Hours & 0.209 & & & \\
& $(0.02)^{* * *}$ & & & \\
Log(Fishing Hours) & & 1.239 & 1.236 & 1.204 \\
& & $(0.06)^{* * * *}$ & $(0.06)^{* * *}$ & $(0.07)^{* * *}$ \\
Work Day (Yes=1) & -0.020 & -0.032 & -0.051 & -0.011 \\
& $(0.06)$ & $(0.05)$ & $(0.06)$ & $(0.06)$ \\
Trip mode & & & & \\
(i) Party Boat & -0.317 & -0.291 & -0.330 & -0.316 \\
& $(0.48)$ & $(0.49)$ & $(0.49)$ & $(0.46)$ \\
(ii) Private Boat & -0.291 & -0.179 & -0.232 & -0.089 \\
& $(0.44)$ & $(0.45)$ & $(0.46)$ & $(0.43)$ \\
\hline
\end{tabular}


Table 1.9 - Continued from previous page

\begin{tabular}{lcccc}
\hline \multirow{2}{*}{ Variables } & \multicolumn{4}{c}{ Number of Fish Caught as Dependent Variable } \\
& $(1)$ & $(2)$ & $(3)$ & $(4)$ \\
\hline (iii) Shore & -1.572 & -1.302 & -1.354 & -1.118 \\
& $(0.43)^{* * *}$ & $(0.45)^{* * *}$ & $(0.46)^{* * *}$ & $(0.43)^{* * *}$ \\
(iv) Enhanced Fishing Site & -0.819 & -0.515 & -0.580 & -0.485 \\
& $(0.44)^{*}$ & $(0.46)$ & $(0.47)$ & $(0.43)$ \\
& & & & \\
Weather Controls & Yes & Yes & Yes & Yes \\
Area Fixed Effects & Yes & Yes & No & Yes \\
Month and Year Fixed Effects & Yes & Yes & Yes & No \\
AIC & 51068 & 48833 & 49804 & 51792 \\
\hline
\end{tabular}

Notes: $\mathrm{N}=3,182$. Each column represents a new model with varying fixed effects. Model 2 with the relatively better model fit criteria is used to predict the expected catch rate in the Multinomial Logit Models. Standard errors are given in parentheses. $* * *, * *$ and $*$ denotes significance at 1 percent, 5 percent and 10 percent. 
ESTIMATING HABIT-FORMING AND VARIETY-SEEKING BEHAVIOR:

NON-MARKET VALUATION OF BIRDING SITE CHOICE

\section{PREFERENCES}

(To be submitted to Journal of the Association of Environmental and Resource

Economists.)

By

Priya Behanan ${ }^{1}$, Todd Guilfoos ${ }^{1}$ and Sonja Kolstoe ${ }^{2}$

${ }^{1}$ Department of Environmental and Natural Resource Economics,

University of Rhode Island

${ }^{2}$ Department of Economics and Finance, Department of Environmental Studies, Salisbury University 


\title{
CHAPTER 2
}

\begin{abstract}
In this research, we introduce a two-stage model to account for habit forming and variety-seeking behavior when examining location choice preferences among recreational birdwatchers. The first stage employs Case-Based Decision Theory (CBDT) to estimate the similarity or dissimilarity weights for each site attribute followed by the second stage, where we apply the predicted probabilities from the CBDT model into a mixed logit estimation. We compare the qualitative fit of the following models; a model without accounting for habit forming or variety-seeking behavior, models that include habit forming or variety-seeking site attribute variables using a linear functional form, and the two-stage model. Our study estimates a statistically significant welfare value for the combined effect of habit forming and variety-seeking behavior. We also find evidence that the two-stage model marginally outperforms the more traditional models.
\end{abstract}

\subsection{Introduction}

The choice of where to go for outdoor recreation is often dynamic and depends on the past experience of the individual. Discrete choice modeling has increasingly incorporated aspects of habit formation and variety-seeking (Adamowicz, 1994; Hailu et al., 2005; Smith, 2005) to capture these dynamic aspects of choice. In this paper, we hypothesize that habit forming and variety-seeking behavior take a particular functional form consistent with a general decision theory, case-based decision theory. We provide a simple way to include a decision theory model, 
based on cognitive processes, into the discrete choice non-market valuation. Our study applies the framework from CBDT to estimate similarity weights for habit formation and dissimilarity weights for variety-seeking behavior among recreational bird watchers. We find that the specific forms of utility and assumptions about past experience do play an important role in non-market valuation.

Previous experience with a site can be incorporated to account for variety-seeking and habit forming behavior (Adamowicz, 1994; Hailu et al., 2005; Smith, 2005). Adamowicz (1994) examine the effect of habit formation and variety-seeking in recreation sites by transforming previous visits to each site to form depreciation rates; Hailu et al. (2005) estimate recreation demand after incorporating frequency of previous trips to each site and other place attachment variables in a travel cost model. Other studies such as Smith (2005); Hunt (2005) and Smith and Wilen (2002) uses state dependence, a variable which is a function of past choices, to account for any influence from previous experiences to a site. All the above studies conclude that decision-makers past choices have a significant effect when modeling recreational site choice preferences.

In this work, we incorporate case-based decision theory (CBDT) (Gilboa and Schmeidler, 1995) to location choice modeling, which is similar to the existing models of variety-seeking and habit formation. CBDT is an alternative decision theory to Expected Utility which under certain axioms can be described by specific mathematical representations of Utility. In CBDT, when a person faces a new choice problem they ask themselves: how similar is this case (i.e. choice) to past cases (i.e. choices) and then uses those similarities to construct an expectation over choice sets. The construct of CBDT is useful for dynamic choice environments like recreational choice behavior for two reasons. First, the formulation of CBDT captures variety-seeking and habit forming behavior through the concept of the similarity function (Gilboa and Schmeidler, 1995; Shepard, 1987; Magnusson and Ekehammar, 1978; Nosofsky, 1992). Second, CBDT captures how expectations form under new problems. Expected Utility Theory (EUT) relies on a fully rational decision-maker 
with complete information about states of the world, in CBDT, rationality is bounded (Kahneman, 2003). In EUT, agents are not surprised by new states of the world, rather they update the probability that they give to a state of the world, perhaps with a Bayesian process (Harsanyi, 1978). In this way, people cannot be 'surprised' by a new problem. Variety-seeking behavior can lead to changes in the feasible set of alternatives as well as taste preferences of the decision maker. The marginal utility derived from an additional unit of an attribute may turn negative fast if the satisficing point is met as soon as the chosen alternative is experienced (McAlister and Pessemier, 1982).

We choose CBDT because it suggests itself from other empirical applications in other domains (Pape and Kurtz, 2013; Guilfoos and Pape, 2016; Ossadnik et al., 2013; Kinjo and Sugawara, 2016; Bleichrodt et al., 2017) and also suggest specific functions for estimation ${ }^{10}$. We propose a two-stage model which incorporates CBDT into the standard random utility model used in location choice modeling. We use similarity functions that have been used in other research to capture similarity or habit formation behavior (Shepard, 1987; Magnusson and Ekehammar, 1978; Nosofsky, 1992). The presence of habit forming behavior depends on the similarity between past and current consumption of particular good or attribute (Pollak, 1970). Distance metrics are used in similarity indices to measure the similarity or dissimilarities between past and current problems.

Bird watching is one of the most popular recreational activities in the country. The 2016 National Survey of Fishing, Hunting, and Wildlife-Associated Recreation Report ${ }^{11}$ estimates that 45.1 million US residents participate in bird watching. Among them 16.3 million US residents travel to locations popular for bird watching, also called birding sites. During such travels birdwatchers, also known as birders, spend on accommodation, food, transportation and bird watching equipment. The direct and indirect expenditures associated with bird watching is not only appropriated as

\footnotetext{
${ }^{10}$ Other decision theories are more ambigious as to how to operationalize the specific functions of choice to distinguish themselves.

${ }^{11} \mathrm{https} / / /$ wsfrprograms.fws.gov/Subpages/NationalSurvey/nat ${ }_{\text {s }}$ rvey2016.pdf
} 
employment income but also for conservation purposes. Understanding site choice behavioral pattern of bird watchers can, therefore, be beneficial in terms of economic returns for the host state as well as in terms conservation and preservation of bird species. Analyzing birder behavior helps in realizing the common interest among various stake holders. Preserving and maintaining locations rich in bird species are one of the main objectives for bird watchers, researchers, social planners, conservationists and other bird enthusiasts. Similarly, such locations serve as revenue generators by attracting birders and tourists for the state. Therefore, research and behavioral modeling related to bird watchers and their choice preferences can provide useful information for policymakers and conservation efforts. Birders also exhibit behavior that could be described as dynamic. Often birders will have trips that follow certain patterns, or search for specific species of birds, which one would expect to exhibit both variety-seeking and habit formation behavior.

Habit forming behavior is common in recreational demand models. While place attachment arises when a particular site is visited repeatedly causing the formation of emotional ties (Hailu et al., 2005), habit formation may occur from visiting sites with a particularly desired site attribute. For instance, a birder may repeatedly choose sites that are covered in forests because they prefer to watch birds that are mainly found in such habitats or they may just enjoy the aesthetics affiliated with a forest landscape. Studies on birder motivations have categorized them into affiliationoriented motivation, achievement-oriented, appreciative-oriented and conservationoriented (Decker and Connelly, 1989; McFarlane, 1994). Either one or a combination of more than one of these motivations can prompt habit formation or variety-seeking behavior. For instance, achievement-oriented birders tend to follow specific birds that are found in sites that have common attributes or target a specific genre of birders, thereby, prompting a similarity or dissimilarity pattern across site choice preferences over time.

We examine birding site preferences by using a two-stage model. In the first stage, we use CBDT to model a non-linear structural equation that captures dynamic 
aspects of habit formation and variety-seeking behavior. In the second stage, we apply the predicted probabilities from the first stage using a linear functional form and mixed logit estimation to obtain welfare estimates of site attributes. To evaluate the performance of this two-stage model, we also run two additional benchmark models that use methods cited in previous studies that are used to estimate habit formation and variety-seeking behavior (Adamowicz, 1994; Smith, 2005; Smith and Wilen, 2002; Guadagni and Little, 1983; McAlister, 1982). In the first benchmark model, we transformed the site attributes to form dynamic cumulative differences between current choice and past choices based on the Euclidean squared distance metric. The distance measures are then included in the mixed logit model. In the second benchmark model, we included state dependence variables constructed following the methods in Heckman (1981); Guadagni and Little (1983); Keane (1997) and Smith (2005) for each site attribute. The quantitative fit of the estimated parameters is evaluated among all models, that is, the two-stage model, the two benchmark models as well as a static model which contains no habit formation or variety-seeking variables.

\subsection{Methodology: Two-Stage Model}

We propose a new model that captures the effect of variety-seeking or habit forming behavior in two stages. The first stage in this model uses a linear probability model (LPM) with the functional framework of CBDT and in the second stage we include the predicted probabilities from the first stage (as case-based scores) to account for habit forming or variety-seeking behavior and apply a random parameters logit model to the choice data.

\subsubsection{First Stage: Linear Probability Model with Case-based Scores}

We use the framework of CBDT to construct the first stage estimates. In the CBDT framework, each individual has a memory $(M)$ which accumulates cases. A case $(C)$ 
is a triplet of problems $(P)$, the actions $(A)$ taken to address each problem and the results $(R)$ obtained from applying the actions to the problems. When faced with a choice situation, individuals refer back to their memory of cases and makes choices after weighing the similarity between the current problem $(p)$ and past problems $(q)$. These past problems may be from their own previous experience or experience relayed to them by others (Gilboa and Schmeidler, 1995; Kinjo and Sugawara, 2016). In this study the past trips taken by a birder to birding sites are a part of their memory, where each past trip becomes a case and the problems would constitute the site attributes associated with each birding site. Whether or not the site is chosen would be the action and the result would be the pay-off or outcome from each trip. Agents using a case-based framework use similarity between problems to form expectations. We use a euclidean distance metric in this study to capture the distance between problems. The difference between site attributes $(i)$ of current $(p)$ and past $(q)$ choices are as shown in equation 2.1:

$$
d(p, q)=w_{i}\left(p_{i}-q_{i}\right)^{2}
$$

The parameter $w$ in equation 2.1 is a coefficient to be estimated by the model that weighs the information in the similarity function. The similarity between cases aggregates all euclidean distances across current and past site attributes as given in equation 2.2:

$$
S(p, q)=\frac{1}{\exp \sqrt{\sum_{i=1}^{\# D i m s} d(p, q)}}
$$

Further when referencing cases in the past we index memories over time $T$. The distance metric transformation is dynamic since it is a function of past attributes, similar to Adamowicz (1994); McAlister and Pessemier (1982) and Smith (2005). It is different from these other models and is supposes how memory maps from past experiences to current choices and expectations. 
Dummy variables are included in the model to capture site attributes such as type of land cover, eco-regions, whether the site's a national wildlife refuge, has permanent protections (i.e GAP status 1 or 2, examples include national park and wilderness areas), allows extractive practices (i.e. GAP status 3, examples include National Forests, Recreation Management Areas), areas expected to have endangered species, and urban areas are used to construct the non-linear similarity function between current and past choices. We use an inverse exponential functional form for the similarity function and Euclidean distance to measure the distance between current and past site attributes; both of which are commonly used in the CBDT literature (Pape and Kurtz, 2013; Guilfoos and Pape, 2016) and have roots in psychology (Shepard, 1987). The estimated coefficient for each attribute is interpreted as the similarity weight for each attribute in the similarity function. The magnitude of the weight represents the degree of similarity or dissimilarity between the site attribute of the past and current choice, whereas the sign represents whether or not birdwatchers follow a habit forming or variety-seeking pattern (Guerdjikova, 2007, 2008). A positive sign implies habit forming or similarity whereas negative exhibits varietyseeking or dissimilarity between past and current choice for that site attribute.

An important assumption about this model is that memory is a construct of the information available to the researcher. There maybe reason to believe that some data is omitted from memory or ignored by an agent. This issue plagues all dynamic models with dependence on past attributes or past utility. Simulations may be used to directly model forgetfulness Guilfoos and Pape (2016), but it is unclear how to jointly estimate mixed-logit models of discrete choice using these simulations. Similarly, memory could include observations of birding trips shared by other birders and do not have to be experienced by the agent. For simplicity we assume memory to be limited solely from the birder's own trips.

Equation 2.3 is estimated using the dynamic aspect of the CBDT framework in the first stage. 


$$
y_{n j t}=\alpha+\sum_{t=1}^{T}\left\{\frac{1}{S(p, q)}\right\} \times \frac{1}{T}
$$

The response variable $y$ is a binary indicator for chosen site $j \in 1, \ldots, J$ with $\alpha$ as the estimated constant and $S(p, q)$ representing the similarity function, as provided in 2.2, aggregated across cases $t \in 1, \ldots, T$ for each individual $n \in 1, \ldots, N$. We divide this function by a weighing variable $(T)$ equal to the number of cases in memory. By dividing the similarity function by the number of cases we get an average of similarity between the current case and all cases in memory. After estimation this naturally provides a binding limit to the value of the similarity function between 0 and 1 . We obtain the predicted probabilities $(\hat{y})$ from equation 2.3 , which we call case-based scores, and include them in the second stage model as the dynamic function of past experiences.

The estimated weights from this stage have the intuitive interpretation of varietyseeking or habit formation. For a given memory, variety-seeking behavior will increase a case-based score when considering a case with a different attribute than past cases in memory, while habit forming behavior will decrease the case-based score when considering a case with a different attribute than past cases in memory.

\subsubsection{Second Stage: Mixed Logit Model}

In the second stage, we apply a mixed logit random utility method (RUM) to our data set. This model is widely used in discrete choice literature. The utility function, $U_{n j t}$, for individual $n$, when visiting site $j$ at time $t$ has two components; a deterministic and a stochastic component. The deterministic component in this utility function is assumed to be a linear additive combination of explanatory variables. The stochastic component, $\varepsilon_{n j t}$, accounts for other variables that are unobservable but affects utility. We adapt the general framework followed in Kolstoe et al. (2018) and estimate a linear utility function as shown in equation 2.4

$$
U_{n j t}=\beta_{c} T C_{n j t}+\left(\left(\beta_{0}+\mu\right)+\beta_{1} Y_{d e v}+\beta_{2} T_{t}\right) E S_{j t}+\beta_{i} X_{j t}+\delta \hat{y}+\varepsilon_{n j t}
$$


Equation 2.4 represents the indirect utility function where the travel cost coefficient, $\beta_{c}$, is the marginal utility of net income and is used for further welfare calculations. The mixed logit model allows for taste variation across individuals. This variation is captured in the coefficient, $\beta_{0}$, and random component, $\mu$, both estimated from the variable, expected species richness (ES). The interactions of ES include $T_{t}$, which is a vector of time related variables such as binary indicators for each month and year, and $Y_{d e v}$, which denotes the mean deviation from median household income. The variable $X_{j t}$ represents the vector of site attributes $(i)$ included in the model and our key variable, $\hat{y}$ is used to obtain the case-based estimate $\delta$. The error term, $\varepsilon_{n j t}$ is assumed to be independent and identically distributed (iid) with extreme value distribution.

In the mixed logit model, the choice probabilities are defined to be the integral of the probability of a standard logit model as provided in equation 2.5

$$
P_{n j t}=\int \frac{\exp \left(\mathrm{V}_{n j t}\right)}{\sum_{k=1}^{J} \exp \left(\mathrm{V}_{n k t}\right)} f \theta d \theta
$$

where $j, k \in 1, \ldots, J$ are alternatives and $j \neq k . V_{n j t}$ represents the deterministic component of the utility function and $\theta$ is the mixing distribution containing the random parameter (Train, 2002; Hensher and Greene, 2003).

\subsection{Memory and Welfare}

Calculating welfare measures in terms of willingness to pay (WTP) is an important part of discrete choice modeling (McConnell et al., 1995). Following the assumptions used in welfare theory, we measure the effect of an additional change in site attribute, under individual maximization conditions, by setting the change in utility as zero. We use the estimated marginal utility of price (or travel cost per trip) to obtain the marginal willingness to pay for a unit change in site attribute. When the utility function is linear in parameters, the willingness to pay for a unit change in an 
attribute is estimated by taking the negative ratio between the coefficient estimate of the attribute and the cost coefficient (Hanemann, 1983). However, estimating the change in utility for a unit change in similarity weight in the first stage is relatively complex due to the non-linear functional form of the proposed model.

The aspects of variety-seeking and habit formation depend on past experience explicitly. In the context of a CBDT agent who expresses a willingness to pay, we must make an assumption about memory of experience. One simplification we could make is that memory is empty, in other words, for a birder without extensive data on past experience for which we would assume that our case-based score is equal to zero when constructing measures of welfare for a trip. This would simplify our utility specification to resemble the static model. Another assumption we can make is to take an average memory experience from our sample. This will likely understate the true effect of variety-seeking and habit formation, and could be considered conservative. For instance, let us assume the average distribution of the euclidean distance for each site attribute included in the memory of each birder be representative of history for the sample. Then the marginal effect of change when an individual refers back $T$ cases can be derived following the usual utility maximization conditions. In our study, we constructed the history (memory of cases) for each birder by looking back up to four cases $(T=4)$. So, the first three cases would be the past three trips taken by the individual birders $(T=t-1, t-2$ and $t-3)$ and the fourth case is a discounted memory of all trips preceding the third last trip $(T=t-4, t-5, \ldots T)$. We construct four cases in memory because through trial and error we notice very negligible difference in estimated weights when more trips are included as separate cases in the model.

We can also presume memory to be a combination of select attributes based on specific scenarios. For instance, we can compare the difference in birder preferences between those who visited an urban area during their last visit and those who did not. We derive equation 2.3 from the first stage with respect to site attributes to estimate its marginal effect on similarity scores $\left(\partial y / \partial p_{i}\right)$. Derivations involved in 
the marginal welfare calculations are provided in further detail in Appendix B.2. Since this method discounts all individual memories, we expect the marginal welfare effect for each site attribute to be negligible.

The WTP calculations in the second stage, after the mixed-logit estimation, measures the change in per trip utility in terms of change in cost per trip by dividing the marginal utility of site attribute by the negative marginal utility of price (travel cost per trip). These welfare values are estimated in WTP-space (Train and Weeks, 2005; Hole, 2016, 2007; Scarpa and Rose, 2008). Although, these second stage WTP estimates for site attributes are independent of variety-seeking and habit forming effect, we instead obtain a combined welfare value for such behavior when applying WTP estimation on the predicted estimate of the case-based score $(\delta)$. To obtain the effects of variety-seeking or habit formation on site attributes separately, we jointly estimate the marginal similarity scores for the attribute from the first stage as well as its estimate from the second stage and then proceed with willingness to pay calculations as provided in equation 2.6:

$$
\mathrm{WTP}_{i}=\left[\left(\frac{\partial y}{\partial p_{i}} * \delta\right)+\beta_{i}\right] * \frac{1}{\beta_{c}}
$$

Equation 2.6 represents the marginal WTP for site attribute $i$ after combining the marginal effect of a change on the similarity score $\left(\partial y / \partial p_{i}\right)$ along with the mixed logit estimates, where $p_{i}$ represents current change in site attribute, $\delta$ represents the predicted case-based score estimated in the second stage mixed logit model with $\beta_{i}$ and $\beta_{c}$ coefficient estimates for the site attribute and travel cost respectively.

\subsection{Model Fit Comparison}

To evaluate the fit of this model, we estimate other models; a static model and two benchmark model, that is., the reduced form model and the state dependence model. We compared the in-sample fit among all models using Akaike Information Criteria (AIC) and Bayesian Information Criterion (BIC). The two benchmark models, which 
is explained in more detail in the next section, includes a third more parameters than the static or the two stage model. This would most likely lead to over-fitting especially in the AICs. To counter this problem, we include the Consistent-Akaike Information Criteria (CAIC) for each of the models. The model with the smaller AIC, CAIC and BIC has a better in-sample fit (Atkinson, 1981; Bozdogan, 1987). In addition, a likelihood ratio (LR) test for each model is also included as an added measure to compare and determine the best model which maximizes the likelihood function.

$$
\mathrm{LR}=-2\left(L L_{R}-L L_{U R}\right)
$$

This test statistic provided in equation 2.7 compares the likelihood scores between the restricted $\left(L L_{R}\right)$ and unrestricted $\left(L L_{U R}\right)$ models and follows chi square distribution (Fosgerau and Bierlaire, 2007).

\section{Static Model}

The static model is a linear additive mixed logit random utility estimation of the general model as shown in Equation 2.4 without including the case-based scores from the first stage. In other words, $\delta$ will not be estimated. This model replicates the framework followed in Kolstoe et al. (2018).

\section{Benchmark Models}

We estimate two benchmark models using the methodology adapted from previous studies on habit formation and variety-seeking (Heckman, 1981; Adamowicz, 1994; McAlister and Pessemier, 1982; Guadagni and Little, 1983; Keane, 1997; Smith, 2005). In the first benchmark model, we transformed the site attributes to form dynamic cumulative differences between current choice and past choices. This transformation of site attributes are also based on the Euclidean distance metric (for comparability) and follows the same framework as provided in equation 2.1. The distance measures for each site attribute are then directly included in the mixed-logit 
model estimation. This is a type of reduced form way to incorporate past attributes into the current choice set. The parameter estimates for the transformed site attributes indicate variety-seeking in case they are positive and habit forming if they are negative (Adamowicz, 1994; McAlister and Pessemier, 1982; McAlister, 1982).

The second benchmark model includes state dependence variables for each site attribute in addition to the variables included in the static model. Proxy variables that measure the previous choices made by individuals are generally termed as state dependence variables (Heckman, 1981; Guadagni and Little, 1983). A recent method used in literature to account for state dependence in discrete choice models is by linearly adding the exponentially smoothed weighted average of past choices into the mixed logit estimation (Smith, 2005; Smith and Wilen, 2002; Keane, 1997). Also, the smoothing parameter used in our data-set is constraint between 0 and 1 , where approaching 1 implies that the recent experiences are less important compared to aggregate experiences and approaching 0 implies the importance of recent experiences. Other studies have used 0.5 (Smith, 2005) as a smoothing parameter. In this study, through trial and error (model fit comparison), we concluded 0.3 as an ideal smoothing parameter for this model. Although previous studies employ this method to obtain state dependence on site choices and not site attributes, the numerous site choices available to birders in our sample size makes it more feasible examine state dependence on site attributes.

\subsection{Data}

Our study uses the eBird database obtained from a citizen science project. This project was initiated to approximate the annual population of bird species. This data set, contributed by members of the eBird community, contains information about sites visited by 221 eBird members in the state of Washington and Oregon for the years 2010 to 2012. This data set is previously used in Kolstoe and Cameron (2017) and Kolstoe et al. (2018) in non-market valuation. We extend this analysis 
to evaluate the methodologies of how to estimate dynamic choice. Members from the eBird community not only provide details regarding bird sightings and birding sites but some also volunteer residential information. Our final data set includes 155,382 birding sites located within a travel distance of 60 minutes from the birder's residence. We do not use sites that are less than one mile from the birder's residence, to exclude backyard birdwatchers.

The travel cost variable is constructed based on the 'best route' suggested by 'mqtime', a Stata software tool that uses MapQuest to map the travel time and distance from the birders residence to the birding site (Voorheis, 2015). Following the framework used in Fezzi et al. (2014) to calculate the value of travel time (VTT) in recreational models using revealed preference, our study assumes one third of the wage rate as the opportunity cost of time. VTT together with the distance traveled (multiplied with mileage rate from AAA) was used to obtain the round trip travel cost (TC). Site attributes include expected species richness (ES); indicators for whether the site is a national wildlife refuge, categorized as GAP status 1 or 3 (National Park, etc.) and GAP status 3 (National Forest, etc.), urban areas and areas that expects relatively more birds that are endangered; land cover types; and eco-region of designations. All of these site attributes are obtained from the National Land Cover Database (NLCD).

The number of people encountered during a recreational visit to a site can impact the utility of the trip itself. The level of congestion to an extent speaks to the popularity of the site. However, a high degree of congestion can adversely affect individual utility (McConnell, 1977; Timmins and Murdock, 2007). Kolstoe and Cameron (2017) has found that birders attach a positive and significant marginal value to congestion/popularity in a birding site and once the threshold of popularity is met, there is a notable fall in marginal utility. The total number of trips taken to a site by birders, within the eBird community, in the same month of the previous year is taken as a proxy to measure the expected congestion per month at each site.

The average number of bird species reported by birders, in the same month of the 
previous year, is used to calculate the expected species richness for each birding site. This bird species count is taken from two data sets; Birdlife International is used for resident bird species and eBird data for nonresident or seasonal bird species. Sites with a high measure of expected species richness are considered to be 'hotspots' for birders. Although, information regarding these hotspots are shared among eBird members, we expect this measure to vary across seasons, site attributes, over time and individual preferences. To account for this heterogeneity, expected species richness (ES) is allowed to vary across birders in the mixed logit model specification. We also include sample selection correction terms in our models to account for possible sample selection bias that may occur due to the volunteered information on birders home address. The propensity for an individual to be in the estimated sample is calculated using a separate probit model. The deviations from the mean propensity is then interacted with key variables of interest and included in the model ${ }^{12}$.The descriptive mean and summary of the variables used in this study is provided in Table 2.1.

In addition to the variables in Table 2.1, we also include the type of land cover and eco-region of the birding site as attributes. Sites are categorized into land cover types based on the classification system used in National Land Cover Database (NLCD) of 2011. We cover 7 land cover types in our model. Our data set also reports 9 types of eco-regions. Further description and mean estimates for each of these land cover and eco-region types are provided in Appendix B.1.

\footnotetext{
${ }^{12}$ Refer to the online appendix http://dx.doi.org/10.1016/j.ecolecon.2017.02.013 for details on sample selection bias
} 
Table 2.1: Description of Variables.

\begin{tabular}{|c|c|c|}
\hline Variable & Description & Mean \\
\hline Travel Cost (TC) & $\begin{array}{l}\text { Round trip travel cost based on dis- } \\
\text { tance times mileage rate (AAA) and } \\
1 / 3 \text { of wage rate from census tract. }\end{array}$ & 41.1 \\
\hline Expected Species Richness (ES) & $\begin{array}{l}\text { Reported count of bird species taken } \\
\text { per month in the previous year. }\end{array}$ & 75.73 \\
\hline Congestion/Popularity & $\begin{array}{l}\text { Share of eBird trips to each site for } \\
\text { the same month, last year. }\end{array}$ & $6.45 \times 10^{-4}$ \\
\hline Expected Endangered Species & $\begin{array}{l}\text { Binary indicator for expectation of } \\
\text { presence of endangered bird species. }\end{array}$ & $8.36 \times 10^{-5}$ \\
\hline Urban Area & $\begin{array}{l}\text { Binary indicator equal to one for } \\
\text { areas with population greater than } \\
50,000 \text { ( } 2010 \text { US Census). }\end{array}$ & 0.61 \\
\hline National Wildlife Refuge & $\begin{array}{l}\text { Binary indicator equal to one for ar- } \\
\text { eas under permanent protection as a } \\
\text { National Wildlife Refugee. These ar- } \\
\text { eas are also rich in bird biodiversity. }\end{array}$ & 0.0044 \\
\hline $\begin{array}{l}\text { GAP status } 3 \text { (National Forest, } \\
\text { etc.) }\end{array}$ & $\begin{array}{l}\text { Binary indicator equal to one for ar- } \\
\text { eas protected with some extractive } \\
\text { use and categorized under GAP status } \\
3 \text { (e.g., National Forests, State Parks, } \\
\text { Recreation Management Areas, Ar- } \\
\text { eas of Critical Environmental Con- } \\
\text { cern). }\end{array}$ & 0.27 \\
\hline $\begin{array}{l}\text { GAP status } 1 \text { or } 2 \text { (National Park, } \\
\text { etc.) }\end{array}$ & $\begin{array}{l}\text { Binary indicator equal to one for ar- } \\
\text { eas under permanent protection and } \\
\text { categorized as GAP status } 1 \text { or } 2 \\
\text { (e.g., National Parks, Wilderness Ar- } \\
\text { eas, National Wildlife Refuges). }\end{array}$ & 0.03 \\
\hline
\end{tabular}




\subsection{Results}

\subsubsection{Two-Stage Model Results}

The first-stage results from the linear probability model (LPM) following the casebased functional form (refer to equation 2.3) is provided in Table 2.2. The estimated coefficients in the LPM are similarity weights or similarity scores assigned to each site attribute. As mentioned before, we use the sign of the estimated weights to identify whether the site attribute is considered to be habit forming or variety-seeking for an average bird watcher. A positive weight implies that a birder exhibits a degree a loyalty to that site attribute whereas a negative weight implies a preference for variety in that site attribute. An exception to this interpretation is the control for a previous site visit in the last period. This is a binary indicator for a visit to a previous sites. The interpretation of this binary variable is that a negative sign implies a case of habit formation and a positive indicates variety-seeking.

We find significance in most of the estimated weights of the site attributes. The magnitude of the weight express the degree of similarity (or dissimilarity), in other words, the larger the estimated weight of the site attribute the greater the degree of similarity. But we can only compare the weights for the standardized values which essentially includes all the binary dependent variables. The type of eco-regions and land covers, seasons, areas categorized as the national wildlife refuge, urban and areas protected under GAP status 3 (e.g. National Forest, etc.) and GAP status 1 or 2 (e.g. National Park, etc.) are all binary dependent variables. We notice that an average birder exhibits a high degree of variety-seeking for majority eco-regions and land cover types. Among them the eco-regions; the Blue Mountains (-14.5), the Coast Range (-10.7) and the Klamath Mountains (-9.9) are statistically significant. Likewise, majority land cover types also exhibit negative and statistically significant similarity scores. The negative similarity score or dissimilarity score of -14.5 for the eco-region indicator for area under Blue Mountains. This estimated dissimilarity 
implies that a birder who once visited the Blue Mountains would prefer to visit a different eco-region in a future trip. Also, since this is one of the more substantial scores, we expect the average birder to be less susceptible to revisit Blue Mountains compared to other eco-regions.

Table 2.2: First Stage Results: Linear Probability Model

\begin{tabular}{|c|c|c|}
\hline \multirow[t]{2}{*}{ Variables } & \multicolumn{2}{|c|}{ Site Visited as Dependent Variable } \\
\hline & Estimates & Std. Err. \\
\hline Constant & $0.007 * * *$ & 0.00 \\
\hline Case $T$ & $26.25 * * *$ & 1.99 \\
\hline \multicolumn{3}{|l|}{ Eco-region Indicators } \\
\hline Blue Mountains & $-14.52 * * *$ & 5.58 \\
\hline Cascades & -0.63 & 1.99 \\
\hline Coast Range & $-10.78 * * *$ & 1.39 \\
\hline Columbia Plateau & 38.11 & 336.31 \\
\hline Eastern Cascades Slopes and Foothills & 0.83 & 5.54 \\
\hline Klamath Mountains & $-9.94 * * *$ & 1.70 \\
\hline Northern Rockies & -49.08 & 336.51 \\
\hline Willamette Valley & 31.84 & 43.88 \\
\hline \multicolumn{3}{|l|}{ Land Cover Indicators } \\
\hline Barren & $-3.32 *$ & 1.70 \\
\hline Shrubland & $-7.31 * * *$ & 1.19 \\
\hline Forest & $-3.56 * * *$ & 1.20 \\
\hline Planted/Cultivated & $-2.72 * *$ & 1.34 \\
\hline Water & -1.17 & 1.34 \\
\hline Wetlands & $-5.59 * * *$ & 1.17 \\
\hline Herbaceous & $-3.48 * *$ & 1.56 \\
\hline \multicolumn{3}{|l|}{ Other Site Attributes } \\
\hline National Wildlife Refuge & $-4.48 * * *$ & 1.13 \\
\hline GAP status 3 (National Forests, etc.) & $2.99 * * *$ & 0.99 \\
\hline
\end{tabular}


Table 2.2 - Continued from previous page

\begin{tabular}{lcc}
\hline \multirow{2}{*}{ Variables } & \multicolumn{2}{c}{ Site Visited as Dependent Variable } \\
& Estimates & Std. Err. \\
\hline GAP status 1 or 2 (National Parks, etc.) & 0.16 & 0.19 \\
Expect Endangered Bird Species & $-19.43^{* * *}$ & 1.93 \\
Urban Area & $11.63^{* * *}$ & 4.16 \\
Seasonality Controls & & \\
\hline Spring & $2.14^{*}$ & 1.10 \\
Summer & $2.37^{* *}$ & 1.09 \\
Fall & $6.19^{* * *}$ & 1.95 \\
Previous Site Visited & $-7.12^{*}$ & 3.93 \\
R-squared & 0.003 & \\
\hline
\end{tabular}

Notes: $N=155,382$. Parameter estimates from the Linear Probability Model (LPM) and the respective standard errors are presented in the above table. We drop the estimates for the eco-region indicator, 'Northern Cascades' due to less cross sectional variation as depicted from the missing standard errors. All the independent variables used in this model are also binary indicators. $* * *, * *$ and $*$ denotes significance at 1 percent, 5 percent and 10 percent.

In addition to site attributes, we include other variables such 'seasons' and 'case' used as an index in the birders' memory. These variables act as controls to adjust for any seasonality and 'case' captures the measure of recency in the LP model. The weight on 'case' indicates that agents discount past memories in relation to how far in the past the memory is. This is consistent with the other work in CBDT and dynamic choice literature (Guilfoos and Pape, 2016; Adamowicz, 1994). We measured the average marginal effect of a change in similarity weight of a site attribute. The estimated results and details on the derivation process are provided in Appendix B.2.

Table 2.3 contains the estimates from the second-stage mixed logit model. The key variable of interest is the case-based predicted probability or case-based score $(\delta)$. The positive significance of this estimate marks the importance of accounting for variety-seeking or habit formation in recreational site choice literature, controlling 
for the static components. The second-stage estimates are in log odds ratios and further welfare calculations are required for direct interpretation in terms of dollar value. The travel cost (TC) estimate is negative and significant as expected. The statistically significant standard deviation for expected species richness (ES (SD)) implies the presence of unobserved heterogeneity. We also include control variables for month and fixed effects, sample selection correction terms and other interaction of ES. The estimated coefficients for the full model including these control variables are provided in Appendix B.3. The results for the site attributes are consistent with the results obtained in Kolstoe and Cameron (2017) and Kolstoe et al. (2018). We find a positive and statistically significant preference for sites that are categorized under GAP status 1 or 2 (such as National Parks) and GAP status 3 (such as National Forests). A positive preference for sites that have a higher endangered bird species expectation. We find that urban areas are not preferred sites for bird watching. Conforming to previous literature, we find a positive preference towards sites that have a certain amount of congestion as it speaks to the popularity of the site however, beyond a certain degree congestion proves to be undesirable when bird watching.

Table 2.3: Mixed Logit Results: Second Stage Model

\begin{tabular}{lcc}
\hline \hline Variables & Site Visited as Dependent Variable \\
& & Std. Err \\
\hline Travel Cost & $-0.036^{* * *}$ & 0.00 \\
Ecoregion Indicators & & \\
Blue Mountains & -0.603 & 0.84 \\
Cascades & $0.673^{* *}$ & 0.32 \\
Coast Range & $0.662^{*}$ & 0.36 \\
Columbia Plateau & -0.363 & 0.75 \\
Eastern Cascades Slopes and Foothills & -0.933 & 0.69 \\
Klamath Mountains & 0.145 & 0.42 \\
Northern Cascades & -0.830 & 0.72 \\
\hline & & Continued on next page
\end{tabular}


Table 2.3 - Continued from previous page

Variables

Site Visited as Dependent Variable

Std. Err

Northern Rockies
Willamette Valley
Land Cover Indicators

Barren

0.194

0.15

Shrubland

0.135

0.14

Forest

$-0.062$

0.11

Planted/Cultivated

$0.202 *$

0.11

Water

$0.373 * * *$

0.11

Wetlands

$0.357 * * *$

0.11

Herbaceous

$-0.322^{*}$

0.19

$\underline{\text { Other Site Attributes }}$

National Wildlife Refuge

$0.796 * * * \quad 0.19$

GAP status 3 (National Forest, etc.)

$0.408^{* * *} \quad 0.08$

GAP status 1 or 2 (National Parks, etc.)

$0.697 * * *$

0.13

Expect Endangered Bird Species

$1.648 *$

0.93

Urban Area

$-0.555 * * *$

0.08

Congestion

$190.404 * * *$

13.38

$(\text { Congestion })^{2}$

$-3,665.54 * * *$

437.66

Case-based Score $(\delta)$

$16.510^{* * *}$

3.96

ES

$$
0.008
$$

0.01

ES (Std. Dev.)

$0.015^{*}$

0.01

ES interacted with time trend and month

Yes

Sample Selection Correction Terms

Yes

Notes: $N=155,372$. The controls variables for time trends and sample selection corrections are included in this model. Refer to Table 2.10 in Appendix B.3 for estimates of all variables used in this model. 


\subsubsection{WTP Results}

In this application of dynamic choice, we notice how stable the estimates of the static model is to inclusion of dynamic elements (Refer to Table 2.12). That is a good sign that any correlation and dependence across time did not bias the coefficients using only cross-sectional variation in the data. Still, the interpretation of welfare may be biased if dynamic choice dependence is omitted as proven by the statistical significance of coefficient estimate of the case-based score in Table 2.3. The combined effect of variety-seeking and habit formation in dollar terms amounts to $\$ 458$ per trip when considering the polar opposite case-scores of 0 and 1 .

The significant estimate for the predicted case-based score in the second stage mixed logit results shows the importance of this effect. However, the marginal estimates for the similarity scores (provided in Table 2.9, Appendix B.2), although some are significant, are negligible and clustered around 0. Table 2.4 provides the WTP calculations for select variables (refer to Table 2.11 in Appendix B.3 for WTP estimates for the remaining site attributes) for the mixed logit models when the birder is assumed to use no memory to form expectations (column 1) and when an average distribution of memory experiences or cases are used in utility maximization (column 2). The difference between the two welfare estimates, provided in column 3 , represents the additional value added in terms of average cost per trip when the marginal effects from the first stage equation is combined with the site attribute coefficient estimates. Although we see a positive or negative value addition when including memory, the conservative nature of presuming an average memory to represent history when deriving marginal effects on similarity score, leads to estimating statistically insignificant difference between the two WTP estimates. This lack of significance is because we discount all memories. Additional information on the outcome or pay-off from each trip taken, as per the CBDT, would help identify the attribute combinations and memory that causes the significant effect $(\$ 458)$ for the combined case-based score in the second stage mixed logit model. 
(1)

No memory Average memory

$T=0$ cases $\quad T=4$ cases

(2) - (1)

Variables

\begin{tabular}{lccc} 
& $T=0$ cases & $T=4$ cases & $(2)-(1)$ \\
\hline Ecoregion Indicators & & & \\
Blue Mountains & -21.77 & -16.63 & 5.14 \\
Cascades & $17.53^{* *}$ & $18.72^{* *}$ & 1.19 \\
Coast Range & 16.33 & $18.80^{*}$ & 2.47 \\
Willamette Valley & $35.00^{* * *}$ & $34.35^{* * *}$ & -0.66 \\
Land Cover Indicators & & & \\
Water & $10.49 * * *$ & $10.48^{* * *}$ & -0.02 \\
Wetlands & $10.23^{* * *}$ & $10.63^{* * *}$ & 0.40 \\
Herbaceous & -8.22 & $-8.67 *$ & -0.45 \\
Other Site Attributes & & & \\
GAP status 1 or 2 (National Parks, etc.) & $20.09^{* * *}$ & $19.32^{* * * *}$ & -0.77 \\
Expect Endangered Bird Species & $50.57 * *$ & $45.80^{*}$ & -4.76 \\
Urban Area & $-15.63^{* * *}$ & $-17.51 * * *$ & -1.88 \\
\hline
\end{tabular}

Notes: $N=155,372$. Columns (1) and (2) represent the WTP or travel cost per trip obtained when the individual uses no memory and when he uses an average distribution as memory following mixed logit estimations respectively. Column (3) provides the difference in WTP between column (2) and (3) to show how including memory or past experience to account for variety-seeking and habit formation affects the welfare amounts for each site attribute. Full table is provided in Appendix B.3 (Table 2.11).

To investigate what leads to this substantial variety-seeking and habit forming effect, we construct memory as a combination of select attributes based on specific scenarios. Suppose for policy purposes we look into a site located at the eco-region, Blue Mountains covered in forest land. We compare two sites, one with these attributes and one without. For simplicity, say the average birder looks back one period in his memory when making the current site choice. Referencing back one period in memory would imply the distance between current and past choice of an attribute to be one $\left(T=1^{2}\right)$. Then the similarity score for a reference site without 
these attributes based on equation 2.3 and using the estimates from Table 2.2 is as provided below in equation 2.8:

$$
\text { CB Score for Site } 1=0.007+\frac{1}{\exp \sqrt{26.25 * T=1}}
$$

where $T=1$ since the agent is referencing back one period in their memory. Similarly, for the site in question, the similarity score for the site at the Blue Mountains with forested land cover is provided in equation 2.9:

$$
\text { CB Score for Site } 2=0.007+\frac{1}{\exp \sqrt{(26.2)+\left(-14.52 * d_{p 1}\right)+\left(-3.5 * d_{p 2}\right)}}
$$

where $d_{p}$ is the euclidean distance metric which is reduced to one and since the agent references back one period for each site attribute. Subsequent WTP calculations based on equation 2.6, results in an increase in WTP by approximately $\$ 23.6$ per trip for an average birder. This difference in WTP (statistically significant) between two sites varies according to the combination of site attributes chosen. For instance, if we consider a site protected under GAP 3 status along the eco-region, Willamette valley, then referencing back one period we estimate an approximate fall in WTP of \$2.5 per trip for the average birder compared to the referent site. Similarly, a site rich in wetland habitats and bird biodiversity (National Wildlife Refuge) located at Klamath Mountains would estimate an increase in WTP by approximately $\$ 35$ per trip for an average birder following the same assumptions about memory.

\subsubsection{Model Comparison}

The results from the LR test provided in Table 2.5 reveals that when compared to the static model, both the two stage model as well as the state dependence model performs better in terms of goodness-of-fit. 
Table 2.5: Likelihood Ratio Test

\begin{tabular}{lll}
\hline \hline Mixed Logit Models & LR & p-value \\
\hline 2-Stage Model & 18.96 & 0.000 \\
Reduced Form Model & 25.51 & 0.225 \\
State Dependence Model & 71.37 & 0.000 \\
\hline
\end{tabular}

Notes: The LR test for all three models; 2-stage, reduced form and state dependence, are conducted keeping the static model as the restricted model. The LR test statistic follows the chi square distribution.

Comparing the AIC, BIC and CAIC among all the models; the two-stage model, the static model and the two benchmark models, we find our proposed two-stage model to have a closer fit to the data using with in-sample fit for both BIC and CAIC. We expected the two benchmark models namely the reduced form and state dependence models, which has relatively more parameters, to have a closer fit with AIC due to over-fitting. The Consistent-AIC (CAIC) controls for overparameterization while following the consistency properties followed by AIC (Bozdogan, 1987).

Table 2.6: Comparison of Model Selection Criteria

\begin{tabular}{llll}
\hline \hline Mixed Logit Models & AIC & BIC & CAIC \\
\hline Static Model & 9254 & 9662 & 9703 \\
2-Stage Model & 9237 & 9655 & 9697 \\
Reduced Form Model & 9271 & 9888 & 9950 \\
State Dependence Model & 9223 & 9830 & 9891 \\
\hline
\end{tabular}

Notes: AIC, BIC and CAIC denotes Akaike Information Criteria, Bayesian Information Criteria and Consistent Akaike Information Criteria respectively. In the above model selection criteria, the smallest represents the preferred model. The estimates for the benchmark models are provided in Appendix B.3 (Table 2.13). 
Based on the model selection criteria (BIC and CAIC) highlighted in Table 2.6, we conclude that the two-stage model is not only comparable but in fact marginally outperforms the other two models. Although the smallest CAIC (or BIC) implies better explanation of data, this difference in in-sample fit is fairly close to each other. This specific domain of choice modeling is a challenge for model fitting, mostly due to the uncertainty involving picking a site choice in each period with, sometimes, many alternative sites. Although this complication does not benefit any model over the others, it does however explain the small margins among all models.

\subsection{Discussion and Conclusion}

This research supports the need to account for habit forming and variety-seeking behavior in recreational choice literature. We propose a two-stage model to account for these behavioral responses that leverages case-based decision theory. The firststage incorporates case-based reasoning where similarity and dissimilarity weights are used to capture the habit forming and variety-seeking behavior across site attributes. We use the predicted fitted values from the first-stage and include them in the second-stage to control for the dynamic aspects of discrete choice. The dynamic aspects captured in the first-stage is significant, both statistically and economically, when incorporated into the second-stage.

This research suggests that the combined effect of variety-seeking and habit formation from the predicted case-based fitted value can reach a maximum welfare amount up to $\$ 458$ per trip. However, the total value of this behavior depends on the combination of attributes contained in the chosen site and the memory of experiences used in the decision making process by the birder. This direct approach to calculate the total value additions due to variety-seeking or habit forming effects by combining select site attributes that resembles an actual site has more relevance in terms of policy implications. Future research is required to identify the proxy measures that approximates the behavior of a representative case based agent. 
The application of case-based framework is suitable to examine behavior when agents are making repeated choices. This study hypothesizes that repeated choices exhibit patterns of similarity or dissimilarity. For instance, the first-stage analysis concludes that birders heavily discount memories in the past. Birders exhibit varietyseeking tendencies for land covers, in other words they typically do not follow a specific land cover type when choosing birding sites. We find that birders exhibit habit forming behavior for sites that are categorized as urban areas, areas under GAP status 3 (National Forests,etc.,) and within a season. So when they visit sites with these attributes, they are more likely to return to these sites in the future and therefore have a higher willingness to pay for those sites. Seasonal behavior captured through case-based scores, increases the weight of past memories of visits to sites made in that season, thereby supporting habit forming behavior across the year.

The conventional case-based decision theory, along with repeated choices, also incorporates the outcome or pay-off obtained from their previous choices. Whether or not the action taken in response to a problem by an individual decision-maker is a success is an important component in CBDT. However, this study manages to incorporate the case-based framework without including a variable that can proxy outcome. Although, we may consider this as a limitation to the study, restrictions to obtaining data or constructing variables that can accurately measure an effect are common problems that adds to the uncertainty of decision theories. Such limitations pose a problem to all decision theories. However, a learning model such as CBDT, that presumes rationality to be bounded and based on the agents memory of experiences, may be able to perform better even with limited information. 


\section{References}

Adamowicz, W. L. (1994). Habit Formation And Variety Seeking In A Discrete Choice Model Of Recreation Demand. Journal of Agricultural and Resource Economics, Volume 19(Number 1):1-13.

Atkinson, A. C. (1981). Likelihood ratios, posterior odds and information criteria. Journal of Econometrics, 16(1):15-20.

Bleichrodt, H., Filko, M., Kothiyal, A., and Wakker, P. P. (2017). Making Case-Based Decision Theory Directly Observable. American Economic Journal: Microeconomics, 9(1):123-151.

Bozdogan, H. (1987). Model selection and Akaike's Information Criterion (AIC): The general theory and its analytical extensions. Psychometrika, 52(3):345-370.

Decker, D. J. and Connelly, N. A. (1989). Motivations for Deer Hunting: Implications for Antlerless Deer Harvest as a Management Tool. Wildlife Society Bulletin (19732006), 17(4):455-463.

Fezzi, C., Bateman, I. J., and Ferrini, S. (2014). Using revealed preferences to estimate the Value of Travel Time to recreation sites. Journal of Environmental Economics and Management, 67(1):58-70.

Gilboa, I. and Schmeidler, D. (1995). Case-Based Decision Theory. The Quarterly Journal of Economics, 110(3):605-639.

Guadagni, P. M. and Little, J. D. C. (1983). A Logit Model of Brand Choice Calibrated on Scanner Data. Marketing Science, 2(3):203-238. Publisher: INFORMS. 
Guerdjikova, A. (2007). Preference for Diversification with Similarity Considerations. In Abdellaoui, M., Luce, R. D., Machina, M. J., and Munier, B., editors, Uncertainty and Risk: Mental, Formal, Experimental Representations, Theory and Decision Library C, pages 63-83. Springer, Berlin, Heidelberg.

Guerdjikova, A. (2008). Case-based learning with different similarity functions. Games and Economic Behavior, 63(1):107-132.

Guilfoos, T. and Pape, A. D. (2016). Predicting human cooperation in the Prisoner's Dilemma using case-based decision theory. Theory and Decision, 80(1):1-32.

Hailu, G., Boxall, P. C., and McFarlane, B. L. (2005). The influence of place attachment on recreation demand. Journal of Economic Psychology, 26(4):581598.

Hanemann, W. M. (1983). Marginal welfare measures for discrete choice models. Economics Letters, 13(2):129-136.

Heckman, J. J. (1981). Heterogeneity and State Dependence. Studies in Labor Markets, pages 91-140. Publisher: University of Chicago Press.

Hensher, D. A. and Greene, W. H. (2003). The Mixed Logit model: The state of practice. Transportation, 30(2):133-176.

Hole, A. (2016). MIXLOGITWTP: Stata module to estimate mixed logit models in WTP space.

Hole, A. R. (2007). A comparison of approaches to estimating confidence intervals for willingness to pay measures. Health Economics, 16(8):827-840.

Hunt, L. M. (2005). Recreational fishing site choice models: insights and future opportunities. Human Dimensions of Wildlife, 10(3):153-172.

Kahneman, D. (2003). Maps of Bounded Rationality: Psychology for Behavioral Economics. American Economic Review, 93(5):1449-1475. 
Keane, M. P. (1997). Modeling Heterogeneity and State Dependence in Consumer Choice Behavior. Journal of Business \& Economic Statistics, 15(3):310-327.

Kinjo, K. and Sugawara, S. (2016). Predicting Empirical Patterns in Viewing Japanese TV Dramas Using Case-Based Decision Theory. The B.E. Journal of Theoretical Economics, 16(2):679-709.

Kolstoe, S. and Cameron, T. (2017). The Non-market Value of Birding Sites and the Marginal Value of Additional Species: Biodiversity in a Random Utility Model of Site Choice by eBird Members. Ecological Economics, 137(C):1-12.

Kolstoe, S., Cameron, T. A., and Wilsey, C. (2018). Climate, Land Cover, and Bird Populations: Differential Impacts on the Future Welfare of Birders across the Pacific Northwest. Agricultural and Resource Economics Review, 47(2):272-310.

Magnusson, D. and Ekehammar, B. (1978). Similar situations-Similar behaviors?: A study of the intraindividual congruence between situation perception and situation reactions. Journal of Research in Personality, 12(1):41-48.

McAlister, L. (1982). A Dynamic Attribute Satiation Model of Variety-Seeking Behavior. Journal of Consumer Research, 9(2):141-150.

McAlister, L. and Pessemier, E. (1982). Variety Seeking Behavior: An Interdisciplinary Review. Journal of Consumer Research, 9(3):311-322.

McConnell, K. E. (1977). Congestion and Willingness to Pay: A Study of Beach Use. Land Economics, 53(2):185-195.

Mcconnell, K. E., Strand, I. E., and Blake-Hedges, L. (1995). RANDOM UTILITY MODELS OF RECREATIONAL FISHING: CATCHING FISH USING A POISSON PROCESS. Marine Resource Economics, 10(3):247-261.

McFarlane, B. L. (1994). Specialization and Motivations of Birdwatchers. Wildlife Society Bulletin (1973-2006), 22(3):361-370. 
Nosofsky, R. M. (1992). Similarity Scaling and Cognitive Process Models. Annual Review of Psychology, 43(1):25-53.

Ossadnik, W., Wilmsmann, D., and Niemann, B. (2013). Experimental evidence on case-based decision theory. Theory and Decision, 75(2):211-232.

Pape, A. D. and Kurtz, K. J. (2013). Evaluating case-based decision theory: Predicting empirical patterns of human classification learning. Games and Economic Behavior, 82:52-65.

Pollak, R. A. (1970). Habit Formation and Dynamic Demand Functions. Journal of Political Economy, 78(4):745-763.

Scarpa, R. and Rose, J. M. (2008). Design efficiency for non-market valuation with choice modelling: how to measure it, what to report and why*. Australian Journal of Agricultural and Resource Economics, 52(3):253-282.

Shepard, R. (1987). Toward a universal law of generalization for psychological science. Science, 237(4820):1317-1323.

Smith, M. D. (2005). State dependence and heterogeneity in fishing location choice. Journal of Environmental Economics and Management, 50(2):319-340.

Smith, M. D. and Wilen, J. E. (2002). State Dependence in Modeling the Spatial Behavior of Renewable Resource Users. Corvallis, Oregon, USA. International Institute of Fisheries Economics and Trade.

Timmins, C. and Murdock, J. (2007). A revealed preference approach to the measurement of congestion in travel cost models. Journal of Environmental Economics and Management, 53(2):230-249.

Train, K. (2002). Discrete Choice Methods with Simulation. Cambridge University Press. 
Train, K. and Weeks, M. (2005). Discrete Choice Models in Preference Space and Willingness-to-Pay Space. In Scarpa, R. and Alberini, A., editors, Applications of Simulation Methods in Environmental and Resource Economics, The Economics of Non-Market Goods and Resources, pages 1-16. Springer Netherlands, Dordrecht.

Voorheis, J. (2015). Mqtime: A Stata Tool for Calculating Travel Time and Distance Using Mapquest web Services:. The Stata Journal. Publisher: SAGE PublicationsSage CA: Los Angeles, CA. 


\section{Appendix B1. Types of Eco-region and Land Cover}

The number of eco-region classifications and its mean statistics are provided in Table 2.7. There are a total of nine eco-region categories in the data set used in this study. These variables are binary indicators which equals to one if the birding site belongs to the respective eco-region. Further details on these eco-region types can be found in Kolstoe and Cameron (2017).

Table 2.7: Types of Eco-region

\begin{tabular}{lc}
\hline \hline Variables & Mean \\
\hline Blue Mountains (Yes=1) & 0.0029 \\
Cascades (Yes=1) & 0.036 \\
Coast Range (Yes=1) & 0.015 \\
Columbia Plateau (Yes=1) & 0.026 \\
Eastern Cascades Slopes and Foothills (Yes=1) & 0.006 \\
Klamath Mountains (Yes=1) & 0.017 \\
Northern Cascades (Yes=1) & 0.0055 \\
Northern Rockies (Yes=1) & 0.0018 \\
Willamette Valley (Yes=1) & 0.29 \\
\hline
\end{tabular}

The mean and description of type of land cover are provided in Table 2.8. All site attributes in this table are binary indicators which equals to one if the birding site destination is categorized as the respective type of land cover. The land cover types are obtained from the 2011 National Land Cover Database (NLDC). 
Table 2.8: Types of Land Cover

\begin{tabular}{llc}
\hline \hline Variables & Description & Mean \\
\hline Barren (Yes=1) & Areas which have less than 15\% veg- & 0.053 \\
& etation. & \\
Shrubland (Yes=1) & Areas with shrubs less than 5 meters & 0.041 \\
& tall. & \\
Forest (Yes=1) & Areas which have deciduous, ever- & 0.143 \\
& green and mixed forests. & \\
Planted/Cultivated (Yes=1) & Areas which have pastures, hay and & 0.097 \\
Water/Perennial Ice/Snow $($ Yes=1) & Areas of open water with less than & 0.109 \\
& 25\% vegetation or soil. & \\
Wetlands (Yes=1) & Areas which have woody and emer- & 0.103 \\
& gent herbaceous wetland & \\
Herbaceous (Yes=1) & Areas which have more than $80 \%$ & 0.042 \\
& herbaceous vegetation. & \\
& Low, medium and high intensity de- & 0.412 \\
& veloped areas and open spaces. & \\
\hline
\end{tabular}

\section{Appendix B2. Estimation of Marginal Change in CB score}

In this section we will be describing in detail how to estimate the marginal change in similarity score when a particular site attribute changes in the first stage.

The first stage equation is based on CBDT, where the utility is a non-linear combination of the inverse exponential of the euclidean squared difference $(d(p, q))$ between the current choice $(p)$ and past choice $(q)$ for each individual across site attributes $(i)$ summed over $T$ periods in the individuals memory. This equation with $y$ as the binary indicator for site chosen is provided in 2.10: 


$$
y=\alpha+\left(\sum_{t=1}^{T}\left\{\frac{1}{\exp \left(\sqrt{\left.\sum_{i=1}^{\operatorname{Dim} w_{i} d(p, q)}\right)}\right.}\right\} \times \frac{1}{T}\right.
$$

The squared difference $(d(p, q))$ between the current choice $(p)$ and past choice $(q)$ across site attributes is shown in 2.11 .

$$
d(p, q)=\left(p_{i}-q_{i}\right)^{2}
$$

The first step to estimate the marginal effect of a change in similarity weight of a site attribute is by making assumptions about the history of cases a representative birder draws from hi memory when making a site choice decision.

For instance, consider an individual (or birder in this study) who refers back to only one case in his memory when making his choice. Then the case-based utility function would simplify to include only one distance measure for each site attribute as provided in equation 2.12 :

$$
y=\alpha+\frac{1}{\exp \left(\sqrt{\sum_{i=1}^{\# D i m} w_{i}\left(p_{i}-q_{i}\right)^{2}}\right)} \times \frac{1}{T}
$$

where $q=p-1$ since we are only looking back one period. Further expanding equation 2.12 we obtain the following equation in 2.13

$$
y=\alpha+\frac{1}{\exp \left(\sqrt{\left.w_{1}\left(p_{1}-q_{1}\right)^{2}+w_{2}\left(p_{2}-q_{2}\right)^{2}+\ldots+w_{i}\left(p_{i}-q_{i}\right)\right)^{2}}\right)} \times \frac{1}{T}
$$

To estimated the marginal effect due to change in one site attribute say $i=1$, we further simplify the equation to 2.14 


$$
y=\alpha+\frac{1}{\exp \left(\sqrt{w_{1}\left(p-q_{1}\right)^{2}+\sum_{i=1}^{\# \operatorname{Dim}} w_{i}\left(p_{i}-q_{i}\right)^{2}}\right)} \times \frac{1}{T}
$$

Following the chain rule for we derive equation 2.14 with respect to the site attribute 1 at current choice $p$ to obtain 2.15

$$
\begin{array}{r}
\frac{\partial y}{\partial p_{1}}=\frac{1}{T} \times \frac{-1}{\exp \left(\sqrt{w_{1}\left(p_{1}-q_{1}\right)^{2}+\sum_{i=1}^{\# \text { \#Dim }} w_{i}\left(p_{i}-q_{i}\right)^{2}}\right)} \\
\times \frac{2 w_{1}\left(p_{1}-q_{1}\right)}{2 \sqrt{w_{1}\left(p_{1}-q_{1}\right)^{2}+\sum_{i=1}^{\# \text { Dim }} w_{i}\left(p_{i}-q_{i}\right)^{2}}}
\end{array}
$$

Equation 2.15 can be simplified and rewritten as 2.16 where $d(p, q)$ represents the euclidean distance measure of site attributes going back one period (Refer to equation 2.11). The weighing variable, $T$, which is used to evenly distribute the function across all cases in the memory is equal to one when we take the marginal effect of the first stage equation ${ }^{13}$.

$$
\frac{\partial y}{\partial p_{1}}=\frac{-w_{1} \sqrt{d_{p_{1}, q_{1}}}}{\left(\exp \sqrt{\sum_{1=1}^{\# \text { Dim }} w_{i} d\left(p_{i}, q_{i}\right)}\right)\left(\sqrt{\sum_{i=1}^{\# \text { Dim }} w_{i} d\left(p_{i}, q_{i}\right)}\right)}
$$

Now, let us consider when the birder refers back to four cases $(T=4)$ in his memory when making a choice. The first stage equation 2.10 can then be expanded to incorporate four cases to form equation 2.17

$$
y=\alpha+\frac{1}{T} \times \frac{\mathrm{I}_{1}}{\exp \left(\sqrt{\sum_{i=1}^{\# D i m} w_{i} d_{t=1}\left(p_{i}, q_{i}\right)}\right)}+\ldots+\frac{\mathrm{I}_{4}}{\exp \left(\sqrt{\sum_{i=1}^{\# D i m} w_{i} d_{t=4}\left(p_{i}, q_{i}\right)}\right)}
$$

In the above equation $I_{t}$ represents the indicator for the case $=\mathrm{t}$. So indicator $I_{1}$ is

\footnotetext{
${ }^{13}$ weight (not to be confused with estimated similarity weights) is constructed to be 0 or 1 depending on the number of cases included in the memory of the agent. Therefore $T=1$ since we are estimating the marginal effect for a change in the site attribute in the current case ( $p$ is for when $t=1$ ).
} 
used to represent that the euclidean distances are taken to be the aggregated squared difference between current choice and past choice, where the past choice is one lag or $q=p-1$. Similarly, $I_{2}$ and $I_{3}$ is for when $q=p-2$ and $q=p-3$ respectively. Since we are considering the birder to have four cases in his memory, $I_{4}$ represents all past choices beyond the fourth lag, that is., $q=p-4, p-5, . ., p-t_{n}$, where $t_{n}$ is the earliest past choice recorded for each birder $(n)$ in the data set. We then estimate the marginal effect of a change in site attribute 1 by taking the partial derivative of equation 2.17. Following the same procedure for when the birder was referring back to one case, we obtain the marginal estimate for a change in site attribute 1 as provided in equation 2.18 below:

$$
\begin{aligned}
& \frac{\partial y}{\partial p_{1}}= \frac{-w_{1} \mathrm{I}_{1} \sqrt{d_{\mathrm{t}=1}\left(p_{1}, q_{1}\right)}}{\left.\exp \sqrt{\sum_{i=1}^{\# \text { Dim }} w_{i} d_{\mathrm{t}=1}\left(p_{i}, q_{i}\right)}\right)\left(\sqrt{\sum_{i=1}^{\# \text { Dim }} w_{i} d_{\mathrm{t}=1}\left(p_{i}, q_{i}\right)}\right)}+\ldots \\
& . .+\frac{-w_{1} \mathrm{I}_{4} \sqrt{d_{\mathrm{t}=4}\left(p_{1}, q_{1}\right)}}{\left(\exp \sqrt{\sum_{i=1}^{\# D i m} w_{i} d_{\mathrm{t}=4}\left(p_{i}, q_{i}\right)}\right)\left(\sqrt{\sum_{1=i}^{\# \text { Dim }} w_{i} d_{\mathrm{t}=4}\left(p_{i}, q_{i}\right)}\right)}
\end{aligned}
$$

We further simplify the above equation to obtain our final marginal effects equation provided in 2.19 .

$$
\frac{\partial y}{\partial p_{1}}=\sum_{\mathrm{t}=1}^{4} \frac{-w_{1} \mathrm{I}_{\mathrm{t}} \sqrt{d_{\mathrm{t}}\left(p_{1}, q_{1}\right)}}{\left.\exp \sqrt{\sum_{i=1}^{\# \text { Dim }} w_{i} d_{\mathrm{t}}\left(p_{i}, q_{i}\right)}\right)\left(\sqrt{\sum_{i=1}^{\# \text { Dim }} w_{i} d_{\mathrm{t}}\left(p_{i}, q_{i}\right)}\right)}
$$

In this study, we constructed the history (memory of cases) for each birder by looking back up to four cases $(T=4)$. We simulated and compared the estimated similarity weights using different number of cases. Through trial and error we notice very slight change in estimated weights when more cases are included in the model. The estimated results from calculating the marginal change in similarity score due to changes in site attributes are provided in Table 2.9. 
Table 2.9: LPM Marginal Similarity Scores

\begin{tabular}{lcc}
\hline \hline Variables $(i)$ & $\partial y / \partial p_{i}$ & Std Error \\
\hline Blue Mountains & $0.0003^{* *}$ & $(0.0001)$ \\
Cascades & 0.0001 & $(0.0003)$ \\
Coast Range & $0.0010^{* * *}$ & $(0.0003)$ \\
Columbia Plateau & -0.0016 & $(0.0138)$ \\
Eastern Cascades Slopes and Foothills & -0.0000 & $(0.0002)$ \\
Klamath Mountains & $0.0005 * * *$ & $(0.0001)$ \\
Northern Rockies & 0.0016 & $(0.0104)$ \\
Willamette Valley & -0.0044 & $(0.0062)$ \\
Barren & $0.0007 *$ & $(0.0003)$ \\
Shrubland & $0.0012 * * *$ & $(0.0003)$ \\
Forest & $0.0010^{* * *}$ & $(0.0004)$ \\
Planted/Cultivated & $0.0007 * *$ & $(0.0003)$ \\
Water & 0.0003 & $(0.0004)$ \\
Wetlands & $0.0016^{* * *}$ & $(0.0004)$ \\
Herbaceous & $0.0005^{* * *}$ & $(0.0003)$ \\
National Wildlife Refuge & $0.0005^{* * *}$ & $(0.0002)$ \\
GAP status 3 (National Forests, etc.) & $-0.0011^{* *}$ & $(0.0005)$ \\
GAP status 1 or 2 (National Parks, etc.) & -0.0000 & $(0.0000)$ \\
Expect Endangered Bird Species & $0.0001 * * *$ & $(0.0000)$ \\
Urban Area & $-0.0046 * * *$ & $(0.0013)$ \\
\hline & & \\
\hline
\end{tabular}

Notes: Standard errors are given in parentheses. $* * *, * *$ and $*$ denotes significance at 1 percent, 5 percent and 10 percent. 


\section{Appendix B3. Additional Tables}

Table 2.10: Mixed Logit Results: Second Stage Full Model

\begin{tabular}{|c|c|c|}
\hline \multirow[t]{2}{*}{ Variables } & \multicolumn{2}{|c|}{ Site Visited as Dependent Variable } \\
\hline & & Std. Err \\
\hline Travel Cost & $-0.036 * * *$ & 0.00 \\
\hline \multicolumn{3}{|l|}{ Ecoregion Indicators } \\
\hline Blue Mountains & -0.603 & 0.84 \\
\hline Cascades & $0.673 * *$ & 0.32 \\
\hline Coast Range & $0.662^{*}$ & 0.36 \\
\hline Columbia Plateau & -0.363 & 0.75 \\
\hline Eastern Cascades Slopes and Foothills & -0.933 & 0.69 \\
\hline Klamath Mountains & 0.145 & 0.42 \\
\hline Northern Cascades & -0.830 & 0.72 \\
\hline Northern Rockies & 0.307 & 0.88 \\
\hline Willamette Valley & $1.313 * * *$ & 0.36 \\
\hline \multicolumn{3}{|l|}{ Land Cover Indicators } \\
\hline Barren & 0.194 & 0.15 \\
\hline Shrubland & 0.135 & 0.14 \\
\hline Forest & -0.062 & 0.11 \\
\hline Planted/Cultivated & $0.202 *$ & 0.11 \\
\hline Water & $0.373 * * *$ & 0.11 \\
\hline Wetlands & $0.357 * * *$ & 0.11 \\
\hline Herbaceous & $-0.322 *$ & 0.19 \\
\hline \multicolumn{3}{|l|}{ Other Site Attributes } \\
\hline National Wildlife Refuge & $0.796 * * *$ & 0.19 \\
\hline GAP status 3 (National Forests, etc.) & $0.408 * * *$ & 0.08 \\
\hline GAP status 1 or 2 (National Parks, etc.) & $0.697 * * *$ & 0.13 \\
\hline Expect Endangered Bird Species & $1.648^{*}$ & 0.93 \\
\hline
\end{tabular}

Continued on next page 
Table 2.10 - Continued from previous page

\begin{tabular}{|c|c|c|}
\hline \multirow[t]{2}{*}{ Variables } & \multicolumn{2}{|c|}{ Site Visited as Dependent Variable } \\
\hline & & Std. Err \\
\hline Urban Area & $-0.555 * * *$ & 0.08 \\
\hline Congestion & $190.404 * * *$ & 13.38 \\
\hline$(\text { Congestion })^{2}$ & $-3,665.54 * * *$ & 437.66 \\
\hline Case-based Score $(\delta)$ & $16.510 * * *$ & 3.96 \\
\hline ES & 0.008 & 0.01 \\
\hline ES (Std. Dev.) & $0.015^{*}$ & 0.01 \\
\hline \multicolumn{3}{|c|}{ ES interacted with time trend and month fixed effects } \\
\hline ES x dev. med H. Inc. $(\$ 10,000)$ & 0.004 & 0.00 \\
\hline ES x Feb & $-0.036 * *$ & 0.01 \\
\hline ES x Mar & 0.006 & 0.02 \\
\hline ES x Apr & 0.009 & 0.02 \\
\hline ES x May & 0.005 & 0.02 \\
\hline ES x Jun & $0.114 * * *$ & 0.03 \\
\hline ES x Jul & -0.007 & 0.02 \\
\hline ES x Aug & 0.020 & 0.02 \\
\hline ES x Sept & 0.026 & 0.02 \\
\hline ES x Oct & 0.014 & 0.02 \\
\hline ES x Nov & $0.042 *$ & 0.02 \\
\hline ES x Dec & $0.059 * *$ & 0.03 \\
\hline ES $x$ time trend(t12=0 in 2012) & 0.006 & 0.01 \\
\hline \multicolumn{3}{|l|}{ Sample Selection Correction Terms } \\
\hline $\mathrm{C} \mathrm{x}$ dev. mean incl. prop & $0.014 * * *$ & 0.00 \\
\hline ES x dev. mean incl. prop & -0.005 & 0.01 \\
\hline
\end{tabular}

Notes: $N=155,372$. Standard errors are given in parentheses. $* * *, * *$ and $*$ denotes significance at 1 percent, 5 percent and 10 percent. The deviation from median household income is denoted as 'dev. med H. Inc. $(\$ 10,000)$ ' in the table and the deviation from mean propensity to be included in the estimated sample is denoted as 'dev. mean incl. prop'. 
Table 2.11: Comparison of WTP: All Estimates

\begin{tabular}{|c|c|c|c|}
\hline \multirow{3}{*}{ Variables } & (1) & (2) & (3) \\
\hline & No memory & Average memory & Diff in WTP \\
\hline & $T=0$ cases & $T=4$ cases & $(2)-(1)$ \\
\hline \multicolumn{4}{|l|}{ Ecoregion Indicators } \\
\hline Blue Mountains & -21.77 & -16.63 & 5.14 \\
\hline Cascades & $17.53 * *$ & $18.72 * *$ & 1.19 \\
\hline Coast Range & 16.33 & $18.80^{*}$ & 2.47 \\
\hline Columbia Plateau & -12.14 & -10.80 & 1.34 \\
\hline Eastern Cascades Slopes and Foothills & -27.13 & -25.85 & 1.28 \\
\hline Klamath Mountains & 1.70 & 4.28 & 2.58 \\
\hline Northern Rockies & 7.18 & 9.13 & 1.95 \\
\hline Willamette Valley & $35.00 * * *$ & $34.35 * * *$ & -0.66 \\
\hline \multicolumn{4}{|l|}{ Land Cover Indicators } \\
\hline Barren & 5.58 & 5.66 & 0.008 \\
\hline Shrubland & 4.92 & 4.31 & -0.61 \\
\hline Forest & -1.47 & -1.25 & -0.22 \\
\hline Planted/Cultivated & $5.82 *$ & $5.91 *$ & 0.09 \\
\hline Water & $10.49 * * *$ & $10.48 * * *$ & -0.02 \\
\hline Wetlands & $10.23 * * *$ & $10.63 * * *$ & 0.40 \\
\hline Herbaceous & -8.22 & $-8.67 *$ & -0.45 \\
\hline \multicolumn{4}{|l|}{ Other Site Attributes } \\
\hline National Wildlife Refuge & $22.12 * * *$ & $22.27 * * *$ & 0.16 \\
\hline GAP status 3 (National Forests, etc.) & $11.29 * * *$ & $10.80 * * *$ & -0.49 \\
\hline GAP status 1 or 2 (National Parks, etc.) & $20.09 * * *$ & $19.32 * * *$ & -0.77 \\
\hline Expect Endangered Bird Species & $50.57 * *$ & $45.80^{*}$ & -4.76 \\
\hline Urban Area & $-15.63 * * *$ & $-17.51 * * *$ & -1.88 \\
\hline
\end{tabular}

Columns (1) and (2) represent the WTP or travel cost per trip obtained when the individual uses no memory and when he uses an average distribution as memory following mixed logit estimations respectively. Column (3) provides the difference in WTP between column (2) and (3) to show how including memory or past experience that accounts for variety-seeking and habit formation affects the welfare amounts for each site attribute. 
Table 2.12: Mixed Logit Results: Second Stage and Static Models

\begin{tabular}{|c|c|c|}
\hline VARIABLES & (1) & (2) \\
\hline Models & 2-stage & Static \\
\hline \multirow[t]{2}{*}{ Travel Cost $(\alpha)$} & $-0.036 * * *$ & $-0.036 * * *$ \\
\hline & $(0.003)$ & $(0.003)$ \\
\hline \multirow[t]{2}{*}{ National Wildlife Refuge } & $0.800 * * *$ & $0.796 * * *$ \\
\hline & $(0.192)$ & $(0.193)$ \\
\hline \multirow{3}{*}{$\begin{array}{l}\text { GAP status } 3 \text { (National Forests, } \\
\text { etc.) }\end{array}$} & $0.408 * * *$ & $0.408 * * *$ \\
\hline & & \\
\hline & $(0.076)$ & $(0.076)$ \\
\hline \multirow{3}{*}{$\begin{array}{l}\text { GAP status } 1 \text { or } 2 \text { (National } \\
\text { Parks, etc.) }\end{array}$} & $0.726 * * *$ & $0.697 * * *$ \\
\hline & & \\
\hline & $(0.128)$ & $(0.129)$ \\
\hline \multirow[t]{2}{*}{ Expect Endangered Bird Species } & $1.828 * *$ & $1.648^{*}$ \\
\hline & $(0.858)$ & $(0.930)$ \\
\hline \multirow[t]{2}{*}{ Urban Area } & $-0.565 * * *$ & $-0.555 * * *$ \\
\hline & $(0.084)$ & $(0.085)$ \\
\hline \multirow[t]{2}{*}{ Congestion } & $189.697 * * *$ & $190.404 * * *$ \\
\hline & $(13.457)$ & $(13.38)$ \\
\hline \multirow[t]{2}{*}{$(\text { Congestion })^{2}$} & $-3,646.657 * * *$ & $-3,665.541 * * *$ \\
\hline & $(438.326)$ & $(437.66)$ \\
\hline \multirow[t]{2}{*}{ ES } & 0.009 & 0.008 \\
\hline & $(0.012)$ & $(0.015)$ \\
\hline \multirow[t]{2}{*}{ ES (Std. Dev.) } & $0.018 * *$ & $0.015^{*}$ \\
\hline & $(0.009)$ & $(0.009)$ \\
\hline \multirow[t]{2}{*}{ Case-based Score $(\delta)$} & & $16.521 * * *$ \\
\hline & & $(3.96)$ \\
\hline Euclidean distance weights & No & No \\
\hline State Dependent Variables & No & No \\
\hline
\end{tabular}


Table 2.12 - Continued from previous page

\begin{tabular}{lcc}
\hline & 2-stage & Static \\
\hline ES Interacted with months & Yes & Yes \\
ES Interacted with time trend & Yes & Yes \\
Eco-region Indicators & Yes & Yes \\
Land Cover Indicators for Sites & Yes & Yes \\
Chosen & & \\
Sample Selection Correction & Yes & Yes \\
Terms & & \\
& & \\
Model Selection Criteria & 9254 & 9237 \\
AIC & 9697 & 9655 \\
BIC & 9703 & 9697 \\
CAIC & & \\
\hline
\end{tabular}

Notes: Standard errors are given in parentheses. ***, ** and $*$ denotes significance at 1 percent, 5 percent and 10 percent.

Table 2.13: Mixed Logit Results: Benchmark Models

\begin{tabular}{lccc}
\hline \hline VARIABLES & $(1)$ & $(2)$ & $(3)$ \\
Models & Reduced Form & State Dependent & 2-stage \\
\hline Travel Cost & $-0.036^{* * *}$ & $-0.036^{* * *}$ & $-0.036^{* * *}$ \\
& $(0.003)$ & $(0.003)$ & $(0.003)$ \\
National Wildlife Refuge & $0.864^{* * *}$ & $0.694^{* * *}$ & $0.796^{* * *}$ \\
& $(0.251)$ & $(0.221)$ & $(0.193)$ \\
GAP status 3 (National Forests, & $0.383^{* * *}$ & $0.211^{*}$ & $0.408^{* * *}$ \\
etc.) & & & \\
& $(0.082)$ & $(0.108)$ & $(0.076)$ \\
GAP status 1 or 2 (National & $0.776^{* * *}$ & $0.697^{* * * *}$ & $0.697^{* * * *}$ \\
Parks, etc.) & & & $(0.129)$ \\
\hline
\end{tabular}


(1)

(2)

(3)

\begin{tabular}{|c|c|c|c|}
\hline & Reduced Form & State Dependent & 2-stage \\
\hline \multirow[t]{2}{*}{ Expect Endangered Bird Species } & 1.738 & $2.00 * *$ & $1.648 *$ \\
\hline & $(1.098)$ & $(0.854)$ & $(0.930)$ \\
\hline \multirow[t]{2}{*}{ Urban Area } & $-0.558 * * *$ & $-0.948 * * *$ & $-0.555 * * *$ \\
\hline & $(0.085)$ & $(0.131)$ & $(0.085)$ \\
\hline \multirow[t]{2}{*}{ Congestion } & $190.229 * * *$ & $187.283 * * *$ & $190.404 * * *$ \\
\hline & $(13.526)$ & $(13.468)$ & $(13.38)$ \\
\hline \multirow[t]{2}{*}{$(\text { Congestion })^{2}$} & $-3,702.269 * * *$ & $-3,590.271 * * *$ & $-3,665.541 * * *$ \\
\hline & $(441.838)$ & $(438.994)$ & $(437.66)$ \\
\hline \multirow[t]{2}{*}{ ES } & 0.010 & 0.009 & 0.008 \\
\hline & $(0.012)$ & $(0.012)$ & $(0.015)$ \\
\hline \multirow[t]{2}{*}{ ES (Std. Dev.) } & $0.016^{*}$ & $0.016^{*}$ & $0.015^{*}$ \\
\hline & $(0.009)$ & $(0.009)$ & $(0.009)$ \\
\hline \multirow[t]{2}{*}{ Case-based Score $(\delta)$} & & & $16.521 * * *$ \\
\hline & & & $(3.96)$ \\
\hline Euclidean distance weights & Yes & No & No \\
\hline State Dependent Variables & Yes & Yes & No \\
\hline ES Interacted with months & Yes & Yes & Yes \\
\hline ES Interacted with time trend & Yes & Yes & Yes \\
\hline Eco-region Indicators & Yes & Yes & Yes \\
\hline Land Cover Indicators & Yes & Yes & Yes \\
\hline Sample Selection Correction & Yes & Yes & Yes \\
\hline \multicolumn{4}{|l|}{$\underline{\text { Model Selection Criteria }}$} \\
\hline AIC & 9276 & 9223 & 9237 \\
\hline BIC & 9933 & 9830 & 9655 \\
\hline CAIC & 9999 & 9891 & 9697 \\
\hline
\end{tabular}

Notes: Standard errors are given in parentheses. $* * *, * *$ and $*$ denotes significance at 1 percent, 5 percent and 10 percent. 
IMPACT OF VISUAL REPRESENTATION OF LABELS IN A CHOICE

EXPERIMENT: VALUING PREFERENCES FOR A LOCAL DAM

(To be submitted to Ecological Economics)

By

Priya Behanan ${ }^{1}$, Simona Trandafir $^{1}$, Emi Uchida $^{1}$, Todd Guilfoos ${ }^{1}$

and Emily Vogler ${ }^{2}$

${ }^{1}$ Department of Environmental and Natural Resource Economics,

University of Rhode Island

${ }^{2}$ Department of Landscape Architecture,

Rhode Island School of Design 


\title{
CHAPTER 3
}

\begin{abstract}
This paper uses a split sample labeled choice experiment to examine the effects of introducing visual representations of labels on survey responses. Each label represents a policy alternative for an existing dam that has been issued a Letter of Deficiency, the West Street Dam in Keene, NH. We test how information delivery, specifically text, images with text, and video with text, affects the valuation of dam alternatives such as dam removal by the surrounding community. Our findings suggest that willingness to pay for dam modifications is $\$ 36$ to $\$ 78$ higher in the image treatment versus the text-only treatment. We also find that willingness to pay is lower across the dam alternatives relative to the status quo when the video treatment is administered. Additionally, respondents would pay an additional \$34 in the video treatment group compared to text-only treatment group to keep and repair the dam to its original state over removing the dam. .
\end{abstract}

\subsection{Introduction}

The use of visual representations has been found to help decision-makers better comprehend the presented information (Townsend and Kahn, 2014). Using visualizations in a choice experiment has been found to not only increase in-sample predictive power but also reduce gain-loss asymmetry (Bateman et al., 2009; Matthews et al., 2017). However, the literature on non-market valuation has underutilized visualization as a technique to explore how different forms of the same information affect choice and valuation (Shr et al., 2019). When choice sets are visually represented in the form of 
an image or video, individuals process them in a gestalt manner: quickly and easily as a whole, which in turn increases the perception of the variety among alternatives compared to their textual or verbal counterparts (Townsend and Kahn, 2014). Making decisions about projected future alternatives for the built environment can be complex, technical and at times challenging for the general public to understand (AlKodmany, 1999; Wissen et al., 2008; Hayek, 2011; Lovett et al., 2015; Salter et al., 2009). To understand how the mode of information impacts complex decisions that affect communities, we employ a choice experiment and explore how visualizations affect residents' value of alternative management options and related attributes for a historic New England dam.

This study uses a labeled choice experiment to examine the effects of visualization in the context of three treatments: text-only, an image with text, and video with text. We find significant differences between the three modes of information in the willingness to pay (WTP) for specific dam alternatives. When images and text are used, we find that respondents are WTP $\$ 56$ more on average for dam alterations other than removal over keeping the dam than when only provided textual information. When video and text are used, respondents are WTP \$34 more to keep the dam over removing the dam than when only provided textual information. Among all treatment groups, the image with text (or image) treatment has a higher willingness to pay across all alternatives and the video with text (or video) treatment lowers the willingness to pay for all alternatives compared to the status quo option to keep and repair dam to its original state. However, among them only the dam modification alternatives in the image treatment and the alternative to remove the dam in the video treatment are statistically significant. We also find a change in the preference ranking of dam alternatives in the image treatment. Since visualization enables a better assessment of the provided alternatives due to increased comprehension (Townsend and Kahn, 2014), we expect this shift in valuation to be closer to the true preference of the decision-maker.

Previous studies find visualizations of future alternatives in choice experiments to 
increase the ability of participants to comprehend information. Matthews et al. (2017) examine the willingness to pay for different coastal erosion management options using visualizations of virtual beach environments. Despite finding slight differences in willingness to pay, this study reported a relatively better in-sample predictive power in the choice experiment containing video treatment. Bateman et al. (2009) use virtual reality to compare the magnitude of asymmetry between willingness to pay and willingness to accept among the numeric, virtual reality, and numeric with virtual reality treatments. They conclude that the virtual reality treatments attenuate loss aversion, thereby reducing the gap between the two welfare measures. Other studies such as Patterson et al. (2017) and Rid et al. (2018) have used three dimensional (3D) films in their choice experiment survey to obtain visual treatment effects. A more recent study by Shr et al. (2019) used visual representations in choice experiment surveys to value landscape attributes in green infrastructure using a generalized mixed logit model. Their study suggests that providing images over the text-only option helps participants to better focus on the attributes.

In labeled choice experiments, each alternative in a choice set is assigned a label that depicts a policy scenario, a location, or a brand name. We use labels to represent alternative dam policies, such as dam removal or dam repair, and estimate the value for the policy itself. The existing literature related to visualizations uses unlabeled choice experiment designs (Bateman et al., 2009; Shr et al., 2019; Matthews et al., 2017). Survey respondents may have a positive or negative inclination towards a particular label. Defining each choice alternative with a label is expected to increase the predictive validity of the model since it is more relatable to an actual policy scenario (Blamey et al., 2000). In the non-market valuation literature, studies often use labels to represent locations to account for spatial heterogeneity (Lizin et al., 2016; Upton et al., 2012).

We make several contributions to the literature in this study. First, we test the effect of the mode of information in a labeled choice experiment within the context of dam removal and other dam alternatives. Our primary hypothesis is that the 
method of transmitting information about dam removal will impact the choices that subjects make and their valuation of attributes, which has been underutilized in choice experiments. Second, we obtain valuations for multiple dam choice alternatives, and to the best of our knowledge only few studies have examined the preferences for alternative dam management other than dam removal (Song et al., 2019; Weir et al., 2020). Lastly, we obtain the valuation of attributes such as wetland habitat, fish passage, historical structure, and recreational opportunities, and evaluate the effect of external funding for dam management options.

\subsubsection{Dams in New England}

New England has over 14,000 dams, many of which are small dams that were built over a century ago to power the early colonial and industrial mills. Safety concerns due to aging infrastructure and increasing efforts to improve fish passage have prompted a trend towards dam removal in the past two decades (Fox et al., 2016; Magilligan et al., 2016). Many small dams have not only ceased to be functional but are also increasingly costly to repair. Despite this, in cases throughout New England, the removal of dams have been met with protests from residents. The reasons behind this conflict vary from the dam being identified as a part of the history and culture of the neighboring community, a general reluctance to change or outsider (such as government) involvement (Fox et al., 2016).

Our study area is the city of Keene in New Hampshire that contains a small dam found along the mainstem of the Ashuelot River called the West Street dam. The West Street dam was built in 1775 to supply electric power to the Faulkner and Colony mills. This dam is 15.6 feet tall and has a 134-foot-long spillway made out of cutting masonry stone. Upstream of the spillway, there is a 1,700-foot long earthen dike that extends along the western edge of the river. Although micro hydropower was an option being considered for the dam, it was determined that it was not financially feasible for the dam to generate hydropower (Ropeik, 2018). The upstream wetlands created by the impoundment are wetland habitat for rare and endangered species such 
as the dwarf wedge mussels. Moreover, the dam, the reservoir, and the adjacent Ashuelot River Park provide an opportunity for several recreational activities such as kayaking, hiking, fishing and bird watching for the residents of Keene ${ }^{14}$. In 2008, the City of Keene received a Letter of Deficiency (LOD) from the state of New Hampshire, Department of Environmental Services (NHDES) Dam Bureau regarding the West Street dam. This letter highlights three significant concerns about this dam. First, there is water leakage around the gates, which is a common problem among aging dams. Unchecked water leaks can eventually lead to dam failure. Another issue raised is that the inoperable pond drains may fail to open or seize and fail to close, leaving the pond to gradually drain out. The last issue listed in the LOD was the vegetation growing on the earthen dike that can cause serious structural deterioration and distress and can eventually lead to the failure of earthen dams.

In 2008, city officials along with other members of the community ${ }^{15}$ explored potential future options for this dam. They hired a private firm, VHB ${ }^{16}$, to prepare a technical report that describes the feasibility behind removing the dam, repairing the dam, or consider developing a hydropower facility (VHB, 2016). Although it was determined that hydropower is not financially feasible, the findings from this report were used in our research. Further investigation was conducted on-site by a team of researchers ${ }^{17}$. The findings from this site assessment report provide adequate background on plausible dam management options and how it affects the ecology, flood levels and water quality surrounding the dam. Both the VHB technical report and the site assessment report were used to identify the dam alternatives and attributes used in the choice experiment. In this study, we examine the residents' preferences for the following five alternatives of the West Street dam:

(i) Keep and repair the dam: The first alternative is to keep the dam as it is after re-

\footnotetext{
${ }^{14}$ This information was obtained from a focus group session and charrette conducted as a part of this research. The participants are members of the community in our study area, Keene.

${ }^{15}$ Group of residents from Keene formed the West Street Hydro Inc., a nonprofit organization, with the aim to investigate the possibility of developing a hydropower facility at the dam.

${ }^{16}$ Company website: https://www.vhb.com/

${ }^{17}$ West Street Dam Investigative report was prepared by a team of researchers from Keene State College (KSC) as a part of the multi-state New England Sustainability Consortium (NEST) research.
} 
pairing all the issues identified in the LOD. In this case, the historic structure of the dam would remain visible and the surrounding wetland habitat stays unaffected. However, there would be no fish passage or habitat connectivity up and downstream of the dam. And while it is one of the least expensive alternatives in the short term, this alternative would require long-term maintenance.

The next three alternatives involve upgrading or modifying the dam after undertaking the necessary repairs. Higher upfront cost along with long-term maintenance makes them relatively more expensive.

(ii) Technical Denil fish ladder: The second alternative is to add a technical Denil fish ladder. This allows limited fish passage and habitat connectivity up and downstream of the dam. Although the dam would still be visible, a portion of it would be blocked by the Denil fish ladder.

(iii) Nature-like fishway: The third alternative involves gradually increasing the elevation of the river downstream of the dam through a series of rock pools. Nature-like fishways provide improved fish passage and habitat connectivity up and downstream but the dam is no longer visible.

(iv) Pool and weir bypass channel: In the fourth alternative, a channel is constructed to the west of the dam to bypass the dam and connect the river upstream of the dam to the river downstream of the dam. In this case, the dam would remain in place without obstructing its view.

In all of the above alternatives, the upstream water elevation would remain the same, maintaining the wetlands and recreational opportunities in the park.

(v) Remove the dam: Dam removal provides full habitat connectivity and fish passage up and downstream. A portion of the dam structure could remain on either side of the river channel to mark the historic location of the dam. As a result of removing the dam, the upstream water elevation would be lowered, potentially draining the upstream wetlands, impacting rare species 
that are found in the wetland, and reducing the recreational opportunities on the impoundment. While this alternative is more expensive up-front, once the dam is removed, there is no long-term cost or maintenance required.

\subsection{Methodology}

The labels used in the choice experiment represent the five policy alternatives applicable to the West Street dam. Discrete choice modeling follows the random utility framework where, in a given set of alternatives, the decision-maker chooses that alternative which provides him maximum utility (McFadden, 1980).

\subsubsection{Visualization Treatments}

We construct two types of visual treatments: rendered still images and a video. The first visual treatment involves the use of three-dimensional (3D) visualizations of the dam alternatives (Figure 3.1). Within this treatment, two types of images were used to describe the alternatives. The first image type was a photo-realistic image at eye-level that aimed to give the viewers a sense of the experiential and aesthetic qualities of alternative (Figure 3.1, right images). The second image type was a birds-eye-view diagram that aimed to provide a larger geographic frame and understanding of how the alternative would impact the river upstream and downstream of the dam (Figure 3.1, left images).

Both visuals were developed using data available from GIS and the City's CAD file that was then modeled in the 3D modeling program, Rhino. Water elevation data was brought in from the VHB technical report to model the projected impact of removal to the water elevation. Once the physical landscape features were modeled in Rhino, two views were exported for the final visualizations. The eye-level view was brought into photoshop to add photographs of the surrounding context and textures that could capture the material qualities of the projected future landscapes. The birds-eye-view diagram was rendered in Rhino using VRAY prior to being exported. 
Both the birds-eye-view and the eye-level view were brought into InDesign to provide annotations of the various impacts of the alternative.

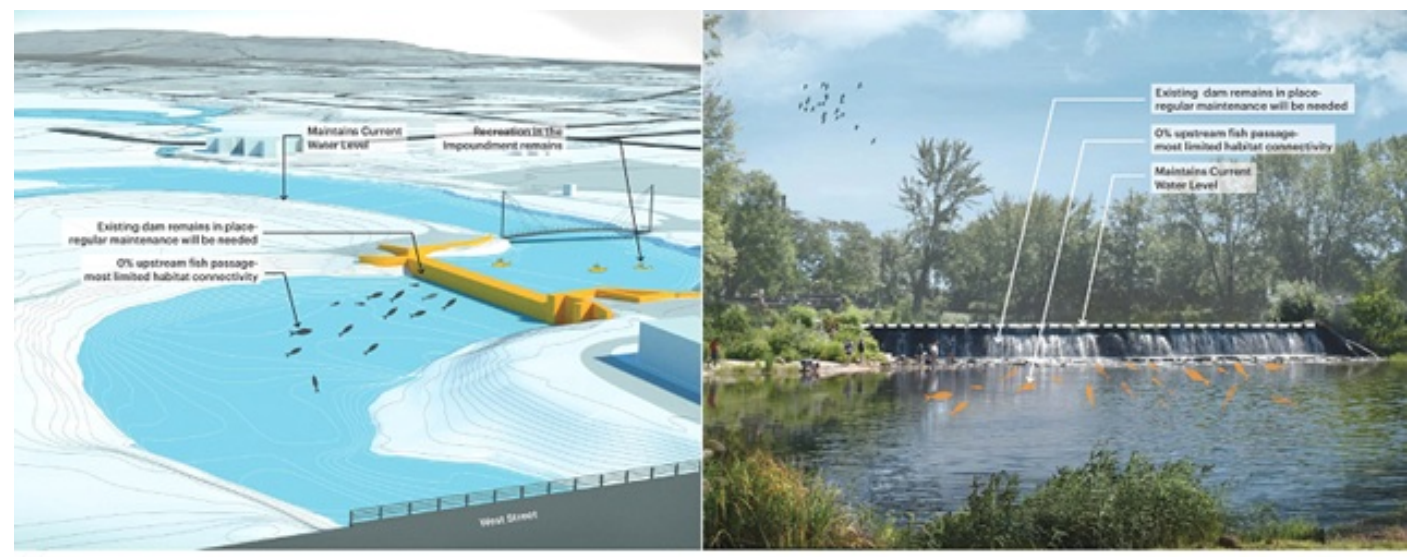

(a)

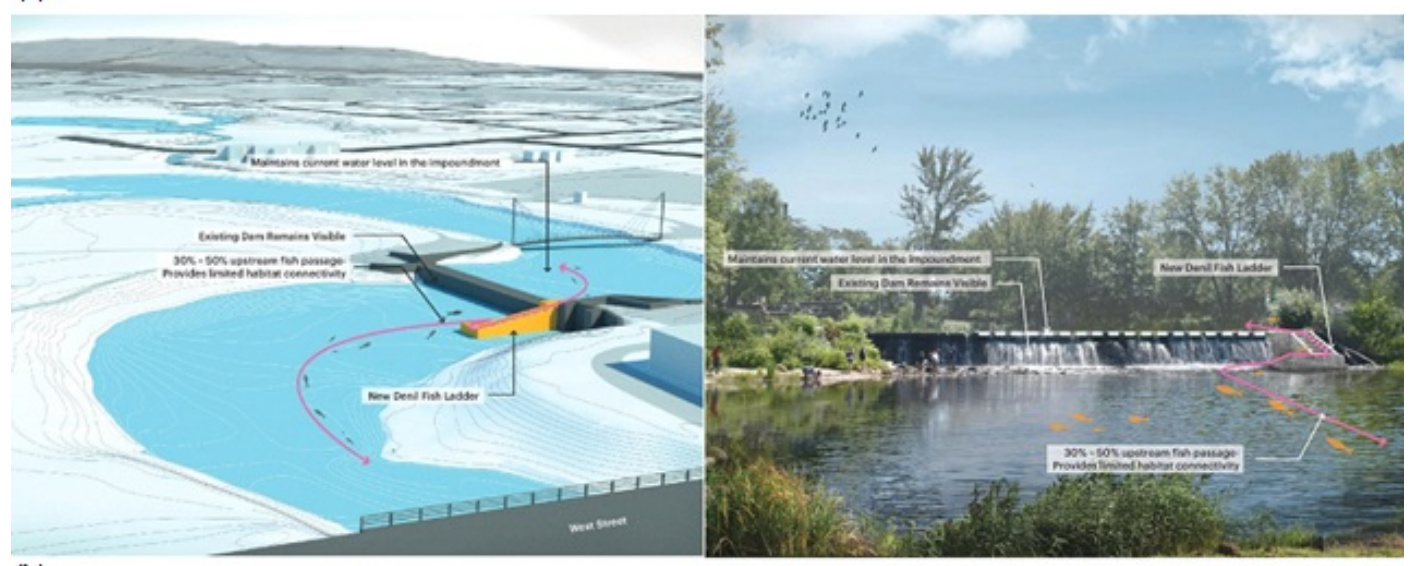

(b)

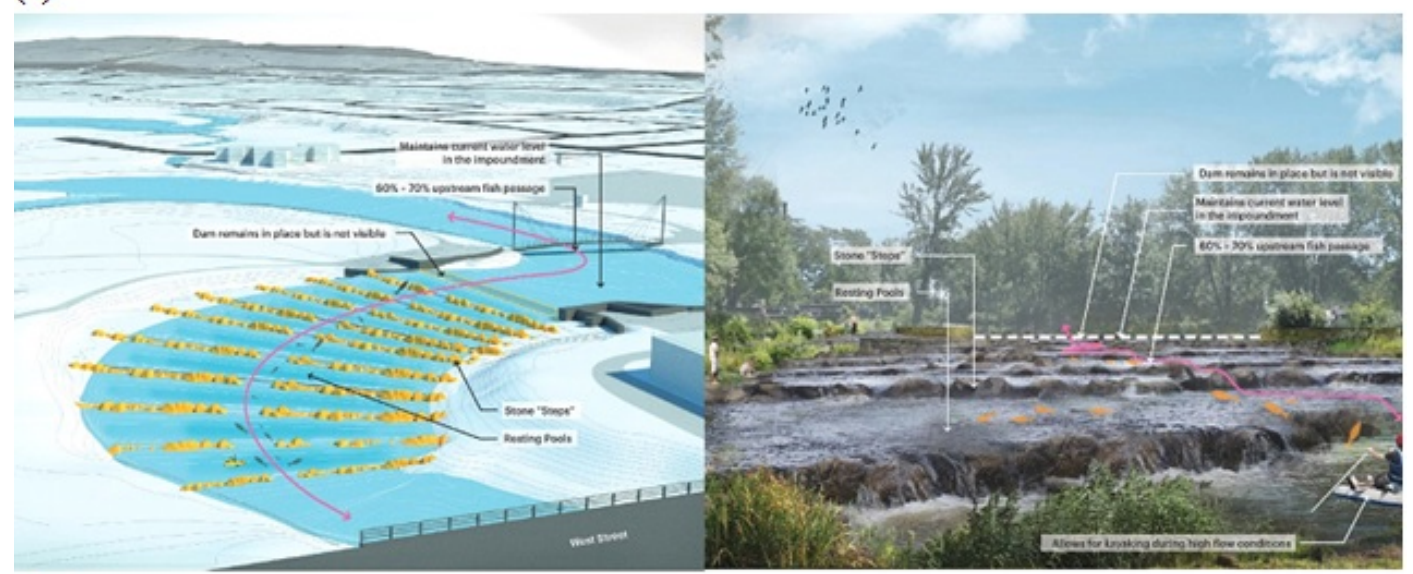

(c)

Figure 3.1: Visual representation of alternatives displayed in the image treatment (a) Repair Dam, (b)Technical Denil Fish Ladder and (c) Nature-like Fishway 


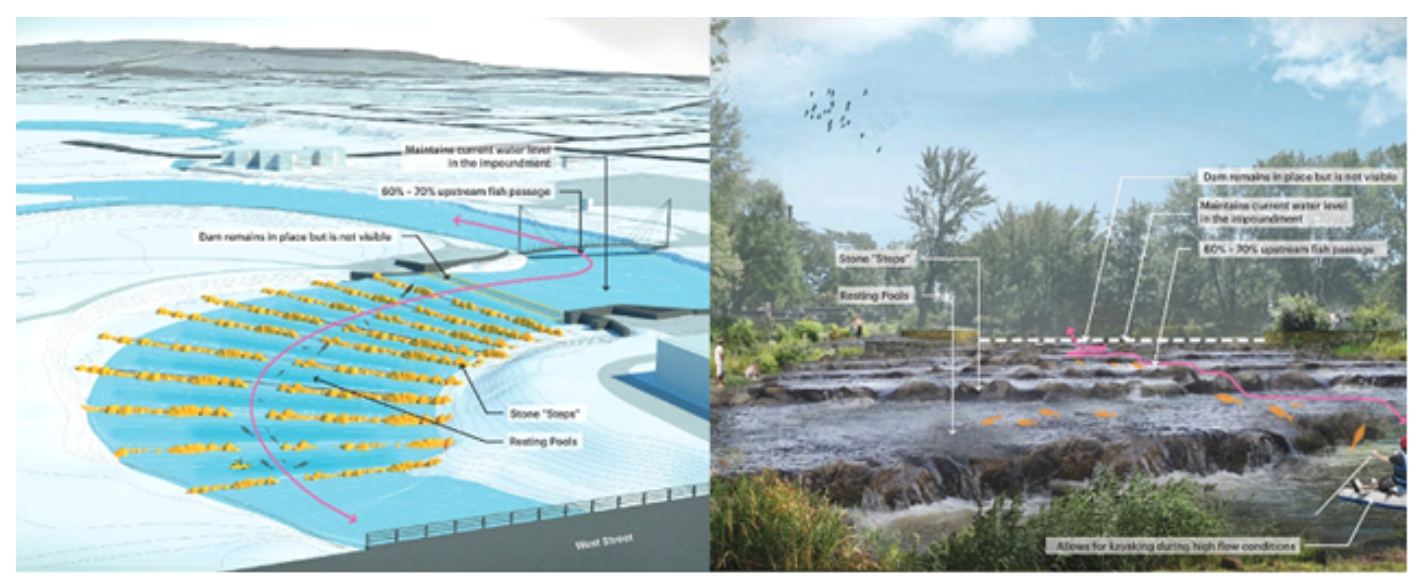

(d)

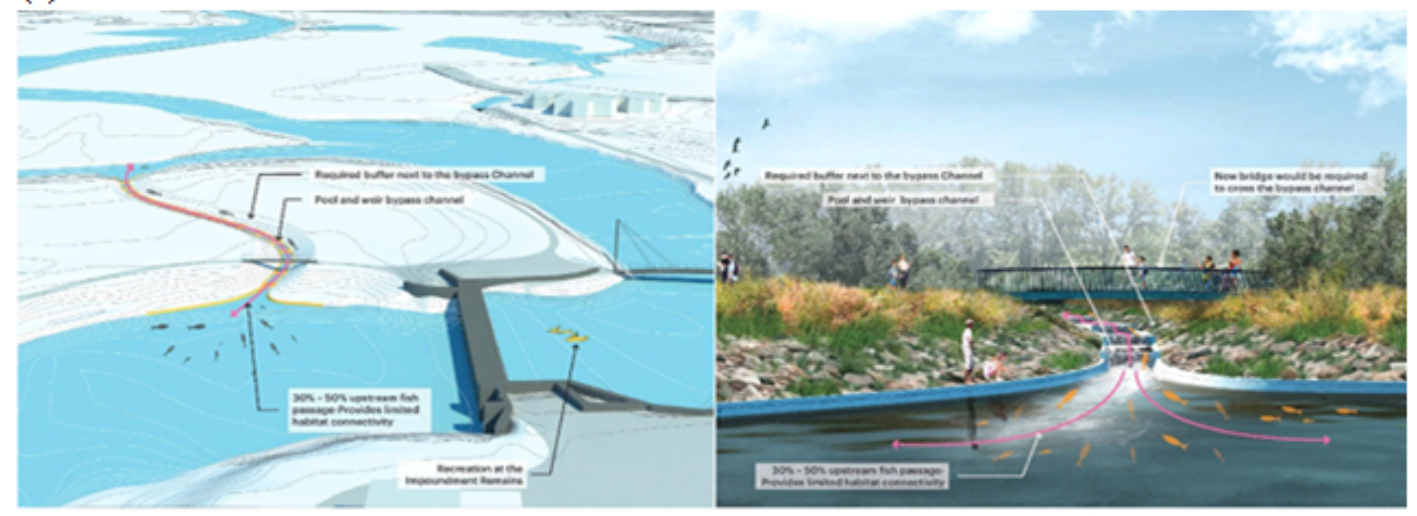

(e)

Figure 3.2: Visual representation of alternatives displayed in the image treatment (d) Pool and Weir Bypass Channel and (e) Remove Dam

The second visual treatment was a six-minute video ${ }^{18}$. This video has three sections. The first section provides a broad regional context about dams, the second section provides information about the watershed and downstream dams, and the third section provides the two images (eye-level and birds-eye-view) and descriptions of the five alternatives. The video was produced using Adobe Aftereffects and offered a voice-over guided narration to communicate about key issues at the regional, watershed and site scale. We maintained consistency of information across all three treatments by ensuring that the narration of the video matches the text used in the images, such that the only difference is the ability to visualize the information provided. For the first two sections of the video (regional and watershed-scale) the information was communicated through 2D maps created using GIS software. For

\footnotetext{
${ }^{18}$ The video is available upon request from the authors.
} 
the third section, the same 3D images that were used in the image treatment were used for the video. In addition, during the transition from the regional scale to the site scale, drone footage provides a visual image of the surrounding site context.

\subsubsection{Attributes}

The six attributes used in the choice experiment include percentage increase in movement of fish passage up and down the stream, preserving wetland habitat, percentage of historical dam structure's visibility, the annual number of days available for access to recreational activities (mostly water sports since activities such as hiking and birdwatching remain unaffected), the percentage of the total cost funded by external sources, and the annual cost per year. These attributes were selected for the choice experiment based on previous literature on projects related to dams (Song et al., 2019), minutes from previous public meetings, a steering committee of town officials and regional experts, and a focus group session conducted with residents from Keene, NH. The focus group discussion, hosted at the local Public Library, provided information on the type of attributes related to the West Street dam which are valued by the residents of Keene. In addition to valuing the aesthetics associated with wetland habitat and the recreational activities surrounding the dam, participants also expressed the importance of this dam in the history and culture of Keene.

The levels associated with each attribute were identified based on the VHB technical report and from other on-site investigations conducted as a part of the multi-state New England Sustainability Consortium (NEST) research project known as 'The Future of Dams' 19 (Ropeik, 2018). The levels of attributes are categorized into separate ranges to emulate a realistic scenario for each alternative as shown in Fig 3.3 (Adamowicz et al., 1998). For instance, the alternative to keep and repair the dam (repair) is the least-cost option with no fish movement, lack of funding sources, better visibility of historic structure of the dam and more wetland area relative to dam removal. Removing the dam (remove), on the other hand, promotes

\footnotetext{
${ }^{19}$ The project website: https://www.newenglandsustainabilityconsortium.org/dams
} 
fish passage, reduces the wetland area, has more opportunity for funding and limited visibility of the historic structure of the dam. Similarly, for the three dam modification alternatives, (pool and weir bypass channel (bypass), nature-like fishway (fishway) and technical Denil fish ladder (ladder), the attribute ranges were based on the site assessment report and consultations with experts in this field ${ }^{20}$.

\begin{tabular}{|c|c|c|}
\hline Attributes & Dam Alternatives & $\begin{array}{l}\text { Attribute Levels in } \\
\text { ranges }\end{array}$ \\
\hline \multirow{4}{*}{$\begin{array}{l}\text { Percentage } \\
\text { increase in fish } \\
\text { passage up and } \\
\text { down the } \\
\text { stream }\end{array}$} & Repair & $0 \%$ \\
\hline & Bypass, Fishway and & $30 \%, 40 \%, 50 \%, 60 \%$ \\
\hline & Ladder & $70 \%$ \\
\hline & Remove & $90 \%, 100 \%$ \\
\hline \multirow{2}{*}{$\begin{array}{l}\text { The acreage of } \\
\text { upstream } \\
\text { wetland }\end{array}$} & $\begin{array}{l}\text { Repair, Bypass, Fishway } \\
\text { and Ladder }\end{array}$ & $\begin{array}{l}88 \text { acres, } 96 \text { acres, } 105 \\
\text { acres }\end{array}$ \\
\hline & Remove & 64 acres, 76 acres \\
\hline \multirow{4}{*}{$\begin{array}{l}\text { Visibility of } \\
\text { historic dam } \\
\text { structure }\end{array}$} & Repair & $100 \%$ \\
\hline & Bypass & $90 \%, 100 \%$ \\
\hline & Ladder & $60 \%, 70 \%, 80 \%$ \\
\hline & Fishway and Remove & $0 \%, 10 \%, 20 \%, 30 \%$ \\
\hline $\begin{array}{l}\text { Number of } \\
\text { recreation days } \\
\text { per year }\end{array}$ & $\begin{array}{l}\text { Repair, Bypass, Fishway, } \\
\text { Ladder } \\
\text { and Remove }\end{array}$ & $\begin{array}{l}60 \text { days, } 92 \text { days, } 153 \text { days, } \\
184 \text { days }\end{array}$ \\
\hline \multirow{3}{*}{$\begin{array}{l}\text { Percentage of } \\
\text { the total cost } \\
\text { funded by } \\
\text { external } \\
\text { sources }\end{array}$} & Repair & $0 \%$ \\
\hline & $\begin{array}{l}\text { Bypass, Fishway and } \\
\text { Ladder }\end{array}$ & $30 \%, 40 \%$ \\
\hline & Remove & $80 \%, 90 \%$ \\
\hline \multirow{3}{*}{$\begin{array}{l}\text { Annual cost } \\
\text { per household }\end{array}$} & Repair & $\$ 20, \$ 25, \$ 30, \$ 35, \$ 45$ \\
\hline & Bypass, Fishway and & $\$ 25, \$ 30, \$ 35, \$ 45, \$ 65$, \\
\hline & $\begin{array}{l}\text { Ladder } \\
\text { Remove }\end{array}$ & $\begin{array}{l}\$ 75, \$ 80, \$ 90 \\
\$ 15, \$ 20, \$ 25, \$ 30, \$ 35\end{array}$ \\
\hline
\end{tabular}

Figure 3.3: Attributes and attribute levels used in the choice experiment

The site assessment report provided information on wetland acreage upstream

\footnotetext{
${ }^{20}$ Academic researchers who are a part of this collaborative project (NEST: Future of Dams) were consulted to provide an approximate range for attributes such as visibility, cost, external funds and habitat connectivity for each dam alternative.
} 
and how they differ with dam modification and/or removal options. The attribute representing recreation denotes the number of viable days for activities such as hiking, birdwatching, canoeing, kayaking, swimming, and fishing. The levels for the number of recreation days per year were calculated based on the average air and water temperature, precipitation, and water elevations for the study area. The information on weather for Keene, NH was obtained from NOAA's (National Oceanic and Atmospheric Administration) National Centers for Environmental Information $(\mathrm{NCEI})^{21}$. Due to the small size of the dam, findings from the technical report reveal a limited change to water elevation. Therefore, no alternative specific ranges are provided for this attribute. However, the focus group findings reveal that this dam has a high recreational value and a common perception among the residents of Keene is a change in opportunity for recreation if the dam is removed or altered. The attribute for funding is introduced as a within-subject treatment, where each respondent was presented with the same choice experiment question twice, one with no information about the percentage of cost covered by external funding sources and the other with the information about the percentage of cost covered by external funding sources.

The choice experiment was designed using Ngene software with a Bayesian efficient design following the framework adapted from Scarpa and Rose (2008) that minimizes the D-error for a multinomial logit model. The prior estimates and expected signs of parameters used in this design were based on literature review and findings from the focus group. Conditional constraints were included in the design to account for the varying attribute levels according to the dam alternative. The design generated twenty-four choice sets categorized into four choice set groups. Each survey participant was asked to make twelve decisions corresponding to six pairs of choice sets (each pair containing one with funding attribute and one without the funding attribute). The option to keep and repair the dam (or repair), which was considered as the status quo alternative, was present in every choice set. Figure 3.4 provides an example of a sample choice set.

\footnotetext{
${ }^{21}$ The website: https://www.ncdc.noaa.gov/ provides details about the NCEI and details about how to obtain weather data and information.
} 


\begin{tabular}{|c|c|c|c|}
\hline DAM ALTERNATIVE & $\underline{\text { Repair Dam }}$ & $\underline{\text { Fish Ladder }}$ & $\frac{\text { Nature-like }}{\underline{\text { Fishway }}}$ \\
\hline $\begin{array}{c}\text { FISH PASSAGE } \\
\text { percentage increase in fish passage } \\
\text { up and down the stream }\end{array}$ & $0 \%$ & $30 \%$ & $60 \%$ \\
\hline $\begin{array}{c}\text { WETLAND } \\
\text { area of upstream wetlands }\end{array}$ & 105 acres & 88 acres & 96 acres \\
\hline $\begin{array}{c}\text { VISIBILITY OF HISTORIC } \\
\text { DAM STRUCTURE } \\
\text { percentage of dam structure visible }\end{array}$ & $100 \%$ & $80 \%$ & $10 \%$ \\
\hline $\begin{array}{l}\text { RECREATION DAYS PER } \\
\text { YEAR } \\
\text { number of days available per year } \\
\text { for water sports }\end{array}$ & 153 days & 184 days & 92 days \\
\hline $\begin{array}{c}\text { FEDERAL FUNDING } \\
\text { percentage of total cost funded } \\
\text { by external sources }\end{array}$ & $0 \%$ & $40 \%$ & $40 \%$ \\
\hline $\begin{array}{c}\text { ANNUAL COST TO YOU } \\
\text { amount paid each year for the next } 5 \\
\text { years }\end{array}$ & $\$ 20$ & $\$ 65$ & $\$ 75$ \\
\hline
\end{tabular}

Figure 3.4: Sample choice experiment

\subsubsection{Survey Design and Recruitment}

The online survey was designed using Qualtrics. Since we are interested in learning about residents' preferences, the participants eligible for taking this survey were residents of Keene who are 21 years of age and above. We chose this age limit to minimize the responses from college students since they are more likely to be out-of-state temporary residents. The survey has four main sections. The first section includes questions about awareness and levels of association and encounter with the West Street dam. The next section provides the participants with adequate background information about dams in New England, the West Street dam and the concerns listed in the Letter of Deficiency (LOD). The following section provides treatment-specific descriptions (text-only, text with image or text with video) about the five possible alternatives for the dam along with choice experiment questions on alternative management options for the dam. Each choice experiment is followed by 
the question "Which option do you think is the BEST?". The final section includes demographic questions. With four choice set groups and three treatment groups, we had a total of twelve online survey versions. We randomly assigned participants to each of the treatment groups to maintain treatment balance (Refer to Table 3.9 in Appendix C1).

A mixed-mode, non-probability sampling was employed to recruit participants for this survey. The first method is a two-step approach involving face-to-face distribution of invitation cards followed by an internet survey. We distributed survey invitation cards, (included as a supplementary file) at frequently visited places in Keene such as grocery stores, farmers' markets, town fairs, and churches. The invitation cards were distributed by researchers from regional universities, using a script for a thirtysecond explanation of the importance of participating in the survey. The researchers distributed the invitation cards during the period spanning from September 2019 to December 2019, including both week and weekend days, event, and non-event days. For example, on two occasions, the invitations were distributed during major events in Keene: The Fall Fest and the Pumpkin Fest. The invitation cards were given to subjects who met the eligibility criteria and agreed to participate in a 20 -minute online survey. The invitation card includes an online web address to the survey as well as a one-time password necessary to access the survey and avoid repeated survey participants. Monetary compensation in the form of an eGift card was promised to all those who completed the survey. A total of 1,203 invitation cards were distributed of which we received 316 completed survey responses that meet the eligibility criteria. This approach to survey data collection received a response rate of $26.2 \%$ which is above average for a web survey. A response rate of this magnitude usually requires prenotification or reminders (Kaplowitz et al., 2012; Porter and Whitcomb, 2003, 2007).

To attain an adequate sample size, we employed two other survey distribution modes. First, we recruited via flyers. Flyers with project contact information for those who are interested in partaking in the survey were distributed via a community 
listserv and in popular cafes in Keene. We received 17 completed surveys among the participants who responded to the flyer. We do not have information on how many people gained knowledge of the survey via the flyer, hence we cannot provide a response rate. Second, we recruited via email. We purchased resident email addresses and distributed customized survey links through Qualtrics. The email distribution method resulted in a 3.5\% (49 out of 1,384 emails) response rate. After eliminating incomplete and spurious surveys we have a total of 302 usable surveys. Of the 302 responses, 98 responses were from the text-only treatment, 104 from the text with image treatment and the remaining 100 from the text with video treatment.

The socioeconomic characteristics from the survey data were compared to the population data of Keene from the US Census. Summary statistics show that the demographic distribution in the collected survey data set reasonably resembles the population estimates (Table 3.1). 
Table 3.1: Socioeconomic Characteristics of Survey Participants

\begin{tabular}{llcc}
\hline \hline Variable & Percentage & $\begin{array}{c}\text { Survey Sample } \\
(\mathrm{n}=302)\end{array}$ & $\begin{array}{c}\text { ACS 2018 } \\
(\mathrm{N}=23,056)\end{array}$ \\
\hline Gender & Male & 46.7 & 47.1 \\
Income groups & Less than \$25,000 & 10.1 & 10.8 \\
& \$25,000 to \$49,999 & 17.1 & 13.2 \\
& \$50,000 to \$74,999 & 19.8 & 23.4 \\
& \$75,000 to \$99,999 & 22.8 & 17.7 \\
& \$100,000 to \$149,999 & 15.8 & 17.8 \\
& \$150,000 to \$199,999 & 7.7 & 8.6 \\
& \$200,000 or more & 6.7 & 8.6 \\
Education & High school or higher & 97.3 & 93.2 \\
Employment & Employed & 54.9 & 60.1 \\
& Unemployed & 0.99 & 2.9 \\
Housing Tenure & Renter-occupied & 33.7 & 46.4 \\
& Owner-occupied & 65.6 & 53.6 \\
& Median & 47 & 36 \\
\hline
\end{tabular}

Notes: The third and fourth columns are in percentage (\%) except for Age which is the median. The population statistics are derived from the American Community Survey (2018) and Census (2010). Since our data only includes those who are at least 21 years of age, we expect a variation in median age between our sample and ACS.

The survey respondents are slightly older and more educated than the target population. We also observe a higher proportion of the respondents who are homeowners and fall in the mid-income categories. Presuming our sample is a good representative of the population of Keene, we find that about 40 percent of residents are aware that efforts are being taken to alter the dam and 31 percent have experienced alterations pertaining to dams other than the West Street Dam. Further analysis of the distribution of our data reveals that participants have varying levels of connection with the West Street Dam (Fig 3.5). The levels of connection are in terms of how well the 


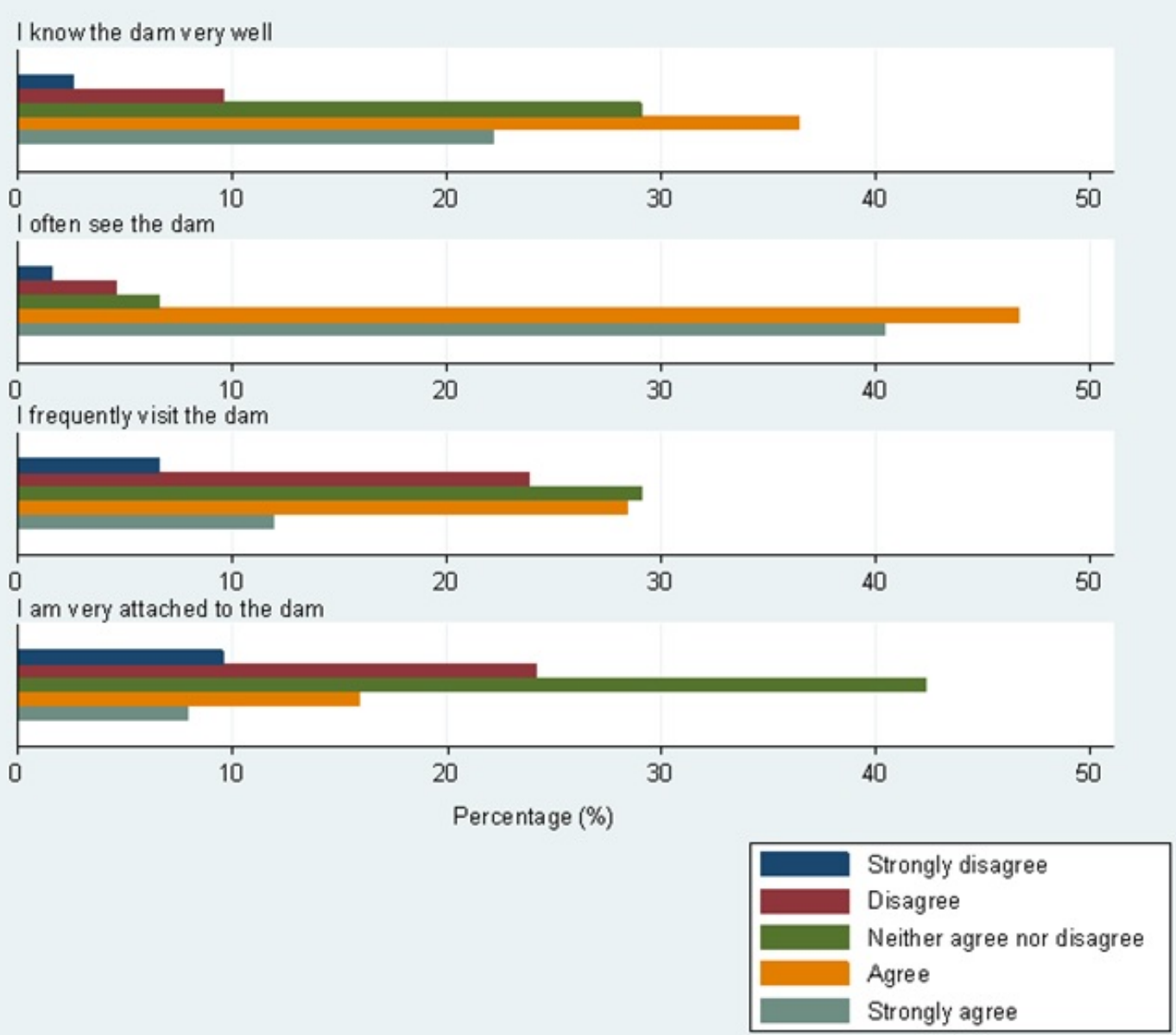

Figure 3.5: Levels of connection with the dam

participant knows the dam, how often they see or visit the dam and how attached they are to the dam. We find that approximately 59 percent of residents know the dam well, 87 percent often see the dam, 40 percent visit the dam and 24 percent claim to be attached to this dam ${ }^{22}$. We expected a high percentage of residents to see the dam often since it is located at the heart of the city of Keene. More than half of our sample population responded positively when asked whether they know the dam very well, however, this does not mean those who did not respond positively do not know of the existence of the dam, instead, we presume they have less knowledge about the dam. In this study, we use the different levels of connections with the dam to explore sources of preference heterogeneity.

\footnotetext{
${ }^{22}$ We combined both 'agree' and 'strongly agree' for these percentages
} 


\subsubsection{Econometric Model}

The discrete choice modeling approach used in this study is based on the random utility framework adapted from McFadden and Train (2000). The random utility theory presumes that an individual compares the expected utility among the given set of alternatives and chooses the alternative which provides him with maximum utility (McFadden, 2001). The utility function for individual $n$ when choosing the alternative $j \in 1, \ldots, J$ from a choice set $t \in 1, \ldots, T$ depends on observable (or deterministic) and unobservable (or stochastic) components as provided in equation 3.1:

$$
U_{n j t}=V_{n j t}+\varepsilon_{n j t}
$$

The unobservable random component, $\varepsilon_{n j t}$ be identically and independently distributed (iid) and follows the extreme value type 1 distribution (Hensher and Greene, 2003). The observable component in the utility function, $V_{n j t}$, is a linear additive combination of explanatory variables $(x)$ that determines the utility of the chosen alternative. The standard logit probability, conditional on the coefficient vector $\beta_{n}$, for the multinomial logit specification for individual $n$ choosing alternative $k$ among the $j$ alternatives, where $j, k \in 1, \ldots, J$, in choice set $t$, is provided in equation 3.2:

$$
L_{n k t}\left(\beta_{n}\right)=\frac{\exp \left(V_{n k t}\right)}{\sum_{j \in J n t} \exp \left(V_{n j t}\right)}
$$

To accommodate correlations across choices made by the same individual and to account for individual heterogeneity we use a panel mixed multinomial logit model. Panel models are often used in longitudinal data sets where repeated choices are made by the same person. This method, also called the error-component logit, relaxes the assumption that choices are independent within the same individual (Bliemer and Rose, 2010; Greene and Hensher, 2007; Train, 1998; Scarpa et al., 2005). The mixed logit probability is defined as the integral of the conditional probabilities over the distribution density of parameters. The parameters are estimated by maximizing the 
simulated log likelihood function, where the likelihood function is the joint density of conditional probabilities sampled across the choice sequences (Train, 1998). The mixed logit probability is provided in equation 3.3:

$$
P_{n j t}=\int \prod_{t=1}^{T} L_{n j t}\left(\beta_{n}\right) f(\beta) d \beta
$$

By including the mixing distribution, $f(\beta)$, we assume that the coefficient estimates of the attributes vary across individuals (Train, 2002). The explanatory variables specified in the observed component include binary indicators for each dam alternative $\left(D_{a l t}\right)$, the attributes used in the choice experiment $\left(X_{a t t}\right)$ and binary indicators representing visual and funding treatments $\left(D_{T}\right)$. To test the treatment effects on the choice of dam alternative, we interact the binary indicators for each alternative with the treatment indicators. The general utility specification for our model is defined in equation 3.4:

$$
U_{i j t}=\beta_{C} \operatorname{Cost}_{i j t}+\beta_{0} D_{A L T j}+\beta_{T} D_{A L T j} D_{T}+\left[\beta_{a t t} X_{a t t}\right]\left[\mu_{i j t}+\sigma_{i}\right]+\varepsilon_{i j t}
$$

The $\beta$ 's (apart from the cost coefficient) represents a vector of coefficients where $\beta_{0}$ is the vector of alternatives specific constants (ASC) pertaining to each dam alternative, $\beta_{T}$ represents image, video and funding treatment effects and $\beta_{\text {att }}$ are coefficient estimates for attributes. In our analysis, we specify all attributes used in the choice experiment as random parameters while keeping the remaining variables including cost as fixed. The application of mixed logit allows us to estimate mean $(\mu)$ and standard deviation $(\sigma)$ for the random parameters.

The coefficient estimates obtained from discrete choice models are then used to derive welfare measures. Given the linear nature of parameters and assuming constant marginal utility for price (or cost coefficient), we estimate the willingness to pay (WTP) for a unit change in an attribute $(x)$ by taking the negative ratio between the coefficient estimate of the attribute and the cost coefficient as provided in equation 


$$
W T P=-\frac{\beta_{x}}{\beta_{\text {cost }}}
$$

We use the delta method to estimate the confidence intervals for the welfare measures (Hole, 2016). The estimated marginal welfare amounts for each attribute are expressed in dollars per household per year. We also calculate the willingness to pay for an attribute after treatment effects (visual treatment or funding treatment) by adding together the marginal WTP of the attribute and marginal WTP of the treatment interacted with the attribute.

The main hypothesis in this study is to examine the visual treatment effects. Based on the framework provided in equation 3.4, we define our hypothesis as $H_{A}: \beta_{M T}, \beta_{V T} \neq 0$, where $\beta_{M T}$ and $\beta_{V T}$ are the estimated image and video treatment effects, respectively. We assess the difference between text and image treatment groups as well as between text and video treatment groups by interacting the indicator for dam labels $\left(D_{A L T}\right)$ with the image $\left(D_{M T}\right)$ and video $\left(D_{V T}\right)$ treatment indicators $\left(D_{M T}, D_{V T}\right.$ are included in $\left.D_{T}\right)$. The text treatment group is used as the base category in this model. We hypothesize a statistical significance in the subsequent coefficients, $\beta_{M T}$ and $\beta_{V T}$, thus estimating the visual treatment effects.

Given the severity of dam conflicts in New England, this research provides insight on residents' value towards attributes and different management options available for a dam in their neighborhood with the estimated ASCs $\left(\beta_{0 j} \neq \beta_{0 k} ; j \neq k\right)$ and attribute effects $\left(\beta_{\text {att }} \neq 0\right)$. The ASCs $\left(\beta_{0}\right)$ are estimated by including dam alternatives as labels in the choice experiment representing the marginal utility or preference for the alternative $j$, over the status quo alternative to repair and maintain the dam. We also explore funding treatment effects $\left(\beta_{F}, \beta_{F T} \neq 0\right)$ where we interact $D_{A L T}$ with the binary indicator for the within-subject funding treatment group $\left(D_{F}\right)$. In this specification, we include $D_{F}$ and an additional attribute $X_{F}$ denoting the 'percentage of cost covered by external funding sources', to equation 3.4.

To explore variation among residents' preferences, we attempt further interactions. Proxy variables that measure residents' connection with the dam and study 
area are taken from the survey data and interacted with $D_{A L T}$ to examine their effect on choice. These variables include the number of years lived in the study area, the level of knowledge related to this dam, incidence of seeing and visiting the dam, and the level of attachment towards this dam. Survey questions used to obtain these variables are included in Appendix C2.

\subsection{Empirical Results}

\subsubsection{Effect of Visualization}

The parameter estimates from the mixed logit models with visual treatment effects based on eq. 3.4 are provided in Table 3.2 (Model 1(b)). We find that introducing images in the choice experiment increases the marginal preference for dam modification alternatives, that is., fishway, ladder and bypass, compared to the text treatment, whereas we find no statistically significant difference between the text and video treatment for the same alternatives. However, for the dam alternative, remove, we find no difference between text and image treatments but a significant reduction in marginal utility in the video treatment.

The subsequent willingness to pay (WTP) estimates compared to the text treatment is calculated using the negative significant cost coefficient based on Model 1 in Table 3.2 and is provided in figure 3.6. The vertical line parallel to y-axis in this figure represents the status quo alternative to keep and repair the dam to its original state. The significance mentioned in this figure is based on the confidence intervals estimated using the delta method and implies that the WTP calculated is significantly different from zero. Among the dam modification alternatives, the positive impact on WTP in the image treatment is the largest for nature-like fishway. The WTP increases from $\$ 52$ in the text treatment to $\$ 130^{23}$ in the image treatment for fishway. The image treatment also increased WTP for a bypass channel from $\$ 45$ for text treatment

\footnotetext{
${ }^{23}$ Change in WTP from text to video/image = WTP for text - WTP for video/image; both image and video treatments already contain text description so the change in WTP can be obtained by taking the direct difference between the two.
} 
to $\$ 98$ for image treatment. Likewise, the image treatment raised the WTP for the fish ladder from $\$ 71$ with text description to $\$ 107$. An important finding with image treatment is the switch in most preferred dam alternatives from the Denil fish ladder to nature-like fishway .

Table 3.2: Mixed Logit Results with Treatment Effects

\begin{tabular}{lll}
\hline \hline Variables & Model $1 \quad$ Model 2
\end{tabular}

Std. Err. Std. Err.

\begin{tabular}{lllll}
\hline Cost $(\$)$ & $-0.028 * * *$ & 0.002 & $-0.028 * * *$ & 0.002
\end{tabular}

(a) Attributes

$\begin{array}{lcccc}\text { Fish Passage (\%) } & 0.029 * * * & 0.01 & 0.028 * * * & 0.01 \\ \text { Wetland (acres) } & 0.029 * * * & 0.009 & 0.030 * * * & 0.009 \\ \text { Historical Structure (\%) } & -0.008 & 0.007 & -0.009 & 0.007 \\ \text { Recreation Days } & 0.004 * * * & 0.001 & 0.004 * * * & 0.001 \\ \text { External Funding (\%) } & & & 0.011 & 0.011\end{array}$

(b) Standard deviation (S.D.) of random parameters

$\begin{array}{lllll}\text { Fish Passage (\%) } & 0.108 * * * & 0.008 & 0.109 * * * & 0.008 \\ \text { Wetland (acres) } & 0.116 * * * & 0.008 & 0.117 * * * & 0.008 \\ \text { Historical Structure (\%) } & 0.045 * * * & 0.006 & 0.046 * * * & 0.005 \\ \text { Recreation Days } & 0.016 * * * & 0.002 & 0.016 * * * & 0.002\end{array}$

(c) ASCs associated with binary indicators for each dam alternative $\left(\mathrm{D}_{\text {alt }}\right)$

$\begin{array}{lcccc}\text { Bypass (Yes=1) } & 1.231 * * * & 0.468 & 1.154 * * & 0.475 \\ \text { Fishway (Yes=1) } & 1.439 * & 0.831 & 1.144 & 0.83 \\ \text { Ladder (Yes=1) } & 1.955^{* * *} & 0.459 & 1.916 * * * & 0.462 \\ \text { Remove (Yes=1) } & -2.051 * & 1.094 & -2.417 * * & 1.098\end{array}$

(d) $\mathrm{D}_{\text {alt }}$ interacted with image and video treatment

\begin{tabular}{lcccc} 
Image*Bypass & $1.473^{* * *}$ & 0.563 & $1.498^{* * *}$ & 0.561 \\
Image*Fishway & $2.145^{* * *}$ & 0.793 & $2.177^{* * *}$ & 0.782 \\
Image*Ladder & $1.008^{* *}$ & 0.511 & $1.025^{* *}$ & 0.506 \\
\hline
\end{tabular}


Table 3.2 - Continued from previous page

\begin{tabular}{lcccc}
\hline Variables & \multicolumn{2}{c}{ Model 1 } & \multicolumn{2}{c}{ Model 2 } \\
& \multicolumn{3}{c}{ Std. Err. } & Std. Err. \\
\hline Image*Remove & 1.256 & 1.081 & 1.294 & 1.069 \\
Video*Bypass & -0.464 & 0.526 & -0.462 & 0.512 \\
Video*Fishway & -1.33 & 0.883 & -1.334 & 0.836 \\
Video*Ladder & -0.729 & 0.502 & -0.731 & 0.478 \\
Video*Remove & $-2.919 * * *$ & 1.126 & $-2.940 * * *$ & 1.086 \\
(e) D & & & \\
Fund interacted with funding treatment & & & -0.177 & 0.45 \\
Funding*Fishway & & & 0.122 & 0.469 \\
Funding*Ladder & & & -0.28 & 0.427 \\
Funding*Remove & & & -0.286 & 1.019 \\
Loglikelihood & -2335.95 & & -2328.72 & \\
Observations & 10,872 & & 10,872 & \\
\hline
\end{tabular}

Notes: Number of Individuals $=302$. The chosen dam alternative is the dependent variable.

$* * *, * *$ and $*$ denotes significance at 1,5 and 10 percent.

While the image treatment had no statistically significant treatment effect on WTP for dam removal, the video treatment reduced WTP for from $-\$ 74$ for the text description down to $-\$ 108$. The negative WTP for dam removal implies a positive WTP to maintain the status quo. In other words, full dam removal is less preferred than keeping and repairing the dam to its original state.

\subsubsection{Dam Alternative Preference Order}

The estimated alternative specific constants (ASC) are statistically significant, indicating that the average WTP differs across dam alternatives (Table 3.2 (Model 1(c)). In general, we find the dam modification alternatives to be more likely chosen than the status quo option, i.e., to keep and repair the dam to its original state. This pref- 
erence is denoted in fig.3.6, where the WTP for all three dam modification options is to the right of the reference line indicating the status quo. The estimated WTP (text treatments in fig. 3.6) is $\$ 71 /$ household/year on average for the fish ladder, followed by nature-like fishway and bypass channel at $\$ 52$ and $\$ 45$, respectively. Conforming to early literature (Fox et al., 2016), we observe that dam removal is least preferred, with a negative WTP of $-\$ 74$. Apart from the switch in the most preferred dam alternatives, a general rank order of dam alternatives from most preferred to least preferred was found to be fishway or ladder depending on the presentation of choice, bypass, repair (status quo) and remove.

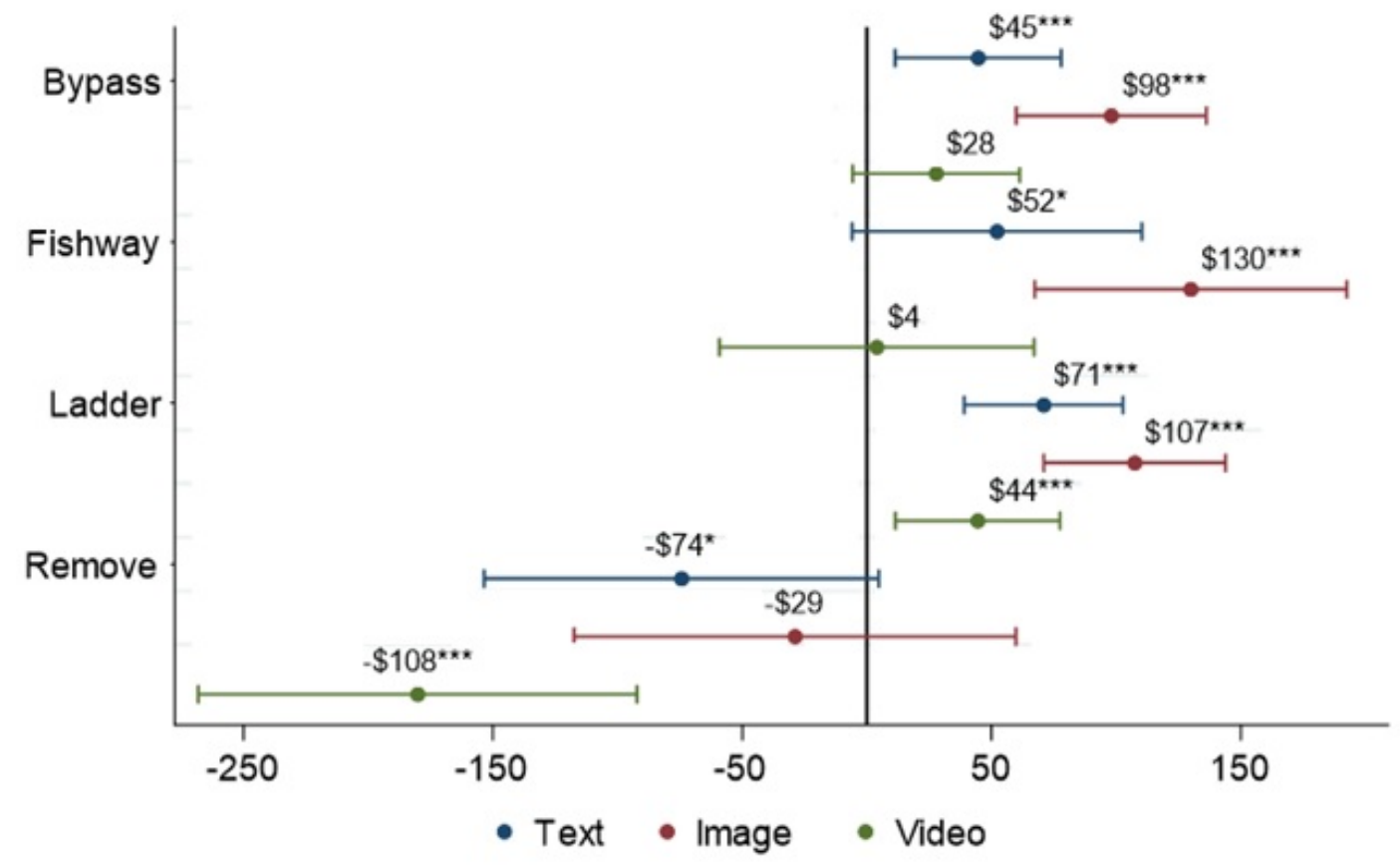

Figure 3.6: Willingness to pay per year $(\$)$

\subsubsection{Effect of External Funding}

Model 2 (c) presented in Table 3.2 includes the funding attribute representing the percentage of the cost funded from external sources and the funding treatment effects on dam alternatives. External funding is found to have no significant effect on choice. We find that for an additional percentage of cost covered by external sources, residents are willing to pay $\$ 0.39$ (Table 3.3). To place this finding in context, subjects are 
willing to pay about an additional $\$ 10$ annually for 5 years if the federal government agrees to cover $25 \%$ of the cost for a dam modification project. However, we were not able to confirm our hypothesis pertaining to funding since this additional WTP from external funding is insignificant. We also find that the presence of funding does not impact the choice of dam alternatives as denoted by the insignificant effect in Table 3.2.

\subsubsection{WTP for Attributes}

Irrespective of the choice of dam alternative, we observe a positive marginal utility in most attributes. The results reveal that an important trade-off considered by survey participants when choosing a dam alternative was between wetland habitat preservation and improving fish passage up and down the river. On average, the subjects are willing to pay $\$ 1.02$ for a one percent increase in fish passage whereas for an additional acre of wetland, they are willing to pay $\$ 1.08$ (Table 3.3). We also find the marginal WTP associated with an additional day of recreational activities is statistically significant $(\$ 0.15)$.

Table 3.3: Annual marginal WTP per household

\begin{tabular}{lc}
\hline \hline Attributes & Dollar $(\$)$ per unit \\
\hline Percentage increase in fish passage & $1.02^{* * *}$ \\
Acreage increase in the upstream wetland area & $1.08^{* * * *}$ \\
Percentage increase in visibility of historic dam structure & -0.32 \\
Increase in available days for recreation & $0.15^{* * *}$ \\
Percentage increase in cost funded by external sources & 0.39 \\
\hline
\end{tabular}

Notes: WTP estimates are based on Model 2 from Table 3.2. ***, ** and * denotes significance at 1,5 and 10 percent. All dollar amounts are in terms of cost per household per year for the next 5 years according to the choice experiment set up.

Surprisingly, despite the West Street dam being identified as a historical landmark for the city of Keene (Ropeik, 2018), the marginal WTP estimate for the percentage 
increase in visibility of historic dam structure is insignificant.

We also find the presence of preference heterogeneity across attributes as denoted by their significant standard deviations. The presence of preference heterogeneity corroborates the use of mixed logit model but also leads us to further examine the effect of individual perception of connection to this dam and study area on the choice of dam alternative. The results of this examination are presented in Appendix C3.

\subsection{Discussion and Conclusion}

Our paper investigated how modes of information delivery impact the willingness to pay for dam management alternatives. Our results confirm previous findings that the method of communicating information has significant impacts on the valuation of alternatives (Matthews et al., 2017; Rid et al., 2018; Shr et al., 2019). Specifically using randomized assignment of text, image with text, and video with text treatments, we found that the addition of visual information in the form of images, raises the average willingness to pay, whereas the addition of video, lowers the average willingness to pay across all alternatives compared to the status quo option to keep and repair dam to its original state. Among them, the residents' increased preferences for dam modification alternatives in the image with text treatment and their increased aversion to removing the dam over keeping the dam in the video with text treatment are statistically significant compared to its textual counterpart. Therefore, our findings indicate that by incorporating alternative specific labels, which in turn adds a certain degree of realism (Blamey et al., 2000), residents despite their familiarity with the dam and surrounding landscape, change their preference patterns depending on the mode of information delivery.

Our research suggests that visualizations can play an important role in decision making around dams. Dammed landscapes are complex social-ecological systems where social dimensions such as history, aesthetics, recreation, and sense of place are intertwined with perceptions and values around nature and ecological services 
(Fox et al., 2016). When considering various dam alternatives, there is a need to incorporate these multiple dimensions in the decision making process. Within our study, the participants who received the text treatment were primarily responding to the effect of the alternative on the ecological and socio-economic attributes and had to rely on any image they may have had of the alternative in their imagination. Visualizations help communicate the visual and aesthetic impact of the alternatives by encouraging a critical comparison between reality and the viewers' concept of these hypothetical future landscapes (Lovett et al., 2015; Salter et al., 2009; Wissen et al., 2008). Although visualizations add to the degree of realism (Shr et al., 2019; Townsend and Kahn, 2014), further investigation is required to ascertain whether it is the image treatment or the video treatment that is considered closer to the true preference of survey respondents.

Introducing images when describing dam alternatives, allows survey respondents to focus more on the visually salient features present in each alternative when making choices (Rid et al., 2018). While Shr et al. (2019) suggest that respondents assert attention towards attributes that are visually salient, our study appropriates images to the dam alternative label. This may be a reason why dam alternatives, especially the modification alternatives, have a higher preference in the image treatment. The switch in the most preferred dam alternative from the Denil fish ladder to nature-like fishway, is that the use of images may have led to an improved understanding of the nature-like fishway, a less known dam alternative compared to Denil fish ladder (Wissen et al., 2008). Between 1992 to 2017, NOAA funded 85 Denil fish ladders and 17 Nature like fishways within the Northeast Region (Turek, 2018). Some of the survey participants may have been more familiar with the fish ladder alternative allowing for them to imagine the visual impact of the fish ladder with only the text description.

The video treatment with guided narration allowed respondents to retrieve information in a gestalt manner (Townsend and Kahn, 2014). Similar to studies such as Shr et al. (2019) and Rid et al. (2018), we find no statistically significant differ- 
ences between the estimates of this treatment compared to the text treatment for dam modification alternatives. The video treatment, however, reinforces the community's aversion to dam removal. The overall decrease in average willingness to pay for each dam alternative in the video treatment is contrary to the results obtained from the image treatment. This divergent result may stem from the way respondents comprehend information retrieved from the video as opposed to images. Another possible explanation behind the overall lower willingness to pay across dam alternatives in the video treatment might be because the addition of video may have drawn out the true willingness to pay values from the respondents. Stated preference methods such as choice experiments sometimes overstate the respondents' willingness to pay (Carlsson and Martinsson, 2001; Johannesson et al., 1998; Lusk and Schroeder, 2004). Therefore, we can speculate that the relatively conservative willingness to pay amounts for dam alternatives in the video treatment is presumably closer to their true preference. Future research using incentive-based approaches are required to confirm this speculation.

Our study concludes that dam modification alternatives that improve fish passage while still maintaining the dam and impoundment are more preferred than the status quo option to keep and repair the dam to its original state. Although residents value migratory fish passage, dam removal, which is most suitable for fish passage, is consistently the least preferred alternative. This finding supports previous studies that suggest that resistance to dam removal is more than just an aversion to change, but rather in direct response to the perceived threat of removal to the historic cultural landscape and individual and collective sense of place (Devine-Wright and Howes, 2010; Fox et al., 2016). While many decisions about dams tend to focus on the binary options of keeping or removing the dam, our study suggests the importance of introducing dam modification alternatives that can achieve multiple objectives.

Lastly, we found that maintaining the visibility of the historical structure was insignificant for the West Street dam. This finding supports previous studies which suggest that place attachment extends beyond the visual to include other affective, 
experiential and cognitive ways of relating to landscapes (Newell and Canessa, 2018; Jorgensen and Stedman, 2001; Devine-Wright and Howes, 2010; Fox et al., 2016). These findings are further supported by correspondence with Keene residents, via focus group sessions, that reveal the importance of their experiences with this dam such as fishing (often with family), swimming at the dam, eating lunch next to the dam on a daily basis, skating on the pond in the winter, taking pictures of their family's generations with the background of the dam structure, canoeing and duck races. Regarding any changes to this dam, the participants are concerned about how these recreational activities, experiences and memories may be impacted when the change is made. There are opportunities for future research to explore the relationship between place attachment and historical landscapes surrounding dams using established methods that measure sense of place (Newell and Canessa, 2018; Jorgensen and Stedman, 2001; Devine-Wright and Howes, 2010).

Our study reinforces the need for credible and legitimate visualizations that can correctly capture the projected future alternatives. Due to the increased recognition accompanied by less reliance on idiosyncratic processing, visualizations help survey respondents better perceive the differences between each dam alternative and subsequent attribute levels. Incorporating visual representation of policy alternatives in a label choice experiment allows participants to make informed decisions that are likely to be closer to their true preferences (Blamey et al., 2000; Townsend and Kahn, 2014). The findings from this research contribute towards multiple fields of economic literature with the use of visualization, actual policy scenarios as labels in choice experiments pertaining to policy relevant topics such as decision making around dams. 


\section{References}

Adamowicz, W., Louviere, J., and Swait, J. (1998). Introduction to Attribute-Based Stated Choice Methods.

Al-Kodmany, K. (1999). Using visualization techniques for enhancing public participation in planning and design: process, implementation, and evaluation. Landscape and Urban Planning, 45(1):37-45.

Bateman, I. J., Day, B. H., Jones, A. P., and Jude, S. (2009). Reducing gain-loss asymmetry: A virtual reality choice experiment valuing land use change. Journal of Environmental Economics and Management, 58(1):106-118.

Blamey, R. K., Bennett, J. W., Louviere, J. J., Morrison, M. D., and Rolfe, J. (2000). A test of policy labels in environmental choice modelling studies. Ecological Economics, 32(2):269-286.

Bliemer, M. C. J. and Rose, J. M. (2010). Construction of experimental designs for mixed logit models allowing for correlation across choice observations. Transportation Research Part B: Methodological, 44(6):720-734.

Fox, C. A., Magilligan, F. J., and Sneddon, C. S. (2016). "You kill the dam, you are killing a part of me": Dam removal and the environmental politics of river restoration. Geoforum, 70:93-104.

Greene, W. H. and Hensher, D. A. (2007). Heteroscedastic control for random coefficients and error components in mixed logit. Transportation Research Part E: Logistics and Transportation Review, 43(5):610-623. 
Hayek, U. W. (2011). Which is the Appropriate 3D Visualization Type for Participatory Landscape Planning Workshops? A Portfolio of Their Effectiveness. Environment and Planning B: Planning and Design, 38(5):921-939. Publisher: SAGE Publications Ltd STM.

Hensher, D. A. and Greene, W. H. (2003). The Mixed Logit model: The state of practice. Transportation, 30(2):133-176.

Hole, A. (2016). MIXLOGITWTP: Stata module to estimate mixed logit models in WTP space.

Kafle, A., Swallow, S. K., and Smith, E. C. (2015). Does Public Funding Affect Preferred Tradeoffs and Crowd-In or Crowd-Out Willingness to Pay? A Watershed Management Case. Environmental and Resource Economics, 60(3):471-495.

Kaplowitz, M. D., Lupi, F., Couper, M. P., and Thorp, L. (2012). The Effect of Invitation Design on Web Survey Response Rates. Social Science Computer Review, 30(3):339-349.

Lizin, S., Brouwer, R., Liekens, I., and Broeckx, S. (2016). Accounting for substitution and spatial heterogeneity in a labelled choice experiment. Journal of Environmental Management, 181:289-297.

Lovett, A., Appleton, K., Warren-Kretzschmar, B., and Von Haaren, C. (2015). Using 3D visualization methods in landscape planning: An evaluation of options and practical issues. Landscape and Urban Planning, 142:85-94.

Magilligan, F. J., Graber, B. E., Nislow, K. H., Chipman, J. W., Sneddon, C. S., and Fox, C. A. (2016). River restoration by dam removal: Enhancing connectivity at watershed scales. Elem Sci Anth, 4(0):000108.

Matthews, Y., Scarpa, R., and Marsh, D. (2017). Using virtual environments to improve the realism of choice experiments: A case study about coastal erosion 
management. Journal of Environmental Economics and Management, 81:193208.

McFadden, D. (1980). Econometric Models for Probabilistic Choice Among Products. The Journal of Business, 53(3):S13-S29.

McFadden, D. (2001). Economic Choices. American Economic Review, 91(3):351378.

McFadden, D. and Train, K. (2000). Mixed MNL models for discrete response. Journal of Applied Econometrics, 15(5):447-470.

Patterson, Z., Darbani, J. M., Rezaei, A., Zacharias, J., and Yazdizadeh, A. (2017). Comparing text-only and virtual reality discrete choice experiments of neighbourhood choice. Landscape and Urban Planning, 157:63-74.

Porter, S. R. and Whitcomb, M. E. (2003). The Impact of Contact Type on Web Survey Response Rates. Public Opinion Quarterly, 67(4):579-588. Publisher: Oxford Academic.

Porter, S. R. and Whitcomb, M. E. (2007). Mixed-Mode Contacts In Web SurveysPaper is Not Necessarily Better. Public Opinion Quarterly, 71(4):635-648. Publisher: Oxford Academic.

Rid, W., Haider, W., Ryffel, A., and Beardmore, B. (2018). Visualisations in Choice Experiments: Comparing 3d Film-sequences and Still-images to Analyse Housing Development Alternatives. Ecological Economics, 146(C):203-217.

Ropeik, A. (2018). Keene Mulls Historic Dam: Future After Hydropower Demo Plan Falls Through.

Salter, J. D., Campbell, C., Journeay, M., and Sheppard, S. R. J. (2009). The digital workshop: Exploring the use of interactive and immersive visualisation tools in participatory planning. Journal of Environmental Management, 90(6):2090-2101. 
Scarpa, R., Ferrini, S., and Willis, K. (2005). Performance of Error Component Models for Status-Quo Effects in Choice Experiments. In Scarpa, R. and Alberini, A., editors, Applications of Simulation Methods in Environmental and Resource Economics, The Economics of Non-Market Goods and Resources, pages 247-273. Springer Netherlands, Dordrecht.

Scarpa, R. and Rose, J. M. (2008). Design efficiency for non-market valuation with choice modelling: how to measure it, what to report and why*. Australian Journal of Agricultural and Resource Economics, 52(3):253-282.

Shr, Y.-H. J., Ready, R., Orland, B., and Echols, S. (2019). How Do Visual Representations Influence Survey Responses? Evidence from a Choice Experiment on Landscape Attributes of Green Infrastructure. Ecological Economics, 156:375386.

Song, C., Omalley, A., Roy, S. G., Barber, B. L., Zydlewski, J., and Mo, W. (2019). Managing dams for energy and fish tradeoffs: What does a win-win solution take? Science of The Total Environment, 669:833-843.

Townsend, C. and Kahn, B. E. (2014). The "Visual Preference Heuristic": The Influence of Visual versus Verbal Depiction on Assortment Processing, Perceived Variety, and Choice Overload. Journal of Consumer Research, 40(5):993-1015.

Train, K. (2002). Discrete Choice Methods with Simulation. Cambridge University Press.

Train, K. E. (1998). Recreation Demand Models with Taste Differences over People. Land Economics, 74(2):230-239.

Upton, V., Dhubháin, N., and Bullock, C. (2012). Preferences and values for afforestation: The effects of location and respondent understanding on forest attributes in a labelled choice experiment. Forest Policy and Economics, 23:17-27. 
Weir, M. J., Ashcraft, C. M., Diessner, N. L., McGreavy, B., Vogler, E., and Guilfoos, T. (2020). Language effects on bargaining. PLOS ONE, 15(3):e0229501. Publisher: Public Library of Science.

Wissen, U., Schroth, O., Lange, E., and Schmid, W. A. (2008). Approaches to integrating indicators into 3D landscape visualisations and their benefits for participative planning situations. Journal of Environmental Management, 89(3):184-196. 


\section{Appendix C1: Sub sample balance across treatments}

Table 3.4: Socioeconomic Characteristics across Treatments

\begin{tabular}{llccc}
\hline \hline Variable & Percentage & $\begin{array}{c}\text { Text } \\
(\mathrm{n}=98)\end{array}$ & $\begin{array}{c}\text { Image with text } \\
(\mathrm{n}=104)\end{array}$ & $\begin{array}{c}\text { Video with text } \\
(\mathrm{n}=100)\end{array}$ \\
\hline Gender & Male & 44.9 & 47.1 & 48 \\
Education & High school or higher & 80.6 & 87.4 & 84 \\
Employment & Employed (full time $)$ & 53.1 & 52.9 & 59 \\
Housing Tenure & Renter-occupied & 37.76 & 24.04 & 40 \\
& Owner-occupied & 61.22 & 74.96 & 59 \\
Age & Median & 47.5 & 51 & 42 \\
\hline
\end{tabular}

Notes: The total sample is 302 . The estimates provided in the third, fourth and fifth columns are in percentage (\%) except for Age which is the median age.

\section{Appendix C2: Select Survey Questions}

How many years have you lived in Keene, $\mathrm{NH}$ ?
$0-5$ years
$6-10$ years
$11-15$ years
More than 15 years

Figure 3.7: Survey Question: Number of years in Keene 
Please indicate your level of agreement or disagreement with each of the following statements by checking ONE box per line.

\begin{tabular}{|c|c|c|c|c|}
\hline & $\begin{array}{l}\text { Strongly } \\
\text { agree }\end{array}$ & Agree & $\begin{array}{l}\text { Neither agree } \\
\text { nor disagree }\end{array}$ & Disagree \\
\hline $\begin{array}{l}\text { I know the West Street } \\
\text { Dam very well }\end{array}$ & $\bigcirc$ & 0 & 0 & $\mathrm{O}$ \\
\hline $\begin{array}{l}\text { I often see the West } \\
\text { Street Dam }\end{array}$ & 0 & $\mathrm{O}$ & $\bigcirc$ & \\
\hline $\begin{array}{l}\text { I frequently visit the } \\
\text { West Street Dam }\end{array}$ & 0 & 0 & 0 & 0 \\
\hline $\begin{array}{l}\text { I am very attached to } \\
\text { the West Street Dam }\end{array}$ & 0 & $\mathrm{O}$ & 0 & $\bigcirc$ \\
\hline
\end{tabular}

Figure 3.8: Survey Question: Levels of connection to the Dam

\section{Appendix C3: Additional Results}

Table 3.4 includes dam alternative interactions with the number of years the resident has lived in the study area. Our findings reveal that those who lived in the study area for five years or less (also considered as base category when comparing years lived as a resident) have a higher marginal preference for fishway and ladder compared to status quo. By comparison to this baseline, those who lived as a resident in the 6 to 10 years have lesser preference for fishway and remove but a larger preference for bypass. We find an even higher marginal preference for bypass among those in the 11 to 15 years category.

Table 3.5: Mixed Logit Results: Interactions with number of years as a resident

\begin{tabular}{lcc}
\hline \hline Variables & \multicolumn{1}{c}{ Std. Err. } \\
\hline Cost $(\$)$ & $-0.029 * * *$ & 0.002 \\
(a) ASCs for $\mathrm{D}_{\text {alt }}$ and represents base category: & Years as a Resident (0 to 5) \\
Bypass (Yes=1) & 0.448 & 0.569 \\
Fishway (Yes=1) & $1.947 * *$ & 0.95 \\
Ladder (Yes=1) & $1.503^{* * *}$ & 0.543 \\
\hline
\end{tabular}


Table 3.5 - Continued from previous page

\begin{tabular}{|c|c|c|}
\hline \multicolumn{2}{|l|}{ Variables } & \multirow{2}{*}{$\begin{array}{c}\text { Std. Err. } \\
1.356\end{array}$} \\
\hline Remove $($ Yes=1) & -1.514 & \\
\hline \multicolumn{3}{|c|}{ (b) $\mathrm{D}_{\text {alt }}$ interacted with image and video treatments } \\
\hline Image*Bypass & $1.583 * * *$ & 0.542 \\
\hline Image*Fishway & $2.189 * * *$ & 0.752 \\
\hline Image*Ladder & $0.839^{*}$ & 0.47 \\
\hline Image*Remove & 1.312 & 1.256 \\
\hline Video*Bypass & 0.279 & 0.47 \\
\hline Video*Fishway & 0.167 & 0.624 \\
\hline Video*Ladder & 0.001 & 0.39 \\
\hline Video*Remove & -0.705 & 0.953 \\
\hline \multicolumn{3}{|l|}{ (c) Years as a Resident } \\
\hline Years as a Resident (6 to 10 )*Bypass & $1.772 * * *$ & 0.583 \\
\hline Years as a Resident (6 to 10$)^{*}$ Fishway & $-1.549 * *$ & 0.779 \\
\hline Years as a Resident (6 to 10$) *$ Ladder & 0.246 & 0.504 \\
\hline Years as a Resident (6 to 10$) *$ Remove & $-2.009 *$ & 1.115 \\
\hline Years as a Resident (11 to 15$)^{*}$ Bypass & $2.277 * * *$ & 0.669 \\
\hline Years as a Resident (11 to 15 )*Fishway & -0.436 & 0.871 \\
\hline Years as a Resident (11 to 15 )*Ladder & 0.927 & 0.585 \\
\hline Years as a Resident (11 to 15 )*Remove & -0.25 & 1.359 \\
\hline Years as a Resident (more than 15 )*Bypass & -0.242 & 0.472 \\
\hline Years as a Resident (more than 15 )*Fishway & $-1.860 * * *$ & 0.617 \\
\hline Years as a Resident (more than 15 )*Ladder & 0.172 & 0.398 \\
\hline Years as a Resident (more than 15 )*Remove & $-2.486 * * *$ & 0.956 \\
\hline
\end{tabular}


Table 3.5 - Continued from previous page

\begin{tabular}{lll}
\hline Variables & Std. Err. \\
\hline Loglikelihood & -2294.55 & \\
Observations & 10,872 & \\
\hline
\end{tabular}

Notes: Number of Individuals $=302$. All variables in Table 4 (Model 1) are estimated in the model.

Our results also report that those who live in the study are for a relatively long time, that is., more than 15 years, experience a significant fall in marginal preference for remove compared to keep and repair. Irrespective of the number of years lived, we find that including image treatments consistently increases the marginal preference for the dam modification alternatives.

Tables 3.5 presents the mixed logit results when accounting for participants' degree of connection with the neighborhood dam. Variables such as the level of knowledge about the dam (Model 1), the incidence of seeing the dam (Model 2), the incidence of visiting the dam (Model 3) and the level of attachment towards the dam (Model 4) were interacted with dam alternatives and included as four separate models

We find that the residents who have claim to have a higher level of knowledge and more incidence of seeing the dam to have a significantly higher marginal preference for all dam modification alternatives, compared to the status quo option to keep and repair the dam. On the other hand, there is a fall in marginal preference for remove among those who have a higher incidence of visiting and attachment to the dam. Additionally, we notice an overall negative marginal preference for all dam alternatives among those who have a higher level of attachment to the dam, out of which we find the negative estimate significant for both fishway and remove compared to keeping and repairing the dam to its original state. 
Table 3.6: Mixed Logit Results: Connection to the Dam

\begin{tabular}{lcccc}
\hline \hline Variables & Model 1 & Model 2 & Model 3 & Model 4 \\
& Know & See & Visit & Attach \\
\hline Cost $(\$)$ & $-0.028 * * *$ & $-0.028^{* * *}$ & $-0.028 * * *$ & $-0.028 * * *$ \\
& $(0.002)$ & $(0.002)$ & $(0.002)$ & $(0.002)$ \\
Level of connection*Bypass & $0.312^{*}$ & $0.561 * * *$ & -0.204 & -0.228 \\
& $(0.184)$ & $(0.193)$ & $(0.175)$ & $(0.184)$ \\
Level of connection*Fishway & $0.764 * * *$ & $0.485^{*}$ & -0.023 & $-0.923 * * *$ \\
& $(0.259)$ & $(0.261)$ & $(0.256)$ & $(0.272)$ \\
Level of connection*Ladder & $0.572 * * *$ & $0.349 * *$ & 0.087 & -0.267 \\
& $(0.162)$ & $(0.159)$ & $(0.156)$ & $(0.162)$ \\
Level of connection*Remove & 0.269 & -0.101 & $-0.596 *$ & $-2.139 * * *$ \\
& $(0.351)$ & $(0.434)$ & $(0.340)$ & $(0.400)$ \\
\hline Loglikelihood & -2325.77 & -2322.25 & -2323.93 & -2313.81 \\
\hline
\end{tabular}

Notes: Due to possible correlations between levels of connection, four separate models for each of the levels, that is., level of knowledge about the dam (Know), the incidence of seeing the dam (See), the incidence of visiting the dam (Visit) and the level of attachment towards the dam (Attach) that are interacted with dam alternatives are included column wise from left to right, respectively. All variables in Table 3.2 (Model 1) are included in this model. 


\section{BIBLIOGRAPHY}

Adamowicz, W., Boxall, P., Williams, M., and Louviere, J. (1998). Stated Preference Approaches for Measuring Passive Use Values: Choice Experiments and Contingent Valuation. American Journal of Agricultural Economics, 80(1):64-75.

Adamowicz, W. L. (1994). Habit Formation And Variety Seeking In A Discrete Choice Model Of Recreation Demand. Journal of Agricultural and Resource Economics, Volume 19(Number 1):1-13.

Al-Kodmany, K. (1999). Using visualization techniques for enhancing public participation in planning and design: process, implementation, and evaluation. Landscape and Urban Planning, 45(1):37-45.

Atkinson, A. C. (1981). Likelihood ratios, posterior odds and information criteria. Journal of Econometrics, 16(1):15-20.

Bateman, I. J., Day, B. H., Jones, A. P., and Jude, S. (2009). Reducing gain-loss asymmetry: A virtual reality choice experiment valuing land use change. Journal of Environmental Economics and Management, 58(1):106-118.

Blamey, R. K., Bennett, J. W., Louviere, J. J., Morrison, M. D., and Rolfe, J. (2000). A test of policy labels in environmental choice modelling studies. Ecological Economics, 32(2):269-286.

Bleichrodt, H., Filko, M., Kothiyal, A., and Wakker, P. P. (2017). Making Case-Based Decision Theory Directly Observable. American Economic Journal: Microeconomics, 9(1):123-151. 
Bliemer, M. C. J. and Rose, J. M. (2010). Construction of experimental designs for mixed logit models allowing for correlation across choice observations. Transportation Research Part B: Methodological, 44(6):720-734.

Bockstael, N. E. and Opaluch, J. J. (1983). Discrete modelling of supply response under uncertainty: The case of the fishery. Journal of Environmental Economics and Management, 10(2):125-137.

Bozdogan, H. (1987). Model selection and Akaike's Information Criterion (AIC): The general theory and its analytical extensions. Psychometrika, 52(3):345-370.

Bujosa, A., Riera, A., Hicks, R. L., and McConnell, K. E. (2015). Densities Rather than Shares: Improving the Measurement of Congestion in Recreation Demand Models. Environmental and Resource Economics, 61(2):127-140.

Carlsson, F. and Martinsson, P. (2001). Do Hypothetical and Actual Marginal Willingness to Pay Differ in Choice Experiments?: Application to the Valuation of the Environment. Journal of Environmental Economics and Management, 41(2):179192.

Cerigioni, F. and Fabra, U. P. (2019). Retrieving Preferences when some Choices are Automatic. Universitat Pompeu Fabra, (1673):47.

Cinti, A., Shaw, W., Cudney-Bueno, R., and Rojo, M. (2010). The unintended consequences of formal fisheries policies: Social disparities and resource overuse in a major fishing community in the Gulf of California, Mexico. Marine Policy, $34(2): 328-339$.

Decker, D. J. and Connelly, N. A. (1989). Motivations for Deer Hunting: Implications for Antlerless Deer Harvest as a Management Tool. Wildlife Society Bulletin (19732006), 17(4):455-463.

Devine-Wright, P. and Howes, Y. (2010). Disruption to place attachment and the 
protection of restorative environments: A wind energy case study. Journal of Environmental Psychology, 30(3):271-280.

Fezzi, C., Bateman, I. J., and Ferrini, S. (2014). Using revealed preferences to estimate the Value of Travel Time to recreation sites. Journal of Environmental Economics and Management, 67(1):58-70.

Fosgerau, M. and Bierlaire, M. (2007). A practical test for the choice of mixing distribution in discrete choice models. Transportation Research Part B: Methodological, 41(7):784-794.

Fox, C. A., Magilligan, F. J., and Sneddon, C. S. (2016). "You kill the dam, you are killing a part of me": Dam removal and the environmental politics of river restoration. Geoforum, 70:93-104.

Gilboa, I., Gayer, G., and Lieberman, O. (2007). Rule-Based and Case-Based Reasoning in Housing Prices. B.E. Journal of Theoretical Economics, Vol.7, $\mathrm{n}^{\circ} 1: p p .1-37$.

Gilboa, I. and Schmeidler, D. (1995). Case-Based Decision Theory. The Quarterly Journal of Economics, 110(3):605-639.

Gilboa, I. and Schmeidler, D. (2001). A Theory of Case-Based Decisions. Cambridge University Press.

Greene, W. H. and Hensher, D. A. (2007). Heteroscedastic control for random coefficients and error components in mixed logit. Transportation Research Part E: Logistics and Transportation Review, 43(5):610-623.

Guadagni, P. M. and Little, J. D. C. (1983). A Logit Model of Brand Choice Calibrated on Scanner Data. Marketing Science, 2(3):203-238. Publisher: INFORMS.

Guerdjikova, A. (2007). Preference for Diversification with Similarity Considerations. In Abdellaoui, M., Luce, R. D., Machina, M. J., and Munier, B., editors, 
Uncertainty and Risk: Mental, Formal, Experimental Representations, Theory and Decision Library C, pages 63-83. Springer, Berlin, Heidelberg.

Guerdjikova, A. (2008). Case-based learning with different similarity functions. Games and Economic Behavior, 63(1):107-132.

Guilfoos, T. and Pape, A. (2019). Case-based learning and estimation. Working Paper.

Guilfoos, T. and Pape, A. D. (2016). Predicting human cooperation in the Prisoner's Dilemma using case-based decision theory. Theory and Decision, 80(1):1-32.

Hailu, G., Boxall, P. C., and McFarlane, B. L. (2005). The influence of place attachment on recreation demand. Journal of Economic Psychology, 26(4):581598.

Hanemann, W. M. (1983). Marginal welfare measures for discrete choice models. Economics Letters, 13(2):129-136.

Harsanyi, J. C. (1978). Bayesian Decision Theory and Utilitarian Ethics. The American Economic Review, 68(2):223-228. Publisher: American Economic Association.

Hayek, U. W. (2011). Which is the Appropriate 3D Visualization Type for Participatory Landscape Planning Workshops? A Portfolio of Their Effectiveness. Environment and Planning B: Planning and Design, 38(5):921-939. Publisher: SAGE Publications Ltd STM.

Heckman, J. J. (1981). Heterogeneity and State Dependence. Studies in Labor Markets, pages 91-140. Publisher: University of Chicago Press.

Hensher, D. A. and Greene, W. H. (2003). The Mixed Logit model: The state of practice. Transportation, 30(2):133-176. 
Hess, S., Daly, A., and Batley, R. (2018). Revisiting consistency with random utility maximisation: theory and implications for practical work. Theory and Decision, 84(2):181-204.

Hole, A. (2016). MIXLOGITWTP: Stata module to estimate mixed logit models in WTP space.

Hole, A. R. (2007). A comparison of approaches to estimating confidence intervals for willingness to pay measures. Health Economics, 16(8):827-840.

Holland, D. S. (2008). Are Fishermen Rational? A Fishing Expedition. Marine Resource Economics, 23(3):325-344.

Hunt, L. M. (2005). Recreational fishing site choice models: insights and future opportunities. Human Dimensions of Wildlife, 10(3):153-172.

Johannesson, M., Liljas, B., and Johansson, P.-O. (1998). An experimental comparison of dichotomous choice contingent valuation questions and real purchase decisions. Applied Economics, 30(5):643-647.

Jorgensen, B. S. and Stedman, R. C. (2001). SENSE OF PLACE AS AN ATTITUDE: LAKESHORE OWNERS ATTITUDES TOWARD THEIR PROPERTIES. Journal of Environmental Psychology, 21(3):233-248.

Kahneman, D. (2003). Maps of Bounded Rationality: Psychology for Behavioral Economics. American Economic Review, 93(5):1449-1475.

Kaplowitz, M. D., Lupi, F., Couper, M. P., and Thorp, L. (2012). The Effect of Invitation Design on Web Survey Response Rates. Social Science Computer Review, 30(3):339-349.

Keane, M. P. (1997). Modeling Heterogeneity and State Dependence in Consumer Choice Behavior. Journal of Business \& Economic Statistics, 15(3):310-327. 
Kinjo, K. and Sugawara, S. (2016). Predicting Empirical Patterns in Viewing Japanese TV Dramas Using Case-Based Decision Theory. The B.E. Journal of Theoretical Economics, 16(2):679-709.

Kolstoe, S. and Cameron, T. A. (2017). The Non-market Value of Birding Sites and the Marginal Value of Additional Species: Biodiversity in a Random Utility Model of Site Choice by eBird Members. Ecological Economics, 137(C):1-12.

Kolstoe, S., Cameron, T. A., and Wilsey, C. (2018). Climate, Land Cover, and Bird Populations: Differential Impacts on the Future Welfare of Birders across the Pacific Northwest. Agricultural and Resource Economics Review, 47(2):272-310.

Lizin, S., Brouwer, R., Liekens, I., and Broeckx, S. (2016). Accounting for substitution and spatial heterogeneity in a labelled choice experiment. Journal of Environmental Management, 181:289-297.

Lovett, A., Appleton, K., Warren-Kretzschmar, B., and Von Haaren, C. (2015). Using 3D visualization methods in landscape planning: An evaluation of options and practical issues. Landscape and Urban Planning, 142:85-94.

Lusk, J. L. and Schroeder, T. C. (2004). Are Choice Experiments Incentive Compatible? A Test with Quality Differentiated Beef Steaks. American Journal of Agricultural Economics, 86(2):467-482. Publisher: Oxford Academic.

Magilligan, F. J., Graber, B. E., Nislow, K. H., Chipman, J. W., Sneddon, C. S., and Fox, C. A. (2016). River restoration by dam removal: Enhancing connectivity at watershed scales. Elem Sci Anth, 4(0):000108.

Magnusson, D. and Ekehammar, B. (1978). Similar situations-Similar behaviors?: A study of the intraindividual congruence between situation perception and situation reactions. Journal of Research in Personality, 12(1):41-48.

Manski, C. F. (1977). The structure of random utility models. Theory and Decision, 8(3):229-254. 
Manzini, P. and Mariotti, M. (2014). Welfare economics and bounded rationality: the case for model-based approaches. Journal of Economic Methodology, 21(4):343360.

Martinson, K. S. and Shelby, B. (1992). Encounter and Proximity Norms for Salmon Anglers in California and New Zealand. North American Journal of Fisheries Management, 12(3):559-567.

Matthews, Y., Scarpa, R., and Marsh, D. (2017). Using virtual environments to improve the realism of choice experiments: A case study about coastal erosion management. Journal of Environmental Economics and Management, 81:193208.

McAlister, L. (1982). A Dynamic Attribute Satiation Model of Variety-Seeking Behavior. Journal of Consumer Research, 9(2):141-150.

McAlister, L. and Pessemier, E. (1982). Variety Seeking Behavior: An Interdisciplinary Review. Journal of Consumer Research, 9(3):311-322.

McConnell, K. E. (1977). Congestion and Willingness to Pay: A Study of Beach Use. Land Economics, 53(2):185-195.

McConnell, K. E. (1995). Consumer Surplus from Discrete Choice Models. Journal of Environmental Economics and Management, 29(3):263-270.

McConnell, K. E., Strand, I. E., and Blake-Hedges, L. (1995). Random utility models of recreational fishing: catching fish using a poisson process. Marine Resource Economics, 10(3):247-261.

McFadden, D. (1974). The measurement of urban travel demand. Journal of Public Economics, 3(4):303-328.

McFadden, D. (1980). Econometric Models for Probabilistic Choice Among Products. The Journal of Business, 53(3):S13-S29. 
McFadden, D. (2001). Economic Choices. American Economic Review, 91(3):351378.

McFadden, D. and Train, K. (2000). Mixed MNL models for discrete response. Journal of Applied Econometrics, 15(5):447-470.

McFarlane, B. L. (1994). Specialization and Motivations of Birdwatchers. Wildlife Society Bulletin (1973-2006), 22(3):361-370.

Mistiaen, J. A. and Strand, I. E. (2000). Location Choice of Commercial Fishermen with Heterogeneous Risk Preferences. American Journal of Agricultural Economics, 82(5):1184-1190.

Morey, E. R., Shaw, W. D., and Rowe, R. D. (1991). A discrete-choice model of recreational participation, site choice, and activity valuation when complete trip data are not available. Journal of Environmental Economics and Management, 20(2):181-201.

Murdock, J. (2006). Handling unobserved site characteristics in random utility models of recreation demand. Journal of Environmental Economics and Management, $51(1): 1-25$.

Newell, R. and Canessa, R. (2018). From sense of place to visualization of place: examining people-place relationships for insight on developing geovisualizations. Heliyon, 4(2). Publisher: Elsevier.

Nosofsky, R. M. (1992). Similarity Scaling and Cognitive Process Models. Annual Review of Psychology, 43(1):25-53.

Ossadnik, W., Wilmsmann, D., and Niemann, B. (2013). Experimental evidence on case-based decision theory. Theory and Decision, 75(2):211-232.

Pape, A. D. and Kurtz, K. J. (2013). Evaluating case-based decision theory: Predicting empirical patterns of human classification learning. Games and Economic Behavior, 82:52-65. 
Patterson, Z., Darbani, J. M., Rezaei, A., Zacharias, J., and Yazdizadeh, A. (2017). Comparing text-only and virtual reality discrete choice experiments of neighbourhood choice. Landscape and Urban Planning, 157:63-74.

Pauly, D., Watson, R., and Alder, J. (2005). Global trends in world fisheries: impacts on marine ecosystems and food security. Philosophical Transactions of the Royal Society B: Biological Sciences, 360(1453):5-12.

Pollak, R. A. (1970). Habit Formation and Dynamic Demand Functions. Journal of Political Economy, 78(4):745-763.

Porter, S. R. and Whitcomb, M. E. (2003). The Impact of Contact Type on Web Survey Response Rates. Public Opinion Quarterly, 67(4):579-588. Publisher: Oxford Academic.

Porter, S. R. and Whitcomb, M. E. (2007). Mixed-Mode Contacts In Web SurveysPaper is Not Necessarily Better. Public Opinion Quarterly, 71(4):635-648. Publisher: Oxford Academic.

Ran, T., R, and Kazmierczak, R. (2011). Location Choice Behavior of Gulf of Mexico Shrimpers under Dynamic Economic Conditions. Journal of Agricultural and Applied Economics, Volume 43(Number 1).

Rid, W., Haider, W., Ryffel, A., and Beardmore, B. (2018). Visualisations in Choice Experiments: Comparing 3d Film-sequences and Still-images to Analyse Housing Development Alternatives. Ecological Economics, 146(C):203-217.

Ropeik, A. (2018). Keene Mulls Historic Dam: Future After Hydropower Demo Plan Falls Through.

Rubinstein, A. and Salant, Y. (2011). Eliciting welfare preferences from behavioural data sets. The Review of Economic Studies, 79(1):375-387.

Rubio, G., Brinson, A., and Wallmo, K. (2014). Attitudes and Preferences of Saltwater 
Recreational Anglers: Report from the 2013 National Saltwater Angler Survey, Volume II Regional Analysis.

Salter, J. D., Campbell, C., Journeay, M., and Sheppard, S. R. J. (2009). The digital workshop: Exploring the use of interactive and immersive visualisation tools in participatory planning. Journal of Environmental Management, 90(6):2090-2101.

Scarpa, R., Ferrini, S., and Willis, K. (2005). Performance of Error Component Models for Status-Quo Effects in Choice Experiments. In Scarpa, R. and Alberini, A., editors, Applications of Simulation Methods in Environmental and Resource Economics, The Economics of Non-Market Goods and Resources, pages 247-273. Springer Netherlands, Dordrecht.

Scarpa, R. and Rose, J. M. (2008). Design efficiency for non-market valuation with choice modelling: how to measure it, what to report and why*. Australian Journal of Agricultural and Resource Economics, 52(3):253-282.

Schuhmann, P. W. and Schwabe, K. A. (2004). An Analysis of Congestion Measures and Heterogeneous Angler Preferences in a Random Utility Model of Recreational Fishing. Environmental and Resource Economics, 27(4):429-450.

Shepard, R. N. (1987). Toward a universal law of generalization for psychological science. Science, 237(4820):1317-1323.

Shr, Y.-H. J., Ready, R., Orland, B., and Echols, S. (2019). How Do Visual Representations Influence Survey Responses? Evidence from a Choice Experiment on Landscape Attributes of Green Infrastructure. Ecological Economics, 156:375386.

Smith, M. D. (2005). State dependence and heterogeneity in fishing location choice. Journal of Environmental Economics and Management, 50(2):319-340.

Smith, M. D. and Wilen, J. E. (2002). State Dependence in Modeling the Spatial 
Behavior of Renewable Resource Users. Corvallis, Oregon, USA. International Institute of Fisheries Economics and Trade.

Song, C., Omalley, A., Roy, S. G., Barber, B. L., Zydlewski, J., and Mo, W. (2019). Managing dams for energy and fish tradeoffs: What does a win-win solution take? Science of The Total Environment, 669:833-843.

Timmins, C. and Murdock, J. (2007). A revealed preference approach to the measurement of congestion in travel cost models. Journal of Environmental Economics and Management, 53(2):230-249.

Townsend, C. and Kahn, B. E. (2014). The "Visual Preference Heuristic": The Influence of Visual versus Verbal Depiction on Assortment Processing, Perceived Variety, and Choice Overload. Journal of Consumer Research, 40(5):993-1015.

Train, K. (2002). Discrete Choice Methods with Simulation. Cambridge University Press.

Train, K. and Weeks, M. (2005). Discrete Choice Models in Preference Space and Willingness-to-Pay Space. In Scarpa, R. and Alberini, A., editors, Applications of Simulation Methods in Environmental and Resource Economics, The Economics of Non-Market Goods and Resources, pages 1-16. Springer Netherlands, Dordrecht.

Train, K. E. (1998). Recreation Demand Models with Taste Differences over People. Land Economics, 74(2):230-239.

Upton, V., Dhubháin, N., and Bullock, C. (2012). Preferences and values for afforestation: The effects of location and respondent understanding on forest attributes in a labelled choice experiment. Forest Policy and Economics, 23:17-27.

Voorheis, J. (2015). Mqtime: A Stata Tool for Calculating Travel Time and Distance Using Mapquest web Services:. The Stata Journal. Publisher: SAGE PublicationsSage CA: Los Angeles, CA. 
Weir, M. J., Ashcraft, C. M., Diessner, N. L., McGreavy, B., Vogler, E., and Guilfoos, T. (2020). Language effects on bargaining. PLOS ONE, 15(3):e0229501. Publisher: Public Library of Science.

Wissen, U., Schroth, O., Lange, E., and Schmid, W. A. (2008). Approaches to integrating indicators into 3D landscape visualisations and their benefits for participative planning situations. Journal of Environmental Management, 89(3):184-196. 